UNIVERSIDADE DE SÃO PAULO

FACULDADE DE ZOOTECNIA E ENGENHARIA DE ALIMENTOS

DIOGO DE LUCCA SARTORI

Painel portante estrutural com chapa de partículas de bagaço de cana-de-açúcar e resina de mamona para centro de manejo bovino 
VERSÃO CORRIGIDA

\section{Painel portante estrutural com chapa de partículas de bagaço de cana-de-açúcar e resina de mamona para centro de manejo bovino}

Dissertação apresentada à Faculdade de Zootecnia e Engenharia de Alimentos da Universidade de São Paulo, como parte dos requisitos para a obtenção do Título de Mestre em Zootecnia.

Área de Concentração: Qualidade e Produtividade Animal.

Orientador: Holmer Savastano Junior

Pirassununga 
Dados Internacionais de Catalogação na Publicação

Serviço de Biblioteca e Informação da Faculdade de Zootecnia e Engenharia de Alimentos da Universidade de São Paulo

Sartori, Diogo de Lucca

Painel portante estrutural com chapa de partículas de bagaço de cana-de-açúcar e resina de mamona para centro de manejo bovino / Diogo de Lucca Sartori. --

Pirassununga, 2012 .

$129 \mathrm{f}$.

Dissertação (Mestrado) -- Faculdade de Zootecnia e Engenharia de Alimentos - Universidade de São Paulo. Departamento de Engenharia de Alimentos.

Área de Concentração: Qualidade e Produtividade Animal.

Orientador: Prof. Dr. Holmer Savastano Junior.

1. Instalação zootécnica 2. Resíduo 3. Painéis de partículas 4. Brete 5. Seringa. I. Título. 


\section{DEDICATÓRIA}

Aos meus pais, Alfredo e Heben, pelo apoio incondicional as minhas decisões tomadas e por serem o motivo e a inspiração para sempre continuar em frente. A minha namorada Maria, que participou com amor e companheirismo na fase final desta etapa. 


\section{AGRADECIMENTOS}

Ao Prof. Dr. Holmer Savastano Junior pela orientação e de tornar possível a realização do projeto de pesquisa.

Ao Prof. Dr. Juliano Fiorelli, pela oportunidade oferecida e pelo apoio em minha orientação.

A Gabriela, amiga de pós-graduação, por todos os momentos que compartilhamos e pelo companheirismo nos momentos mais difíceis, assim como também, nos mais felizes.

A Nubia, companheira de pesquisa, pela amizade, preocupação e disposição em sempre ajudar e colaborar em meu trabalho.

Ao Julio, amigo de graduação e agora pós-graduação, pela colaboração e ajuda no desenvolvimento do meu trabalho.

As minhas amigas de laboratório e pós-graduação, Erika e Michelle, pela amizade, ajuda e momentos de descontração.

Aos colegas do Constrambi (Laboratório de Construção e Ambiência), pela participação em meu desenvolvimento nesse tempo de pós-graduação. Em principal ao Zaqueu e Matheus, pelas rizadas e colaboração na realização de meus experimentos.

Aos alunos dos cursos de graduação que participaram de meu trabalho, principalmente ao Igor pela parceria e interesse em ajudar.

À Faculdade de Zootecnia e Engenharia de Alimentos, pela oportunidade de realização do curso de mestrado.

Ao Conselho Nacional de Desenvolvimento Científico e Tecnológico e a Fundação de Amparo à Pesquisa do Estado de São Paulo, pela bolsa de mestrado e pelo apoio financeiro para a realização desta pesquisa. 


\section{RESUMO}

SARTORI, D. L. Painel portante estrutural com chapa de partículas de bagaço de cana-deaçúcar e resina de mamona para centro de manejo bovino. 2012. 129 f. Dissertação (Mestrado) - Faculdade de Zootecnia e Engenharia de Alimentos, Universidade de São Paulo, Pirassununga, 2012.

O presente trabalho teve por objetivo ajustar um processo para fabricação de chapas de partículas de bagaço de cana-de-açúcar e resina poliuretana bi componente à base de óleo de mamona, avaliar tecnicamente as propriedades físico-mecânicas, micro estrutural e de durabilidade desse material e validar seu uso como componente de painel portante para uso como fechamento lateral de instalações zootécnicas para bovino. A qualidade das chapas foi avaliada com base nas prescrições dos documentos normativos NBR 14810 (2006) e ANSI A208.1 (1999). Foram fabricados chapas com partículas com dimensão de até 5 e $8 \mathrm{~mm}$, a fim de identificar a dimensão adequada dessa matéria-prima, para a aplicação das chapas na composição do painel portante. Posteriormente, foi desenvolvido e fabricado um protótipo de painel portante em madeira de reflorestamento e chapas de partículas de bagaço de cana-de-açúcar, que teve seu desempenho estrutural avaliado por meio de ensaio de impacto de corpo-mole. Os resultados obtidos indicam que as chapas com partículas de dimensão de até $8 \mathrm{~mm}$ apresentaram valores de propriedades físico-mecânicas que atendem as recomendações mínimas dos documentos normativos para uso estrutural. O painel portante apresentou desempenho estrutural adequado para resistir às cargas de impacto nas condições de uso, sendo possível indicá-lo com alternativa para fechamento lateral em centro de manejo para bovinos.

Palavras-chave: instalação zootécnica; resíduo; painéis de partículas; brete; seringa 


\begin{abstract}
SARTORI, D. L. Structural self-bearing panel with sugarcane particleboards and castor oil resin for cattle handling facilities. 2012. 129 f. M.Sc. Dissertation - Faculdade de Zootecnia e Engenharia de Alimentos, Universidade de São Paulo, Pirassununga, 2012.

The objective of this study was to adjust a process for the manufacture of particleboards of sugarcane bagasse and bi-component polyurethane resin a base of castor oil, to evaluate its physic-mechanical properties, microstructure and durability of this material and to validate its use as component of self-bearing panel for use as a lateral closure of zootechnics installations for cattle. The particleboard quality was evaluated based on the requirements of normative documents NBR 14810 (2006) and ANSI A208.1 (1999). Particleboards were manufactured with particles size up to 8 and $5 \mathrm{~mm}$, to identify the appropriate size of the raw material for the application in particleboards for composition of the self-bearing panel. Then, a prototype of self-bearing panel in reforestation wood and sugarcane particleboards it was developed and manufactured, which had its structural performance evaluated by soft body impact test. The results indicate that particleboards with particles size up to $8 \mathrm{~mm}$ showed values of physical-mechanical properties that met the minimum recommendations of the normative documents for structural use. The self-bearing panel showed adequate structural performance to withstand impact loads under the conditions of use and it can be designate as an alternative to closing side of cattle handling facilities.
\end{abstract}

Keywords: zootechnics installations; waste; particleboards; working chute; crowding pen 


\section{LISTA DE ILUSTRAÇÕES}

Figura 1 - Brete e seringa comumente utilizados no país............................................. 31

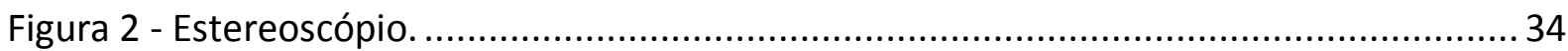

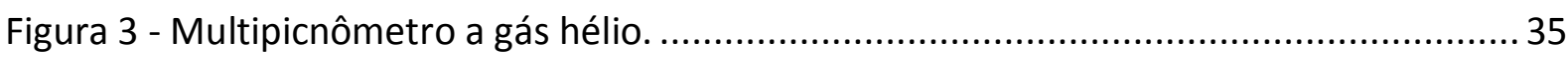

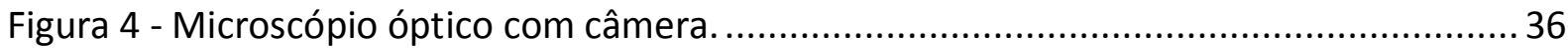

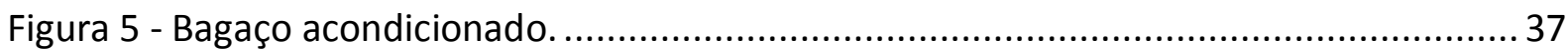

Figura 6 - Detalhe da porção retida na peneira e porção passante no peneiramento do bagaço de cana-de-açúcar....................................................................................... 38

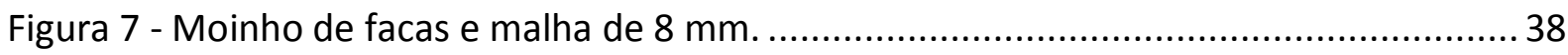

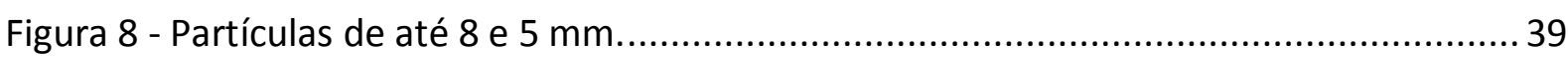

Figura 9 - Pesagem e mistura dos componentes da resina................................................. 39

Figura 10 - Aplicação e pré-mistura da resina ao bagaço de cana-de-açúcar......................... 40

Figura 11 - Vista geral do batedor planetário e homogeneização. ...................................... 40

Figura 12 - Moldagem, pré-prensagem e formação do colchão de bagaço de cana de açúcar e

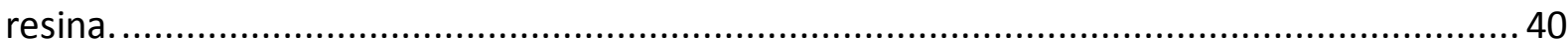

Figura 13 - Prensagem a quente com prensa hidráulica do colchão de bagaço e resina........ 41

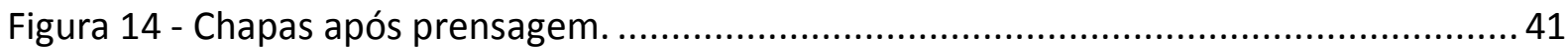

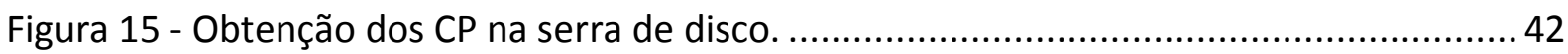

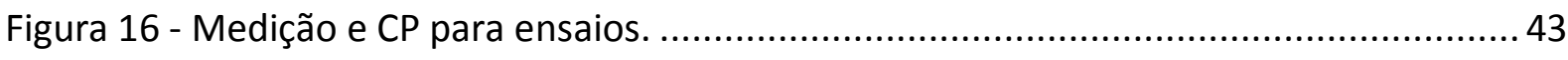

Figura 17 - CP submersos e secando para as medições.................................................. 44

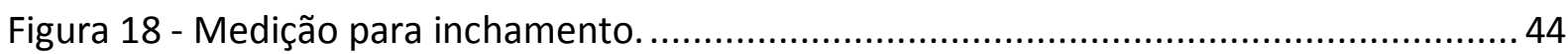

Figura 19 - Máquina universal de ensaios mecânicos com extensômetro externo................ 45

Figura 20 - CP submetido a ensaio de flexão a três pontos. ............................................... 46

Figura 21 - Blocos de tração e suporte para ensaio de TP.................................................. 47

Figura 22 - Colagem dos CP e conjunto CP mais bloco de tração. ...................................... 48

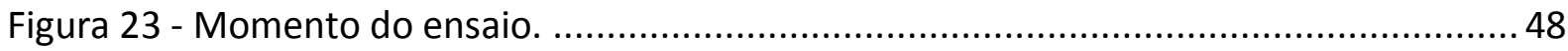

Figura 24 - Campo de envelhecimento natural e CP acondicionados. ............................... 49

Figura 25 - CP em secagem após aplicação de resina................................................... 50

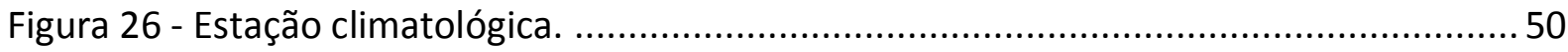

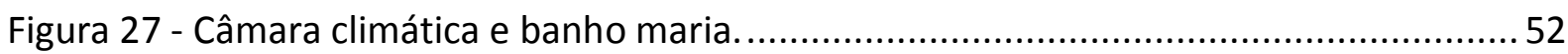


Figura 28 - CP durante as etapas dos ciclos de envelhecimento de vapor de água (a), calor em

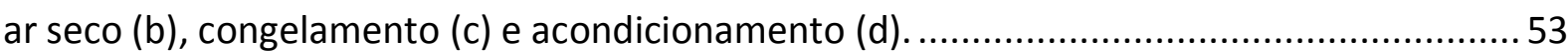

Figura 29 - Microscópio eletrônico de varredura e amostra sendo posicionada. 54 Figura 30 - Processo de fabricação das chapas de partículas, com formação do colchão ((a) e (b)), momento da prensagem com aquecimento (c), detalhe da espessura da chapa (d) e chapas produzidas ((e) e (f)). 56

Figura 31 - Pórtico para a fixação do painel de fechamento, detalhe da fixação do painel no pórtico 58

Figura 32 - Mistura de serragem e areia para enchimento do saco (a) e pesagem do saco (b). 59

Figura 33 - Dispositivo para registro dos deslocamentos transversais. 59

Figura 34 - Fixação do corpo mole e alinhamento com o centro do protótipo. 60

Figura 35 - Bagaço de cana-de-açúcar (a) e chapas produzidas com esse material proveniente da usina A (b); bagaço de cana-de-açúcar (c) e chapas produzidas com esse material proveniente da usina $B(d)$. 68

Figura 36 - Imagens microscópicas ópticas de partículas de bagaço de cana-de-açúcar. 70

Figura 37 - Gráficos Boxplot da densidade aparente de chapas de partículas com diferentes tamanhos 74

Figura 38 - Gráfico comparativo entre os valores médios experimentais e as normas.

Figura 39 - Gráficos Boxplot de inchamento, em 2 h e 24 h, de chapas de partículas com diferentes tamanhos. 77

Figura 40 - Gráfico comparativo entre os valores médios experimentais e as normas. 78

Figura 41 - Gráficos Boxplot de absorção, em 2 h e 24 h, de chapas de partículas com diferentes tamanhos.

Figura 42 - Gráfico comparativo entre os valores médios experimentais.

Figura 43 - Gráficos Boxplot do MOR de chapas de partículas com diferentes tamanhos. .... 84

Figura 44 - Gráfico comparativo entre os valores médios experimentais e as normas. 85

Figura 45 - Gráficos Boxplot do MOE de chapas de partículas com diferentes tamanhos. .... 87

Figura 46 - Gráfico comparativo entre os valores médios experimentais e as normas. 88

Figura 47 - Gráficos Boxplot da Al de chapas de partículas com diferentes tamanhos. 90

Figura 48 - Gráfico comparativo entre os valores médios experimentais e as normas.

Figura 49 - CP com aplicação de resina após período de envelhecimento. 
Figura 50 - CP sem aplicação de resina após período de envelhecimento.

Figura 51 - CP sem aplicação de resina com grande alteração em seu aspecto..................... 94

Figura 52 - CP sem resina com detalhe das delaminações ocorridas.

Figura 53 - Gráficos Boxplot do MOR de chapas de partículas com e sem revestimento de resina após envelhecimento natural.

Figura 54 - Gráfico comparativo entre os valores médios experimentais.

Figura 55 - Gráficos Boxplot do MOE de chapas de partículas com e sem revestimento de resina após envelhecimento natural.

Figura 56 - Gráfico comparativo entre os valores médios experimentais.

Figura 57 - CP com e sem resina após ciclo de envelhecimento.

Figura 58 - Gráficos Boxplot do MOR de chapas de partículas com e sem revestimento de resina após envelhecimento acelerado.

Figura 59 - Gráfico comparativo entre os valores médios experimentais.

Figura 60 - Gráficos Boxplot do MOE de chapas de partículas com e sem revestimento de resina após envelhecimento acelerado. 103

Figura 61 - Gráfico comparativo entre os valores médios experimentais. 104

Figura 62 - Chapa de bagaço da Usina A em aumento de 200X (a) e 1000X (b). 105

Figura 63 - Chapa de partículas com dimensões de até $8 \mathrm{~mm}$ em aumento de 200X (a) e $1000 \times(b)$

Figura 64 - Chapa de partículas com dimensões de até $5 \mathrm{~mm}$ em aumento de 300X (a) e $1000 x(b)$

Figura 65 - Chapa de envelhecimento natural com aplicação externa de resina em aumento de 150X destacando a borda (a), 500X destacando a borda (b), 200X (c) e 1000X (d). 107 Figura 66 - Chapa de envelhecimento natural sem aplicação externa de resina em aumento de 150X destacando a borda (a), 500X destacando a borda (b), 200X (c) e 1000X (d)........ 108 Figura 67 - Chapa de envelhecimento acelerado em aumento de 200X (a) e 1000X (b)..... 109 Figura 68 - Montagem da estrutura em madeira do protótipo. 110

Figura 69 - Parafusamento das chapas aglomeradas na estrutura de madeira.

Figura 70 - Vista lateral e posterior do protótipo e suas dimensões em centímetros.

Figura 71 - Protótipo após finalização da montagem

Figura 72 - Vistas do painel portante em 3D.

Figura 73 - Detalhe da seringa em formato circular. 
Figura 74 - Detalhe da parte interna do brete circular e sua passarela.

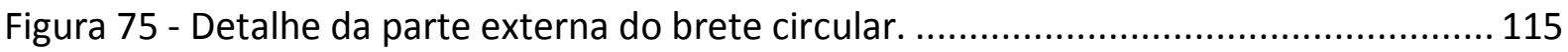

Figura 76 - Vista geral superior do brete e seringa. ...................................................... 115

Figura 77 - Momento do impacto do corpo mole. .............................................................. 116

Figura 78 - Registro do deslocamento horizontal pelo dispositivo no papel milimetrado.... 116

Figura 79 - Detalhe do local de recebimento dos impactos após o ensaio. 


\section{LISTA DE TABELAS}

Tabela 1 - Composição química do bagaço de cana-de-açúcar, em porcentagem de matéria seca.

Tabela 2 - Morfologia da fibra do bagaço de cana-de-açúcar.

Tabela 3 - Parâmetros de produção das chapas de partículas de bagaço de cana-de-açúcar.37

Tabela 4 - Informações do ensaio de envelhecimento natural. 49

Tabela 5 - Dados climatológicos do período, divididos pelas estações do ano.

Tabela 6 - Etapas e descrição dos ciclos de envelhecimento. 52

Tabela 7 - Altura e energia de cada impacto correspondente à massa do saco de areia. 60

Tabela 8 - Análise bromatológica do bagaço de cana-de-açúcar. 67

Tabela 9 - Valor médio e desvio padrão das dimensões das partículas. 69

Tabela 10 - Valores médios de propriedades físico-mecânicas das chapas das duas Usinas. . 71

Tabela 11 - Densidade aparente média de chapas de partículas com bagaço de cana de diferentes comprimentos

Tabela 12 - ANOVA da densidade aparente de chapas de partículas com bagaço de cana de diferentes comprimentos

Tabela 13 - Inchamento médio, em 2 h e 24 h, de chapas de partículas com bagaço de cana de diferentes comprimentos.

Tabela 14 - ANOVA de inchamento em $2 \mathrm{~h}$ de chapas de partículas com bagaço de cana de diferentes comprimentos 79

Tabela 15 - ANOVA de inchamento em $24 \mathrm{~h}$ de chapas de partículas com bagaço de cana de diferentes comprimentos

Tabela 16 - Absorção média, em 2 h e 24 h, de chapas de partículas com bagaço de cana de diferentes comprimentos.

Tabela 17 - ANOVA de absorção em $2 \mathrm{~h}$ de chapas de partículas com bagaço de cana de diferentes comprimentos

Tabela 18 - ANOVA de absorção em 24 h de chapas de partículas com bagaço de cana de diferentes comprimentos

Tabela 19 - MOR médio de chapas de partículas com bagaço de cana de diferentes comprimentos 
Tabela 20 - ANOVA de MOR de chapas de partículas com bagaço de cana de diferentes comprimentos

Tabela 21 - MOE médio de chapas de partículas com bagaço de cana de diferentes comprimentos

Tabela 22 - ANOVA de MOE de chapas de partículas com bagaço de cana de diferentes comprimentos

Tabela 23 - Al média de chapas de partículas com bagaço de cana de diferentes comprimentos

Tabela 24 - ANOVA de TP de chapas de partículas com bagaço de cana de diferentes comprimentos

Tabela 25 - Valores médios de propriedades físico-mecânicas de chapas de partículas com bagaço de cana de diferentes comprimentos.

Tabela 26 - MOR médio de chapas de partículas com bagaço de cana com e sem revestimento após envelhecimento natural.

Tabela 27 - ANOVA do MOR de chapas de partículas com bagaço de cana com e sem revestimento após envelhecimento natural.

Tabela 28 - MOE médio de chapas de partículas com bagaço de cana com e sem revestimento após envelhecimento natural.

Tabela 29 - ANOVA do MOE de chapas de partículas com bagaço de cana com e sem revestimento após envelhecimento natural.

Tabela 30 - MOR médio de chapas de partículas com bagaço de cana com e sem revestimento após envelhecimento acelerado.

Tabela 31 - ANOVA do MOR de chapas de partículas com bagaço de cana com e sem revestimento após envelhecimento acelerado.

Tabela 32 - MOE médio de chapas de partículas com bagaço de cana com e sem revestimento após envelhecimento acelerado.

Tabela 33 - ANOVA do MOE de chapas de partículas com bagaço de cana com e sem revestimento após envelhecimento acelerado.

Tabela 34 - Resultado do ensaio de impacto de corpo mole. 
LISTA DE ABREVIATURAS E SIGLAS

$\begin{array}{ll}\text { ABNT } & \text { Associação Brasileira de Normas Técnicas } \\ \text { AI } & \text { Adesão Interna } \\ \text { ANOVA } & \text { Análise de Variância } \\ \text { ANSI } & \text { American National Standards Institute } \\ \text { CP } & \text { Corpo de Prova/Corpos de Prova } \\ \text { MOE } & \text { Módulo de Elasticidade } \\ \text { MOR } & \text { Módulo de Ruptura } \\ \text { NBR } & \text { Norma Brasileira Registrada } \\ \text { TP } & \text { Tração Perpendicular }\end{array}$




\section{Sumário}

1

Introdução.

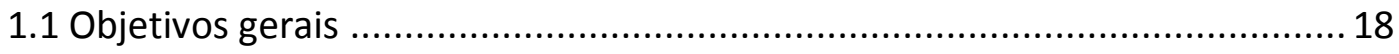

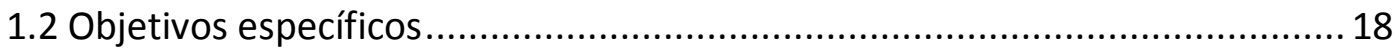

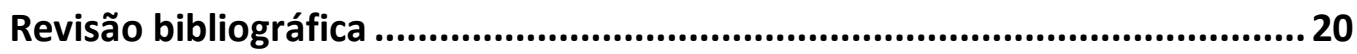

2.1 Bagaço de cana-de-açúcar....................................................................... 20

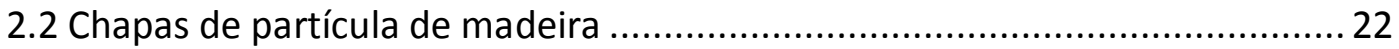

2.3 Painéis de partícula de resíduos lignocelulósicos.......................................... 24

2.4 Adesivos para fabricação de painéis ........................................................... 27

2.5 Construções rurais na pecuária de corte .......................................................29

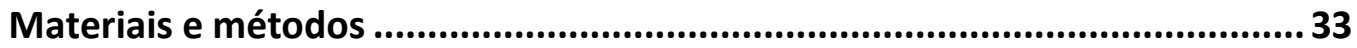

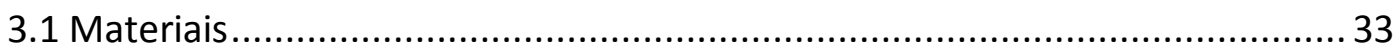

3.2 Métodos de caracterização da matéria prima ............................................ 33

3.2.1 Análise bromatológica do bagaço de cana-de-açúcar............................... 34

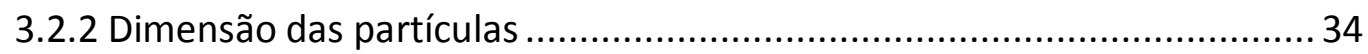

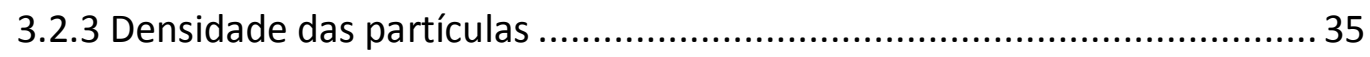

3.2.4 Microscopia óptica das partículas ...................................................... 36

3.3 Processo de fabricação das chapas de bagaço de cana-de-açúcar e resina poliuretana bi componente à base de óleo de mamona . 36

3.4 Caracterização das chapas de bagaço de cana-de-açúcar e resina poliuretana bi componente à base de óleo de mamona

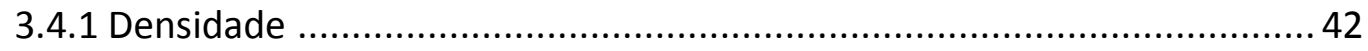

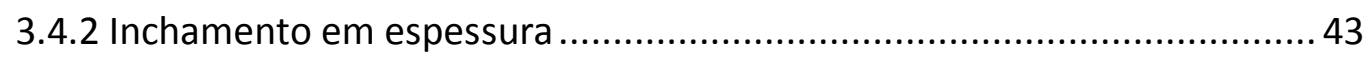

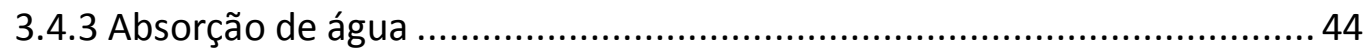

3.4.4 Módulo de ruptura (MOR) e módulo de elasticidade à flexão (MOE) ...... 45

3.4.5 Tração perpendicular às fibras (TP) .................................................. 47

3.4.6 Envelhecimento das chapas de bagaço de cana-de-açúcar e resina poliuretana bi componente à base de óleo de mamona.............................................. 48

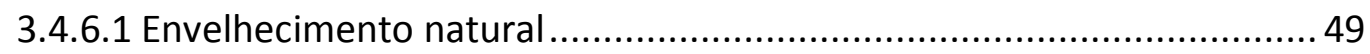

3.4.6.2 Envelhecimento acelerado......................................................... 51

3.4.7 Microscopia eletrônica de varredura (MEV) ......................................... 53

3.4.8 Projeto do painel portante ................................................................ 54 
3.4.8.1 Dimensionamento das chapas

3.4.8.2 Modelo 3D do protótipo aplicado como painel de fechamento lateral 57

3.4.9 Ensaio de impacto de corpo mole .................................................... 58

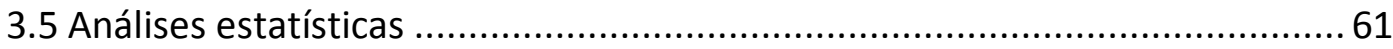

3.5.1 Análises entre chapas de bagaço das duas usinas ................................61 61

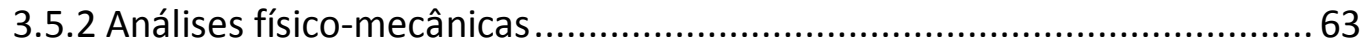

3.5.3 Análises de envelhecimento (natural e acelerado) ...............................65

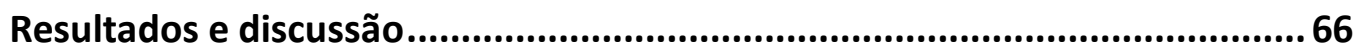

4.1 Caracterização da matéria prima fibrosa ..................................................... 66

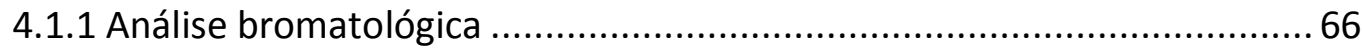

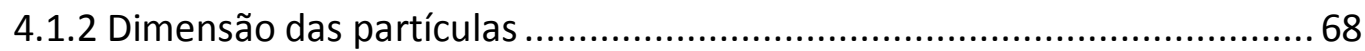

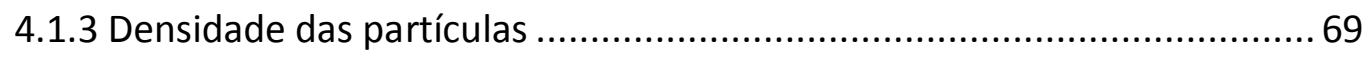

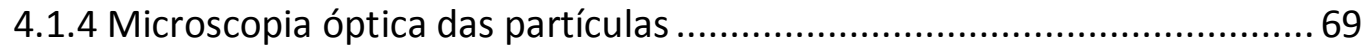

4.2 Caracterização das chapas de bagaço de cana-de-açúcar e resina poliuretana bi componente à base de óleo de mamona 71

4.2.1 Comparativo entre as chapas produzidas com o bagaço das diferentes usinas 71

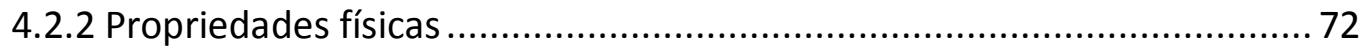

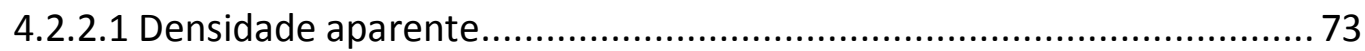

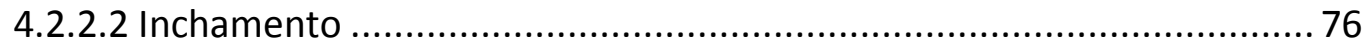

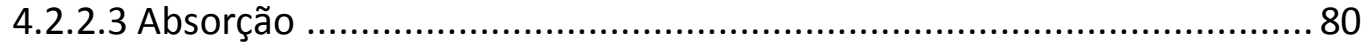

4.2.3 Propriedades mecânicas ....................................................................... 83

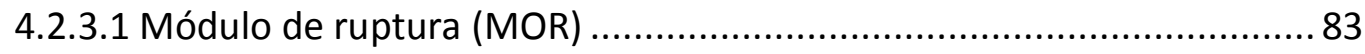

4.2.3.2 Módulo de elasticidade (MOE) ................................................... 86

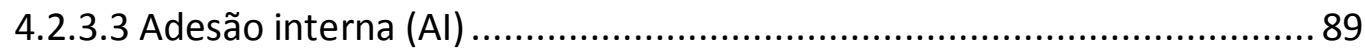

4.2.4 Conclusão dos resultados das propriedades físico-mecânicas (8 mm e 5 $\mathrm{mm})$

4.3 Envelhecimento das chapas de bagaço de cana-de-açúcar e resina poliuretana bi componente à base de óleo de mamona ............................................................... 93

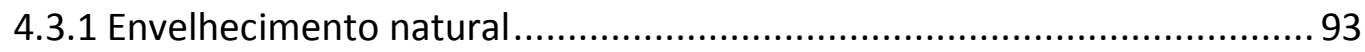

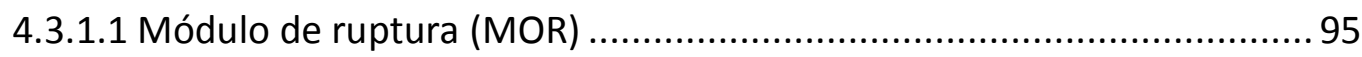

4.3.1.2 Módulo de elasticidade (MOE) .................................................... 97

4.3.2 Envelhecimento acelerado ............................................................. 99 
4.3.2.1 Módulo de ruptura (MOR) ............................................................ 100

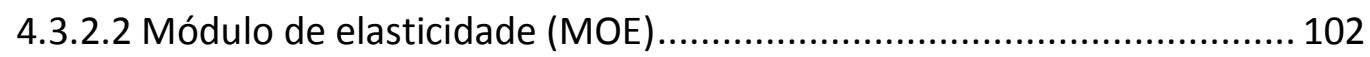

4.4 Microscopia eletrônica de varredura (MEV) ............................................ 105

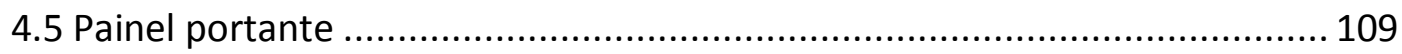

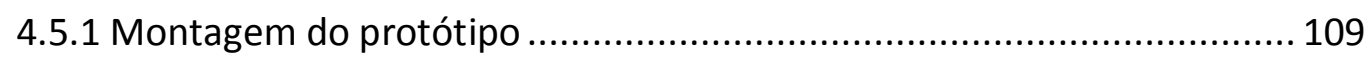

4.5.2 Modelo 3D do protótipo aplicado como painel de fechamento lateral . 112

4.5.3 Ensaio de impacto de corpo mole ................................................... 116

Conclusão.

5.1. Sugestões de continuidade ......................................................... 120 


\section{Introdução}

A tendência contemporânea da relação entre nações tem sido caracterizada pela generalização do conceito de globalização econômica. Nela se experimenta a associação de países com interesses comuns em garantir a manutenção dos mercados e buscar sua expansão em um cenário fortemente marcado pela competitividade e necessidade de alcançar soluções inovadoras para os mais variados problemas. O Brasil tem buscado opções para aumentar a atividade econômica e uma das alternativas é o incentivo ao desenvolvimento de políticas no setor agrícola.

O Centro Mundial sobre Meio Ambiente e Desenvolvimento (CMMAD) define o desenvolvimento sustentável como um processo de transformação no qual a exploração de recursos, a direção de investimentos, a orientação do avanço tecnológico e a mudança institucional se harmonizam e reforçam o potencial presente e futuro, a fim de atender às necessidades humanas (NASCIMENTO, 2003).

Para que haja um desenvolvimento sustentável é fundamental atender as necessidades básicas das pessoas, oferecer condições de concretizar as aspirações por uma vida melhor, manter os padrões de consumo dentro do limite das possibilidades ecológicas a que todos possam aspirar, garantir o crescimento econômico em regiões onde tais necessidades se limitam no âmbito único de exploração, conservar as espécies vegetais, minimizar os impactos adversos sobre a qualidade do ar, da água e de outros elementos naturais, preservando a integridade global do ecossistema (CAMPOS, 2005).

O setor produtivo da agroindústria depende direta ou indiretamente do ambiente como fonte de matérias-primas para o seu desenvolvimento, bem como da utilização de alguns locais para "área de despejo" de seus subprodutos e resíduos gerados durante os ciclos produtivos. A eliminação de rejeitos, quando quantificada, controlada e tratada tornase facilmente passível de depuração pelo ambiente em determinado tempo. Caso contrário este processo pode levar milhares de anos ou, até mesmo, deixar de ocorrer, pela ausência de mecanismos específicos na natureza.

As empresas também sofrem forte pressão por parte da sociedade, já que dependem da aceitação e aprovação desta última para a comercialização de seus produtos (CINTRA; ANDRADE, 2003). Com o intuito de manter sua imagem polida, as organizações 
passaram a priorizar investimentos em áreas antes não consideradas importantes. Assim, conseguem agradar seus clientes, garantir seus lucros e o retorno dos investimentos, mesmo a médio ou longo prazo, assegurando a sua permanência e sustentação ao longo do tempo.

Segundo Ottaman (1994), o ambientalismo ganharia um espaço muito grande nos próximos anos e pelo menos $40 \%$ de todos os novos produtos domésticos deveriam apresentar uma alegação ambiental em seu rótulo. Para consumidores preocupados com a qualidade de vida, as decisões de compra serão cada vez mais influenciadas pelo impacto que os produtos causarão ao meio ambiente. Sendo assim, as empresas que não corresponderem aos anseios (relacionados a questões ambientais) dos consumidores por meio de produtos mais seguros e ecologicamente corretos, estarão arriscadas a perder a sintonia com eles, podendo pagar um alto preço pelo não cumprimento destas novas exigências comerciais. Ao contrário dos anteriores, aqueles comerciantes que prestarem atenção ao chamado do consumidor verão suas oportunidades se multiplicarem.

As indústrias de painéis aglomerados e de fibras, no Brasil, utilizam preferencialmente cavacos de madeira de reflorestamento provenientes de Pinus e de algumas espécies de Eucalipto, o que determina, inclusive, uma melhor qualidade do produto, tendo em vista o melhor controle de homogeneidade da matéria-prima. Porém, os materiais lignocelulósicos provenientes de resíduos agroindustriais vêm sendo uma alternativa para fabricação de painéis.

A agroindústria brasileira apresenta inúmeros resíduos lignocelulósicos com potencialidades de aproveitamento para fabricação de novos materiais como, por exemplo, a casca de coco (BRITO et al., 2004; KHEDARI et al., 2004 e PASSOS, 2005), casca de amendoim (PABLO et al., 1975; CARASCHI et al., 2009 e GATANI, 2009) e bagaço de cana-deaçúcar (WIDYORINI et al., 2005; CONTRERAS et al., 2006; CARASCHI et al., 2008; SILVA et al., 2008 e BATTISTELLE et al., 2009).

Em relação à cultura da cana-de-açúcar, observa-se uma expansão crescente no Brasil, mais especificamente no estado de São Paulo. Segundo relatório da CONAB (2011), o estado possui $52,8 \%$ do total de área destinada no país à produção de cana-de-açúcar, totalizando 4,46 milhões de ha, sendo responsável por 55\% da cana-de-açúcar produzida no Brasil na safra 2011/2012.

No entanto, a indústria sucroalcooleira produz uma quantidade de resíduos significativa, como é o caso, por exemplo, do bagaço da cana. Somente no estado de São 
Paulo, são gerados aproximadamente 146 milhões de t de resíduo por ano; deste montante, 73,3\% é queimado para fornecer calor em forma de energia para operação das usinas e $26,7 \%$ destinado a venda (CONAB, 2011). A queima do produto, além de não agregar valor ao resíduo gerado pela indústria, contribui diretamente com o aquecimento global e com o efeito estufa.

Muitas são as soluções existentes e outras ainda surgirão para diminuir os impactos ambientais causados pelo descarte dos resíduos agroindustriais na natureza. Nessa busca por resultados, muitas são as oportunidades criadas para evitar-se um desastre ecológico ainda maior. Várias empresas estão investindo em novas tecnologias e outras na manutenção de seus equipamentos, de forma a diminuir os gastos e, consequentemente, cumprir seu papel de empresa sustentável e ecologicamente correta promovendo a manutenção do planeta para a vida presente e a de nossos descendentes.

Baseando-se nas informações apresentadas, verifica-se interesse e vasto campo de aplicação para os resíduos agroindustriais, mais especificamente o bagaço da cana-deaçúcar, na fabricação de painéis de partículas.

Uma opção para agregar valor a estes resíduos esta na fabricação de painéis de partículas. As propriedades mecânicas destes painéis permitem sua aplicação em diversas áreas da construção civil, arquitetura e indústria moveleira.

Em países com vocação agrícola, como o Brasil, o uso de resíduos agroindustriais deve ser incentivado. Teixeira et al. (1997) descrevem:

\begin{abstract}
O uso de produtos à base de materiais lignocelulósicos como compensados, chapas duras de fibras, chapas de média densidade e de aglomerado, tem crescido ao longo do tempo, e a tendência é ter sua demanda aumentada devido à escassez da oferta de madeira. Além disso, tem-se intensificado o estudo sobre o melhor aproveitamento de resíduos florestais e agrícolas e mesmo o chamado resíduo urbano, como plásticos, papel de jornal e de revista, papelão e outros, para a produção de painéis a serem usados como móveis, revestimento de automóveis e forros. A produção de painéis alternativos, com aplicação de resíduos de diferentes origens pode contribuir para o atendimento da demanda de painéis. Pode ainda promover a adequada disposição final de resíduos e gerar materiais que preservem os recursos naturais.
\end{abstract}

Pesquisas desenvolvidas avaliaram o comportamento físico-mecânico de painéis de partículas fabricados com diferentes adesivos. As resinas uréia-formaldeído e phenolformaldeído são utilizadas comercialmente e a resina bi componente à base de mamona vem sendo uma alternativa sustentável para substituição dos adesivos comerciais. No 
entanto, vários autores afirmam que manipulações nas variáveis de processamento são necessárias para viabilizar a produção dos respectivos painéis.

Seguindo a tendência de desenvolvimento de produtos sustentáveis e objetivando utilizar resíduos da agroindústria como proposta de agregar valor a este material, evitando seu descarte ou mesmo emprego apenas como material destinado à queima, o presente projeto de pesquisa teve como finalidade produzir chapas de partículas aglomeradas de bagaço de cana-de-açúcar e resina poliuretana bi componente à base de óleo de mamona para avaliar tecnicamente a viabilidade de utilização deste novo produto, por meio da determinação de propriedades físico-mecânicas e de durabilidade e aplicação em um novo sistema construtivo.

As propriedades mecânicas almejadas para estes painéis permitirão sua aplicação na construção rural, nesse caso especificamente em centro de manejo para gado de corte, sendo quase a totalidade desta instalação constituída de madeira. Neste sentido, a procura por um material à base de resíduos agroindustriais que apresente desempenho igual ou superior à madeira e com custo inferior, mostra-se interessante.

\subsection{Objetivos gerais}

Ajustar processo para fabricação de chapas de partículas de bagaço de cana-deaçúcar e resina poliuretana bi componente à base de óleo de mamona, avaliar tecnicamente as propriedades físico-mecânicas e de durabilidade desse material e validar seu uso como componente de um painel portante para uso como fechamento lateral instalações zootécnicas para bovinos.

\subsection{Objetivos específicos}

- Fabricar chapas de partículas de bagaço de cana-de-açúcar e resina poliuretana bi componente à base de óleo de mamona; 
- Determinar propriedades físico-mecânicas, durabilidade e características micro estruturais das chapas de bagaço de cana-de-açúcar e resina à base de óleo de mamona bi componente;

- Construir painel portante estrutural em madeira de reflorestamento e chapas de partículas de bagaço de cana-de-açúcar, para uso como fechamento lateral de centro de manejo de gado de corte;

- Avaliar o comportamento estrutural do painel portante, quando solicitado por esforço de impacto de corpo-mole. 


\section{Revisão bibliográfica}

Nesse item esta contida a revisão de literatura sobre assuntos relacionados as chapas aglomeradas de partículas e a construção rural na bovinocultura de corte. Mais especificamente informações sobre as matérias primas utilizadas, o bagaço de cana-deaçúcar e a resina poliuretana bi componente a base de óleo, e a bovinocultura e o sistema construtivo aplicado no trabalho.

\subsection{Bagaço de cana-de-açúcar}

Segundo Botaro (1996), aproximadamente $50 \%$ em peso do talo da cana-de-açúcar consiste de fibras de alta qualidade, orientadas paralelamente ao eixo axial da planta e são encontradas principalmente na casca. Essas fibras são mais longas do que os elementos fibrosos encontrados no interior do talo e mais resistentes ao ataque de agentes químicos, sendo esta característica comparada até mesmo às das madeiras duras. Cerca de $15 \%$ do bagaço em peso é constituído por fibras internas de tamanhos variados localizados principalmente na região interna do talo da planta. Nesta região encontra-se também a medula que é formada por células parenquimáticas que não apresentam características de fibras e constituem aproximadamente $30 \%$ do bagaço em peso.

Segundo Santana e Teixeira (1993), o bagaço in natura é composto, aproximadamente, por $44,5 \%$ de fibras lignocelulósicas, $50 \%$ de umidade, 2,5\% de sólidos solúveis em água e 3\% de teor de cinza. Battistelle et al. (2009) verificaram que, morfologicamente, o bagaço possui $50 \%$ de fibra, $30 \%$ de tecidos parenquimatosos e $20 \%$ de vasos e epiderme.

Na Tabela 1 são apresentados valores da composição química do bagaço de canade-açúcar encontrados por Ashori et al. (2009), trabalhando com fibra de bagaço de canade-açúcar para produção de MDF, e Carvalho et al. (2006), avaliando a composição químicobromatológica e a digestibilidade do bagaço de cana-de-açúcar, mostrando que sua composição é variável. 
Tabela 1 - Composição química do bagaço de cana-de-açúcar, em porcentagem de matéria seca.

\begin{tabular}{ccc}
\hline \multirow{2}{*}{ Componente } & Carvalho et al. (2006) & Ashori et al. (2009) \\
\cline { 2 - 3 } & Composição (\%) & Composição (\%) \\
\hline Matéria seca & 40,11 & - \\
Proteína bruta & 2,32 & - \\
Fibra em detergente neutro & 59,02 & - \\
Fibra em detergente ácido & 38,34 & - \\
\hline Hemicelulose & 20,68 & 52,70 \\
Celulose & 30,30 & 20,63 \\
Lignina & 7,34 & 0,89 \\
Extrato etéreo & 0,07 & 1,35 \\
\hline Cinzas & 1,22 & \\
\hline
\end{tabular}

Fonte: Adaptado de Carvalho et al. (2006) e Ashori et al. (2009).

Em relação a composição morfológica das fibras do bagaço de cana-de-açúcar, Ashori et al. (2009) encontrou valores que estão apresentados na Tabela 2.

Tabela 2 - Morfologia da fibra do bagaço de cana-de-açúcar.

\begin{tabular}{cc}
\hline Morfologia & \\
\hline Comprimento $(\mathrm{mm})$ & 1,24 \\
Diâmetro $(\mu \mathrm{m})$ & 22,90 \\
Relação de aspecto (C/D) & 54 \\
\hline
\end{tabular}

Fonte: Ashori et al. (2009).

O bagaço de cana-de-açúcar, subproduto da agroindústria, esta disponível em grande quantidade devido ao aumento da área plantada decorrentes principalmente de investimentos públicos e privados na produção alcooleira e da industrialização do processo de produção de açúcar e álcool. Segundo dados da CONAB (2012), a safra de cana-de-açúcar no Brasil referente à $2011 / 2012$ foi de 571,4 milhões de toneladas, o que representa para o país geração de cerca de 160 milhões de toneladas de bagaço de cana-de-açúcar, pois de acordo com Silva et al. (2007), cada tonelada processada de cana-de-açúcar gera um total de $280 \mathrm{~kg}$ de resíduo. 
As projeções de produção de bagaço de cana demonstram um aumento contínuo ao longo dos anos, com uma estimativa de produção de 285,5 milhões de toneladas para a safra 2020/2021, de acordo com CONAB (2011).

Geralmente, o bagaço de cana é queimado em reservatórios de vapor para produzir energia para uso industrial, mas atualmente devido às suas características físico-químicas, está sendo utilizado em um vasto campo de pesquisas, dentre os quais, na produção de ração animal, indústria química para a produção de plástico biodegradável, na produção de bicarbonato de sódio e cloreto de amônio, e também para a manufatura de painéis aglomerados (SILVA, et al. 2007 e ANSELMI, 2007).

Com o objetivo de encontrar uma solução eficaz para os resíduos da indústria sucroalcooleira, vários estudos são desenvolvidos em todo o país, procurando agregar valor aos materiais, almejando a geração de emprego e renda. A produção de chapas de partículas representa uma destas soluções, que almeja o aproveitamento integral do resíduo, criando um novo produto. Várias pesquisas foram desenvolvidas nesse campo do conhecimento, mas muitas questões ainda precisam ser respondidas.

\subsection{Chapas de partícula de madeira}

As chapas aglomeradas surgiram na Alemanha, no início da década de 40 , como forma de viabilizar a utilização de resíduos de madeira, em face da dificuldade de obtenção de madeiras de boa qualidade, devido ao isolamento do país durante a segunda Guerra Mundial (MENDES et al., 2010). Essas chapas são geralmente fabricadas a partir de partículas de madeira aglutinadas por adesivo sintético ou outro aglomerante, sendo o conjunto prensado a quente, por tempo suficiente para que a cura da resina se efetue (IWAKIRI et al., 2004).

A tecnologia de produção de chapas de partículas aglomeradas desenvolveu-se principalmente após a Segunda Guerra Mundial, em função da escassez da matéria-prima e, também, devido à redução das perdas ocorridas tanto na indústria madeireira como na exploração florestal. No Brasil, a produção de painéis de madeira aglomerada teve início em 1966 (MENDES et al., 2003). 
Saldanha (2004) descreve que a importância do setor de chapas de madeira reconstituída pode ser atribuída a fatores como: a necessidade do uso racional dos recursos florestais; restrições no uso e comercialização de madeiras nativas e o melhor aproveitamento da matéria-prima madeira no processamento, fortalecendo mais as indústria de chapas reconstituídos, que utilizam exclusivamente madeiras de florestas plantadas, sendo na sua maioria do gênero Pinus e Eucalyptus.

Segundo o mesmo autor, as chapas reconstituídas principalmente as de partículas, assumiram um papel de destaque no mercado nacional no final dos anos 90 , pois foram eles que apresentaram a maior evolução em inovações tecnológicas, disponibilizando ao mercado novos produtos como: MDF e OSB, matéria-prima alternativa para os setores moveleiros e de construção civil respectivamente.

Castro (2000) cita que só nos últimos quarenta anos o desenvolvimento das chapas de madeira reconstituída ganhou força, surgindo vários tipos de chapas de grandes dimensões, com maior estabilidade dimensional, mas homogênea, sem defeitos, com ganhos de melhorias em relação ás propriedades físicas e mecânicas e resistência à biodeteriorização, adequados a indústria moveleira e a construção civil. Porém, esses produtos só foram possíveis de ser fabricados, a partir do desenvolvimento de resinas sintéticas.

Esses painéis são geralmente fabricados a partir de partículas de madeira aglutinadas por adesivo sintético ou outro aglomerante, sendo o conjunto prensado a quente, por tempo suficiente para que a cura da resina se efetue (IWAKIRI et al., 2004 e HILLIG, 2000).

Segundo Maciel et al. (2004) no Brasil, a madeira para produção de painéis aglomerados vem de florestas plantadas e de empresas produtoras, e entre estas algumas utilizam madeira de Pinus na sua linha de produção, outras empregam apenas Eucalipto e algumas combinam Pinus e Eucalipto em proporções variáveis.

De acordo com Iwakiri et al. (2000), na produção de chapas de partículas aglomerada de madeira, o fator espécie está relacionado principalmente com a densidade. As propriedades físico-mecânicas das chapas de aglomerado são altamente influenciadas pela relação entre a densidade do painel e a densidade da madeira utilizada, a qual é denominada de razão de compactação (MALONEY e KELLY, 1977). Para viabilizar a utilização de espécies de maior densidade, ou partículas de outros materiais, existe a alternativa de 
mistura de diferentes espécies, com maior e menor densidade, visando manter a razão de compactação dentro da faixa aceitável (MOSLEMI, 1974).

Zhang et al. (1998), encontraram um aumento nas propriedades de módulo de elasticidade, módulo de ruptura e ligação interna, com o aumento da densidade das chapas de 0,60 a $0,70 \mathrm{~g} / \mathrm{cm}^{3}$. Wu (1999) constatou a mesma tendência de aumento nestas propriedades, com o aumento na densidade das chapas na faixa de 0,55 a $1,15 \mathrm{~g} / \mathrm{cm}^{3}$, sendo esta, de alta densificação. Porém o inchamento em espessura é maior para chapas de maior densidade, devido à maior quantidade de material lenhoso e maior densificação, resultando na maior liberação de tensões de compressão impostas durante a prensagem (MOSLEMI, 1974; KELLY, 1977).

A princípio, esses painéis também podem ser fabricados a partir de qualquer outro material lignocelulósico que Ihes confiram alta resistência mecânica e peso específico préestabelecido, já que a composição química dos materiais lignocelulósicos é semelhante à da madeira, mais precisamente com a das madeiras duras que contêm menor teor de lignina e maior teor de hemiceluloses do tipo pentosanas (ROWELL et al., 2000).

\subsection{Painéis de partícula de resíduos lignocelulósicos}

O volume de resíduos gerados pela agroindústria brasileira mostra-se como alternativa para atender a necessidade de matéria-prima do setor de painéis aglomerados, sendo possível identificar vários tipos de resíduos lignocelulósicos com potencialidades para esse uso: sabugo de milho, casca de arroz, casca de café, casca de amendoim, caule de bananeira, casca de coco, caule de mandioca, casca de mamona, bagaço de cana, entre outros (OKINO et al. (1997); ROWELL et al. (2000); MENDES (2008); MENDES et al. (2009)).

A produção de painéis de partículas resíduos lignocelulósicos, é uma alternativa que proporciona agregar valor a esse subproduto, possibilitando atender à crescente demanda da indústria de painéis de madeira, além de contribuir com a diminuição do uso da madeira e consequentemente a pressão sobre as florestas, reduzindo custos de produção dos painéis, tornando-os mais competitivos no cenário econômico (MENDES et al., 2010). 
A princípio, chapas aglomeradas podem ser fabricadas a partir de qualquer material lignocelulósico que lhes confiram alta resistência mecânica e peso específico préestabelecido (OKINO et al., 1997).

Quanto às propriedades e qualidade dos painéis, muitos são os fatores que contribuem para as características do produto final, dentre eles pode-se destacar: a densidade do material lignocelulósico, densidade dos painéis, umidade das partículas, razão de compactação, ciclo de prensagem, quantidade e tipo de adesivo (KELLY, 1977 e MALONEY, 1993).

Vários trabalhos foram desenvolvidos visando avaliar a viabilidade de uso de resíduos lignocelulósicos na produção de painéis de partículas, Barros Filho (2009) trabalhou com desenvolvimento e caracterização de chapas aglomeradas a base de cana-de-açúcar, gerado na usina de álcool e açúcar e o gerado no alambique, e resinas uréia-formaldeído e melamina-formaldeído. Comparando seus valores obtidos com a norma CS 236-66 de comercialização de painéis aglomerados de média densidade, os testes físicos atenderam a norma, já para os testes mecânicos não foram atendidos.

José e Beraldo (2006) utilizaram partículas de Bambusa vulgaris Schrad e como aglomerante resina poliuretana à base de óleo de mamona, com a finalidade de buscar sustentabilidade para o processo produtivo. Pelos resultados obtidos pode-se afirmar que a relação custo-benefício, tendo em vista que a resina é o material de maior custo econômico e ambiental na composição da chapa, torna-se mais viável a produção de chapas com $10 \%$ de resina, apesar das chapas com $15 \%$ de resina apresentarem valores superiores aos das chapas com $10 \%$ de resina, porem não demonstram estatisticamente diferença significativa.

Silva (2006) avaliando a viabilidade técnica do emprego de partículas longas e orientadas de bagaço de cana-de-açúcar na confecção de painéis OSB, demonstrou a viabilidade da produção dos painéis, cujas propriedades atenderam aos requisitos das diferentes faixas de uso propostos pela norma EN-300/2002. O autor concluiu que a resina poliuretana à base de mamona e a resina Cascomel M $08 \mathrm{ME}$, são compatíveis com o bagaço de cana-de-açúcar, para a produção de painéis partículas.

Pedrazzi et al. (2006) avaliaram a qualidade de chapas de partículas aglomeradas fabricadas com resíduos da madeira de Eucalyptus saligna, resultantes da picagem das toras para a confecção de cavacos utilizados na produção de celulose. Como conclusões, os autores informam que as propriedades de flexão estática, ligação interna e arrancamento de 
parafusos aumentaram com a densidade da chapa, assim como com o teor de adesivo, independentemente do tipo de resíduo. Os resultados permitiram concluir que utilizando as partículas do tipo palitos ou serragem com maiores percentagens de adesivo e maiores densidades, podem ser produzidas chapas com qualidade satisfatória.

Mendes et al. (2010) avaliaram o efeito da associação de bagaço de cana-de-açúcar com partículas de madeira de eucalipto em diferentes proporções. Os resultados obtidos para painéis produzidos com $12 \%$ de uréia-formaldeído, $75 \%$ de bagaço de cana e $25 \%$ de partículas de madeira de eucalipto, foi a formulação que atendeu os valores estipulados pela norma CS 236-66, com exceção do MOE.

Para a produção de painéis de partículas, o bagaço de cana-de-açúcar está entre os materiais mais promissores dentre outros resíduos agroindustriais, devido ao seu baixo custo e abundância. A estrutura lignocelulósica do bagaço é semelhante à da madeira (SANTANA \& TEIXEIRA, 1993), mais precisamente com a das madeiras duras que contêm menor teor de lignina e maior teor de pentosanas (SOUSA et al., 1986).

Um dos obstáculos à melhor utilização dos painéis de partículas de bagaço de canade-açúcar é a baixa estabilidade dimensional, decorrente da alta tendência à absorção de água, Santana e Teixeira (1993); Rowell e Keany (1991) e Young (1967).

Widyorini et al. (2005) avaliaram as propriedades físicas de painéis de partículas à base de bagaço de cana-de-açúcar e resina ureia-formaldeído. Pelos resultados obtidos, os autores concluem que a densidade média dos respectivos painéis foi de $0,6 \mathrm{~g} / \mathrm{cm}^{3}$.

Contreras et al. (2006) verificaram a possibilidade de fabricação de painéis de partículas à base de cana brava (Gynerium sagittatum) e adesivo fenol-formaldeído (FF) nas proporções de 10 e 13\%. Pelos resultados encontrados de propriedades físico-mecânicas, foram identificados painéis com densidade média de $0,65 \mathrm{~g} / \mathrm{cm}^{3}, \mathrm{MOR}$ médio de $18 \mathrm{MPa} \mathrm{e}$ tração perpendicular igual a 0,35 $\mathrm{MPa}$, atendendo as especificações do documento normativo 847:1991 - Norma Venezolana COVENIN.

Silva et al. (2008) avaliaram o emprego do bagaço da cana-de-açúcar e a resina cascomel M $08 \mathrm{ME}$, como matriz polimérica, na fabricação de painéis de partículas longas e orientadas, semelhante ao OSB. Nesse trabalho, foi mantida fixa a pressão em $5 \mathrm{MPa}$, a porcentagem de resina em $10 \%$ e a temperatura de prensagem variou entre $90^{\circ} \mathrm{C}$ e $130 \circ \mathrm{C}$. Resultados obtidos indicam que os painéis estudados apresentaram comportamento físico- 
mecânico que permite sua comparação com painéis OSB comerciais, e possibilitam sua indicação para usos análogos a tal produto.

Battistelle et al. (2009) avaliaram a possibilidade de produção de painéis de partículas a partir de fibras das folhas caulinares do bambu da espécie Dendrocalamus giganteus, bagaço da cana-de-açúcar (Saccharum officinarum) e resina ureia-formaldeído, como matriz polimérica. Os resultados mostraram que o bagaço da cana-de-açúcar apresenta bom potencial para a produção de painéis de partículas e as propriedades físicomecânicas atendem aquelas estabelecidas pelos documentos normativos.

Mendes et al. (2008) compararam as propriedades físicas e mecânicas de painéis de partículas produzidos com bagaço de cana-de-açúcar oriundos da China, com painéis comerciais produzidos no Brasil à base de madeira de Pinus e Eucalipto. Os autores concluem dizendo que as propriedades mecânicas de MOR e MOE não apresentaram diferença estatística significativa. No entanto, finalizam afirmando que manipulações nas variáveis de processamento são necessárias para viabilizar o uso do bagaço de cana-deaçúcar na produção de painéis de partículas.

Marcilio et al. (2008) propõem a utilização do bagaço da cana-de-açúcar para confecção de chapas de partículas reforçadas com fibras das folhas caulinares do bambu (palha de bambu), da espécie Dendrocalamus giganteus e resina ureia-formaldeído. Com base nos resultados obtidos, os materiais apresentam potencial para serem utilizados na fabricação de chapas de partículas com densidade de até $1 \mathrm{~g} / \mathrm{cm}^{3}$.

\subsection{Adesivos para fabricação de painéis}

Os adesivos são classificados por Olmos (1992) em dois grupos básicos:

-Adesivos de origem natural - nesta categoria destacam-se aqueles de origem animal, amido, caseína, albumina de proteína vegetal, mamona e o tanino (extraídos de algumas espécies de vegetais: barbatimão, angico-preto, acácia, quebracho, dentre outras);

-Adesivos de origem sintética - nesta categoria destacam-se a ureia-formaldeído, resorcinol-formaldeído, fenol-formaldeído, melanina e polivinil. 
Em relação aos adesivos para fabricação de painéis comerciais, a resina à base de uréia-formaldeído e solução aquosa é utilizada frequentemente em razão de seu baixo custo. Segundo Maloney (1996) e Pizzi (1994), devido à necessidade de se diminuir a emissão de formol, produto carcinogênico, proveniente nas resinas uréicas, foram desenvolvidos vários estudos que avaliaram a mistura com outras resinas, como, por exemplo, resina melamínica, a qual confere às chapas maior resistência à umidade.

No entanto, existe uma tendência mundial para o uso de produtos biodegradáveis, não poluentes e originados de insumos renováveis. De acordo com Araújo (1992), esta tendência fez avançar as pesquisas, levando à descoberta da resina poliuretana derivada do óleo de mamona, apresentada na formulação de bi componente.

Conhecida internacionalmente como "Castor Oil", a mamona (Ricinus communis) é uma planta da família das Euforbiáceas, da qual é extraído o óleo de mamona, também conhecido como óleo de rícino. Esta planta é encontrada em regiões tropicais e subtropicais, sendo muito abundante no Brasil. A partir do óleo de mamona torna-se possível sintetizar polióis e pré-polímeros com diferentes características que, quando misturados, dão origem a um poliuretano. Esta mistura poliól (à base de mamona) e pré-polímero, a frio, levam à reação de polimerização da mistura. Esta reação conduz à formação da poliuretana, sendo possível variar a porcentagem do poliól, que definirá maior ou menor dureza ao produto final, bem como o emprego de catalisador adequado a fim de aumentar a velocidade da reação (JOSÉ; BERALDO, 2006).

O desenvolvimento dos poliuretanos derivados de óleo de mamona teve origem nos primeiros trabalhos propostos na década de 40 (VILAR, 1993). O óleo de mamona é obtido da semente da planta "Ricinus Communis", que é encontrada em regiões tropicais e subtropicais, sendo muito abundante no Brasil. É um líquido viscoso, obtido pela compressão das sementes ou por extração com solvente (VILAR, 1993).

As resinas poliuretanas mostram grande versatilidade de aplicação, podendo ser utilizadas em diferentes segmentos industriais. Estas resinas podem ser obtidas com densidades que variam de 6 a $1220 \mathrm{~kg} / \mathrm{m}^{3}$, podendo se apresentar como um elastômero de alta flexibilidade ou de maior dureza, ou como um plástico de engenharia (WOODS, 1990).

As resinas poliuretano podem ser derivadas tanto do petróleo como de fontes naturais, e neste caso tem-se os chamados "biomonômeros" que podem ser obtidos de fontes renováveis, como os óleos vegetais. Estes óleos derivam de um número de vegetais, 
tais como, soja, milho, açafrão, girassol, canola, amendoim, oliva e mamona, entre outros (PETROVIC, 1999).

Nascimento (2006) avaliou a possibilidade de fabricação de painéis OSB com espécies de madeira da caatinga do Nordeste do Brasil e resina poliuretana bi componente de mamona. Os resultados do trabalho indicam a viabilidade de fabricação do referido produto, cujas propriedades mecânicas são equivalentes às das chapas OSB, fabricadas em escala industrial.

Silva (2006) verificou a eficiência de painéis de partículas longas e orientadas oriundas de bagaço de cana-de-açúcar com resina bi componente à base de mamona, afirmando que o painel fabricado apresentou desempenho similar ao OSB derivado da madeira, sendo extremamente viável, valendo ressaltar que foi utilizada toda matéria-prima do bagaço, sem seleção de partículas, caracterizando menor custo. Acrescenta dizendo que existe uma tendência de uso de resinas em temperaturas variando de $90 \circ \mathrm{C}$ a $130 \circ \mathrm{C}$.

\subsection{Construções rurais na pecuária de corte}

Detentor do maior rebanho comercial bovino do mundo, com 176,6 milhões de cabeças (Anualpec, 2010) o agronegócio brasileiro possui a pecuária de corte como uma das mais importantes atividades, representando uma parcela substancial do PIB e gerando mais de nove milhões de empregos diretos e indiretos. A partir da década de 90, com as imposições da globalização, o setor pecuário (corte) tem apresentado avanços expressivos de desenvolvimento, aumentando sua competitividade produtiva e econômica. Firmando-se como o maior exportador mundial de carne bovina, o Brasil vem conquistando cada vez mais mercados por todo mundo.

Atualmente o país ocupa o terceiro lugar no consumo mundial de carne bovina e o segundo em produção de equivalente de carcaça, 7.778 Milhares de toneladas (Anualpec, 2010). Com uma taxa de abate de $23 \%$, representado 41,2 milhões de cabeças por ano. No ano de 2010, o Brasil exportou uma quantia de 1.230.571 toneladas de carne o que representa quase cinco bilhões de dólares. 
A construção rural pode ser entendida como toda aquela que compõe o "habitat" do homem do campo, ou seja, sua habitação e as demais instalações destinadas à produção agrícola e pecuária. No Brasil, por sua extensão territorial e pelas condições favoráveis de clima e relevo, as atividades agrícolas e pecuárias têm sido desenvolvidas em muitos estados, representando importante alternativa de investimento e produção. Assim sendo, evidencia-se o interesse de se intensificar a pesquisa voltada para o atendimento do homem do campo, de suas necessidades, enquanto participante fundamental dos processos produtivos (FERREIRA, 1989).

Atualmente a pecuária brasileira vem sofrendo duras críticas sobre seu método de produção, como sendo responsável por grande parte do desmatamento na floresta amazônica e por contribuir com a emissão de gases de efeitos estufa, no caso o gás metano que é produzido pela fermentação no processo de digestão dos ruminantes. Por esses e outros motivos, a aplicação de novas tecnologias dentro da cadeia produtiva bovina, tem como objetivo contribuir com a melhoria da situação da bovinocultura brasileira.

Inicialmente, a produção de gado de corte não possui muita tecnologia agregada. De maneira geral é extensiva, à base de pasto, exigindo maior área em comparação com a bovinocultura de leite, por exemplo. A produção é anual, requer menos cuidados quando comparada à exploração leiteira. O rebanho abrange maior número de cabeças e, além disso, exige capital inicial maior, apesar das instalações serem mais simples e rústicas, quase sempre se resumindo em centro de manejo e piquetes (SOUZA et al., 2003).

No entanto, com o avanço da necessidade da implantação de novas tecnologias, devido ao aumento da exigência do setor, a busca por instalações mais adequadas e que atendam as novas exigências do mercado estão sendo solicitadas e muitas vezes implantadas pelos produtores rurais. Assim como melhores instalações destinadas ao manejo dos animais, que de acordo com Grandin (1983) no caso dos centros de manejo para os bovinos, quando bem projetados reduzem contusões e hematomas nas carcaças nos bovinos e lesões nas pessoas, além de melhorarem a eficiência do trabalho.

Um centro de manejo para bovinos compreende um grupo de estruturas necessárias ao manejo de bovinos de corte, que entre elas estão os curraletes, seringa, brete, tronco, balança e embarcadouro ou carregador. É usado para confinar seguramente e eficientemente os bovinos para observação, manejo sanitário de rotina e procedimentos de manejo. 
Segundo Huhnke e Harp (2009), o brete e a seringa (Figura 1), são considerados o coração do curral tendo como algumas características desejáveis para o tronco coletivo ser curvado, laterais totalmente fechadas e laterais inclinadas. Já para a seringa principais características desejáveis seriam forma circular e laterais totalmente fechadas. Vowles et al. (1984) trabalhando com movimentação continua de animais em centro de manejo, não indicou diferença significativa entre bretes em linha reta e em curva para o tempo total. Entretanto, quando o tronco coletivo em curva com uma seringa circular são usados em uma situação para espera na entrada para o tronco de contenção, o sistema em curva é mais rápido (VOWLES; HOLLIER, 1982). Seringas em circulo e bretes em curva podem reduzir o tempo desprendido na movimentação dos animais em até 50\% (VOWLES; HOLLIER, 1982).

Grandin (1980) afirma que os bovinos permanecerão mais calmos e moverão mais facilmente através de brete com laterais totalmente fechadas e que os animais refugam frequentemente em seringas construídas com barras que permitem que os animais vejam do outro lado.
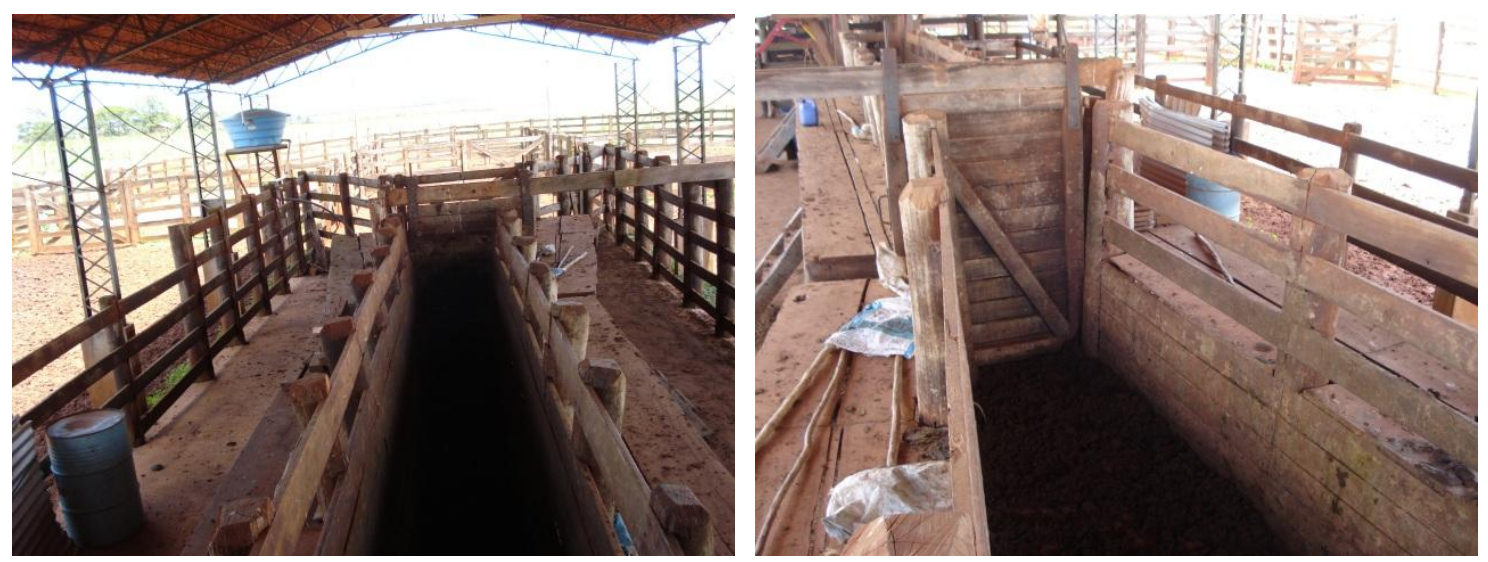

Figura 1 - Brete e seringa comumente utilizados no país.

A seringa é usada para afunilar os animais para o brete, sendo que um projeto adequado de seringa diminui o trabalho necessário com o gado. $\mathrm{O}$ tamanho da seringa deve ser para manejar oito a dez animais ao mesmo tempo.

O brete conduz os animais da seringa para o curralete ou tronco de contenção. Sua finalidade é manter os animais em uma fila única para que possam entrar no tratamento ou área de carga um de cada vez. Deve ter pelo menos $6 \mathrm{~m}$ de comprimento, independente do tamanho do rebanho e suas laterais devem ser sólidas, como as da seringa, para prevenir 
que os animais vejam as pessoas, equipamentos e outras distrações do lado de fora, assim mantendo-os calmos (BICUDO et al., 2002).

Segundo Grandin (1997), instalações corretamente projetadas para o trabalho veterinário, embarque de animais, apartação e outros procedimentos tornarão o manejo dos animais mais eficiente e ajudarão a reduzir o estresse e lesões nos animais. Já o manejo grosseiro, irá diminuir o ganho de peso dos animais e aumentar a perda na produção (GRANDIN, 1980).

Sendo assim, o desenvolvimento de um painel portante, em madeira de reflorestamento e chapas de partículas de bagaço de cana-de-açúcar e resina poliuretana à base de óleo de mamona, pode surgir como uma melhoria não apenas em relação a aplicação de um novo material na construção de centros de manejo para bovinos, mas também aos benefícios que podem trazer ao bem estar do animais e dos trabalhadores. Além de representar um produto sustentável que poderá substituir com eficiência as tábuas de madeira utilizadas em fechamento de seringas e de tronco coletivo de centro de manejo para bovino de corte. 


\section{Materiais e métodos}

Neste item estão descritos os materiais utilizados no desenvolvimento do trabalho, os procedimentos de produção, de ensaios e equipamentos utilizados para a caracterização física e morfológica das partículas do bagaço de cana-de-açúcar, caracterização físicomecânica, micro estruturais e de durabilidade nas chapas de partículas de bagaço de canade-açúcar e resina poliuretana bi componente à base de óleo de mamona e avaliação da resistência ao impacto do painel portante em madeira de reflorestamento e chapas de partículas.

\subsection{Materiais}

O bagaço de cana-de-açúcar foi obtido de duas Usinas sucroalcooleiras diferentes: Usina A, localizada no município de Pirassununga - SP e Usina B, na cidade de Araras - SP.

Para estabelecer a adesão entre as partículas, foi utilizada resina poliuretana bi componente à base de óleo de mamona, sendo um dos componentes poliol derivado do óleo vegetal, e o outro o isocianato polifuncional. Trata-se de um adesivo de cura a frio, podendo ser acelerada com temperatura a partir de $90^{\circ} \mathrm{C}$ (DIAS, 2008).

Para a fabricação do painel portante, foram utilizadas vigas de madeira serrada do gênero eucalyptus sp. oriundas de reflorestamento.

\subsection{Métodos de caracterização da matéria prima}

Com objetivo de avaliar a estrutura morfológica e as propriedades físicas das partículas de bagaço de cana-de-açúcar, utilizadas na fabricação das chapas aglomeradas, foram realizados ensaios para determinar a composição química, dimensão, densidade e estrutura microscópica das fibras do bagaço de cana-de-açúcar. 


\subsubsection{Análise bromatológica do bagaço de cana-de-açúcar}

Esse ensaio foi realizado para identificar as frações matéria seca (MS), proteína bruta (PB), extrato etéreo ( $E E)$, fibra bruta (FB), extrativos não nitrogenados (ENN), matéria mineral ou cinza (MM) existentes no bagaço de cana-de-açúcar provenientes da Usina A e B. A análise bromatológica foi realizada no Laboratório de Nutrição da FZEA/USP e foi utilizado o método de Weende, que permite a identificação de grupos de compostos químicos ou entidades (LANA, 2005).

\subsubsection{Dimensão das partículas}

As dimensões das partículas foram determinadas por meio de um estereoscópio da marca Zeiss, modelo KL 1500 LCD (Figura 2), e uma régua. Foram usadas 100 amostras de fibra do bagaço de cana-de-açúcar, sendo medido o comprimento e largura de cada fibra.

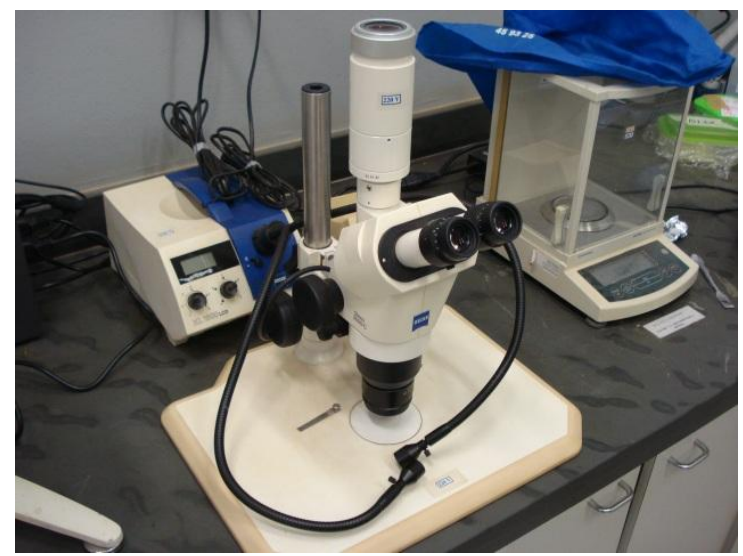

Figura 2 - Estereoscópio. 


\subsubsection{Densidade das partículas}

Para a determinação da densidade das partículas de bagaço de cana-de-açúcar, foi utilizado o equipamento multipicnômetro a gás hélio, marca Quantachrome, Ultrapycnometer 1000 (Figura 3). Para o cálculo da densidade foi utilizado os dados obtidos pelo equipamento e posteriormente a eq. (1):

$$
V_{p}=V_{c}-V_{r}\left(\left(\frac{P_{1}}{P_{2}}\right)-1\right)
$$

Onde:

$V_{p}=$ volume da amostra $\left(\mathrm{cm}^{3}\right) ;$

$V_{c}=$ volume do porta amostra $\left(\mathrm{cm}^{3}\right)$;

$V_{r}=$ volume da referência $\left(\mathrm{cm}^{3}\right)$;

$P_{1}=$ pressão medida depois da pressurização do volume de referência (PSI);

$P_{2}=$ pressão medida depois de incluída Vc (PSI).

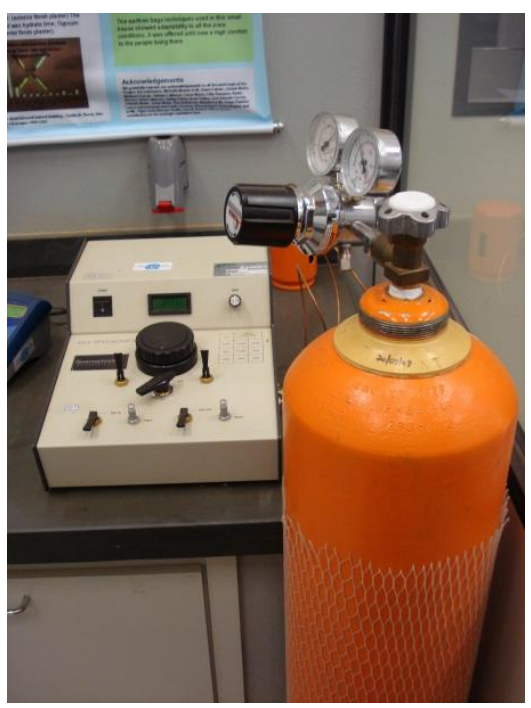

Figura 3 - Multipicnômetro a gás hélio. 


\subsubsection{Microscopia óptica das partículas}

A microscopia ótica das fibras de bagaço de cana-de-açúcar teve por objetivo, realizar imagens para medir largura das partículas e verificar características morfológicas. Foi utilizando um microscópio óptico da marca Carl Zeiss, modelo Axio Image AZM AX10 com câmera de captura Carl Zeiss, modelo Axiocam MRC 5 e software Axio Vision (Release 4.8.2 06-20) (Figura 4).

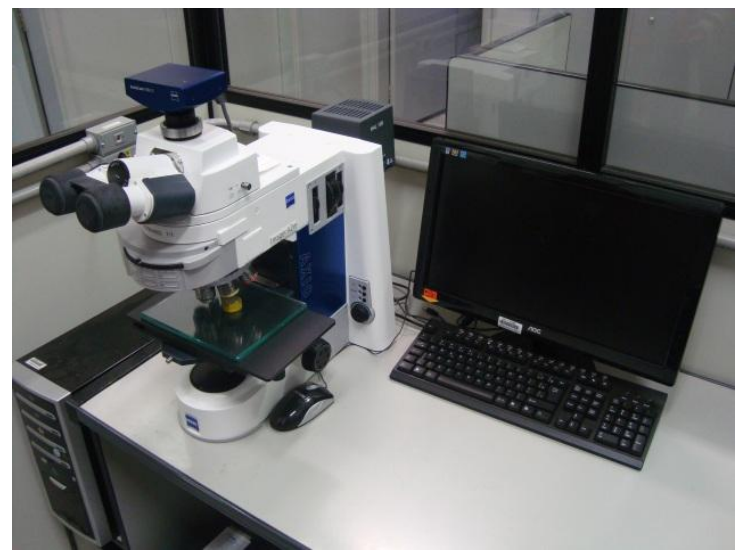

Figura 4 - Microscópio óptico com câmera.

3.3 Processo de fabricação das chapas de bagaço de cana-de-açúcar e resina poliuretana bi componente à base de óleo de mamona

O procedimento utilizado para a fabricação das chapas aglomeradas de partículas utilizados nesse trabalho seguem as premissas indicas por Maloney (1996), que apresenta parâmetros para a produção de painéis de partículas de madeira. Foram produzidas chapas com dois tamanhos de partículas do bagaço de cana-de-açúcar. A Tabela 3 ilustra os parâmetros de produção utilizados nesse trabalho. 
Tabela 3 - Parâmetros de produção das chapas de partículas de bagaço de cana-de-açúcar.

\begin{tabular}{cc}
\hline \multicolumn{2}{c}{ Parâmetros de Produção } \\
\hline Dimensão de partículas* & $5 \mathrm{~mm} \mathrm{e} 8 \mathrm{~mm}$ \\
\hline Densidade aparente da chapa & $1 \mathrm{~g} / \mathrm{cm}^{3}$ \\
Espessura da chapa & $10 \mathrm{~mm}$ \\
Pressão & $5 \mathrm{MPa}$ \\
Temperatura & $100^{\circ} \mathrm{C}$ \\
Tempo de prensagem & $10 \mathrm{~min}$.
\end{tabular}

* dimensão máxima das partículas que passaram na peneira com diâmetros de 5 e $8 \mathrm{~mm}$.

O processo iniciou-se com a coleta do resíduo. Após a coleta o mesmo foi acondicionado sobre uma lona, protegido de chuva e outra fonte de umidade, e do contato com outros tipos de materiais (Figura 5).

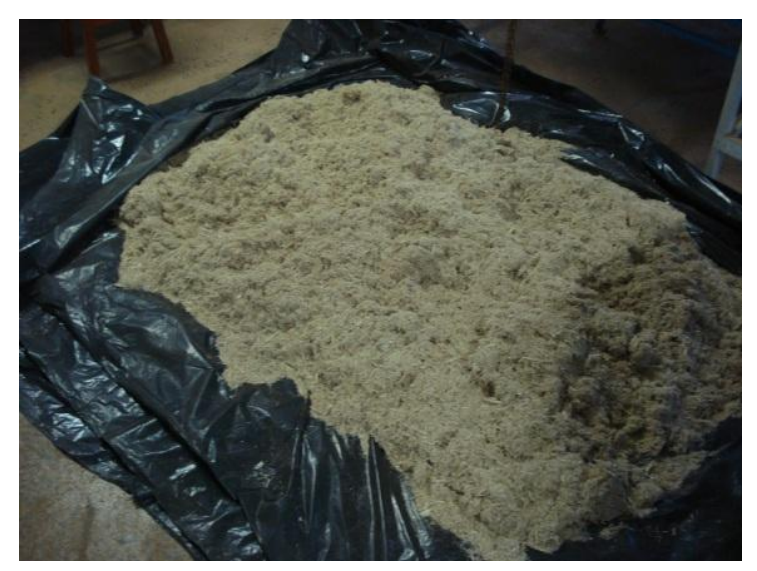

Figura 5 - Bagaço acondicionado.

O bagaço de cana-de-açúcar primeiramente foi seco em estufa $\left(60^{\circ} \mathrm{C}\right)$ para que se chegue a uma umidade aproximada de $3 \%$. Posteriormente passou pelo processo de peneiramento, em peneira com malha de $2 \mathrm{~mm}$. Para os dois tipos de chapas, com tamanhos diferentes de partículas, o material retido na peneira, foi utilizado no processo de fabricação das chapas e o material passante (Figura 6), foi descartado. 

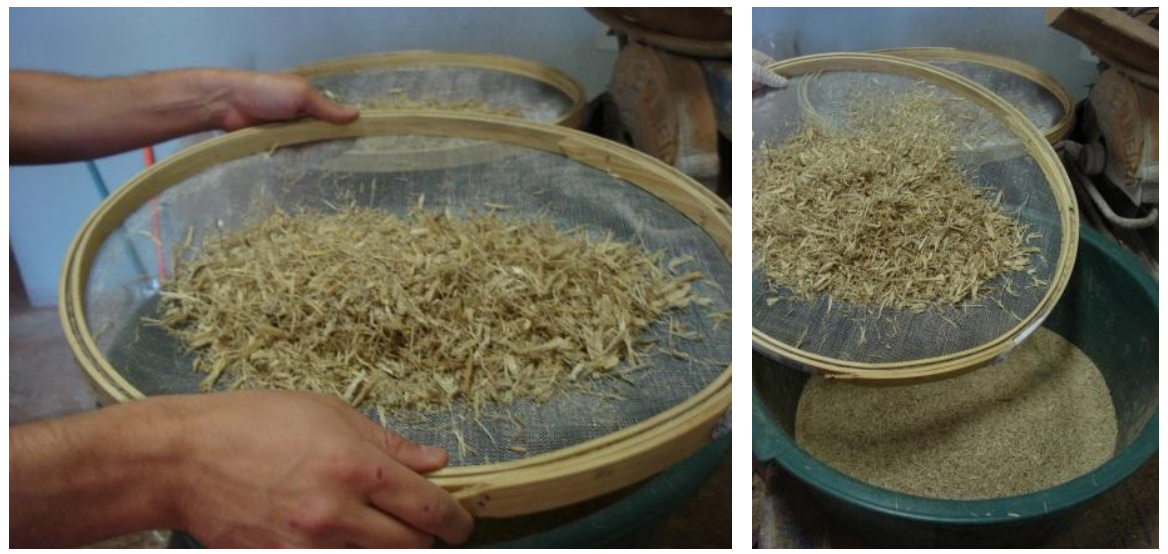

Figura 6 - Detalhe da porção retida na peneira e porção passante no peneiramento do bagaço de cana-de-açúcar.

Para as chapas com comprimento de partícula de até $8 \mathrm{~mm}$, essa porção do material retido, após o peneiramento foi picado em um moinho de facas com malha de 8 $\mathrm{mm}$ (Figura 7).

No caso das chapas com comprimento de partícula de até $5 \mathrm{~mm}$, foi realizado um peneiramento duplo, com peneiras de malhas $2 \mathrm{~mm}$ e $5 \mathrm{~mm}$, respectivamente, sendo o matéria passante utilizado para o processo de fabricação da chapas.
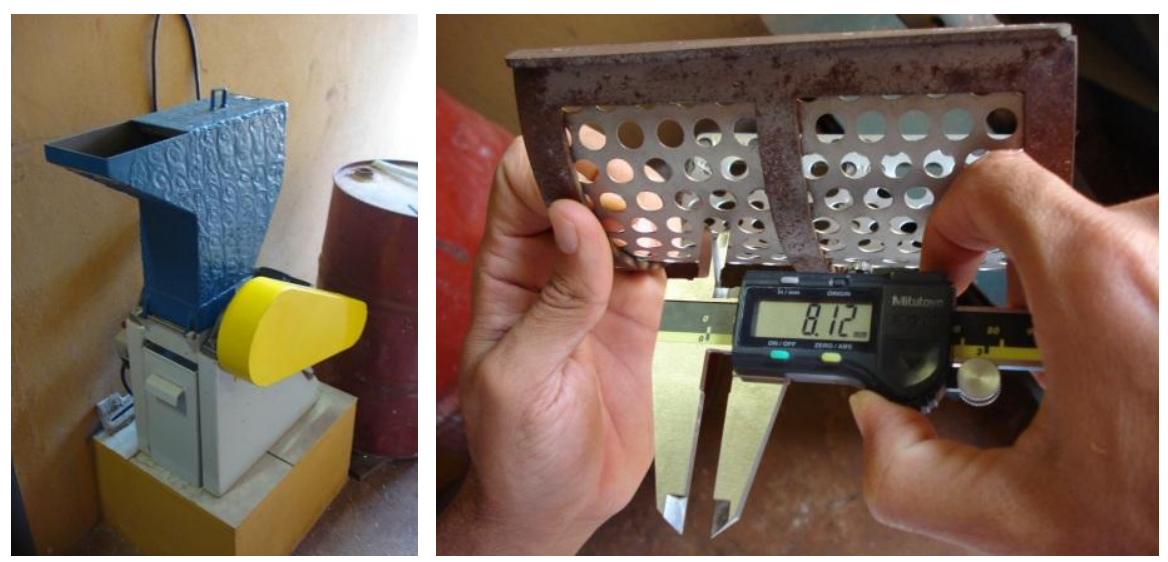

Figura 7 - Moinho de facas e malha de $8 \mathrm{~mm}$.

Por meio desse procedimento, foram obtidos resíduos com comprimentos de partícula diferentes, com dimensões de até 8 e $5 \mathrm{~mm}$, conforme ilustra a Figura 8. Esse procedimento permitiu a retirada da parte fina (partículas menores que $2 \mathrm{~mm}$ ) do bagaço de cana-de-açúcar e a obtenção de partículas com tamanhos mais homogêneos. A opção por utilizar comprimentos de partículas diferentes visou identificar variações nas propriedades 
físico-mecânicas das chapas, almejando comparar e definir qual o tamanho ideal de partícula a ser utilizada na fabricação das chapas.
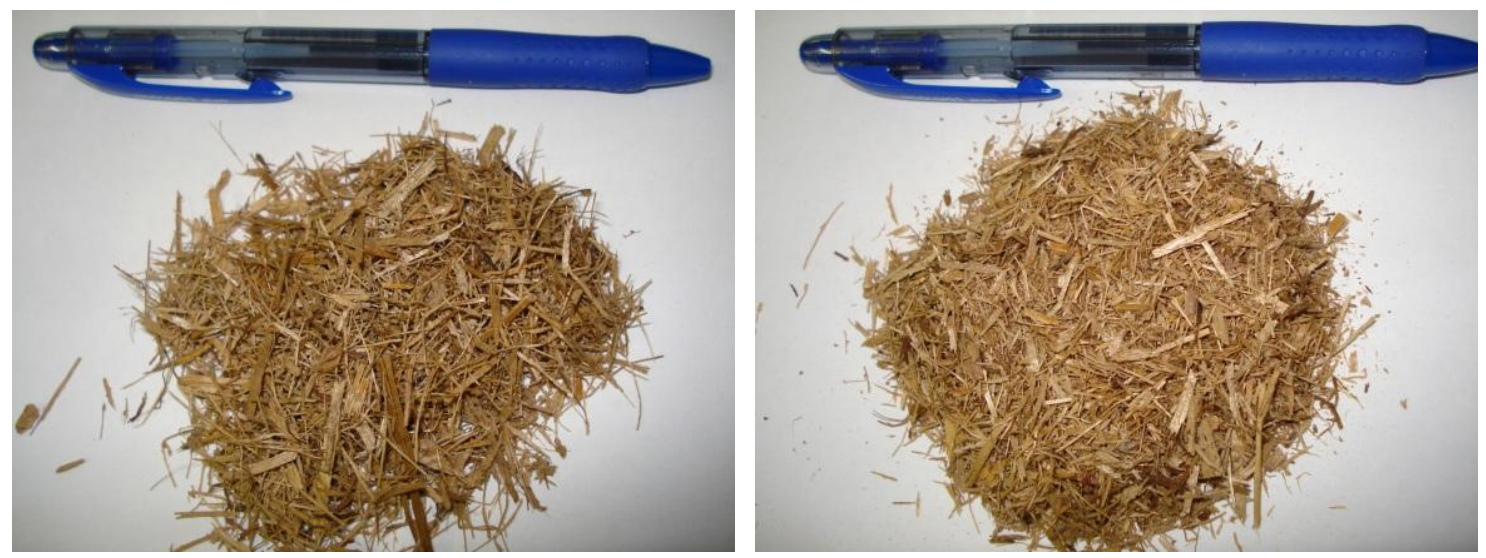

Figura 8 - Partículas de até 8 e $5 \mathrm{~mm}$.

Posteriormente foi feita a mistura dos componentes da resina bi componente, utilizando uma balança analítica (Figura 9), sendo adicionado na proporção de 3 partes do poliol para 1 parte do pré-polímero a base de óleo de mamona na proporção de $15 \%$ em relação à massa seca do resíduo. Posteriormente, foi realizada uma aplicação direta da resina nas partículas do bagaço de cana-de-açúcar (Figura 10), sendo a mistura levada para um misturador planetário por tempo de aproximadamente 5 minutos (Figura 11).
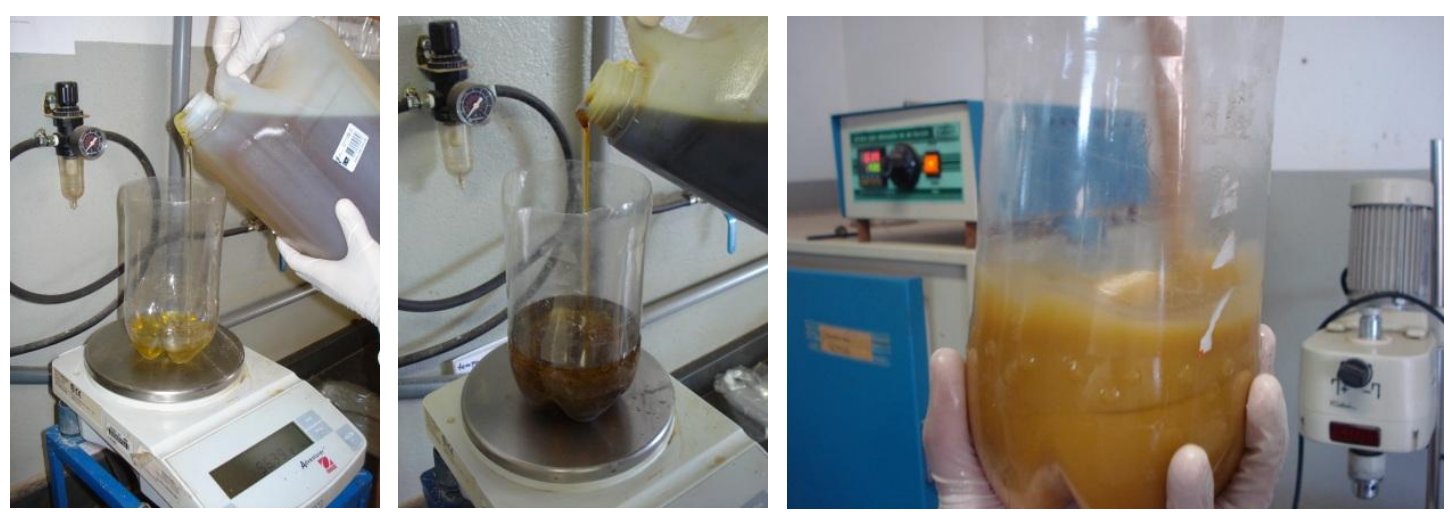

Figura 9 - Pesagem e mistura dos componentes da resina. 

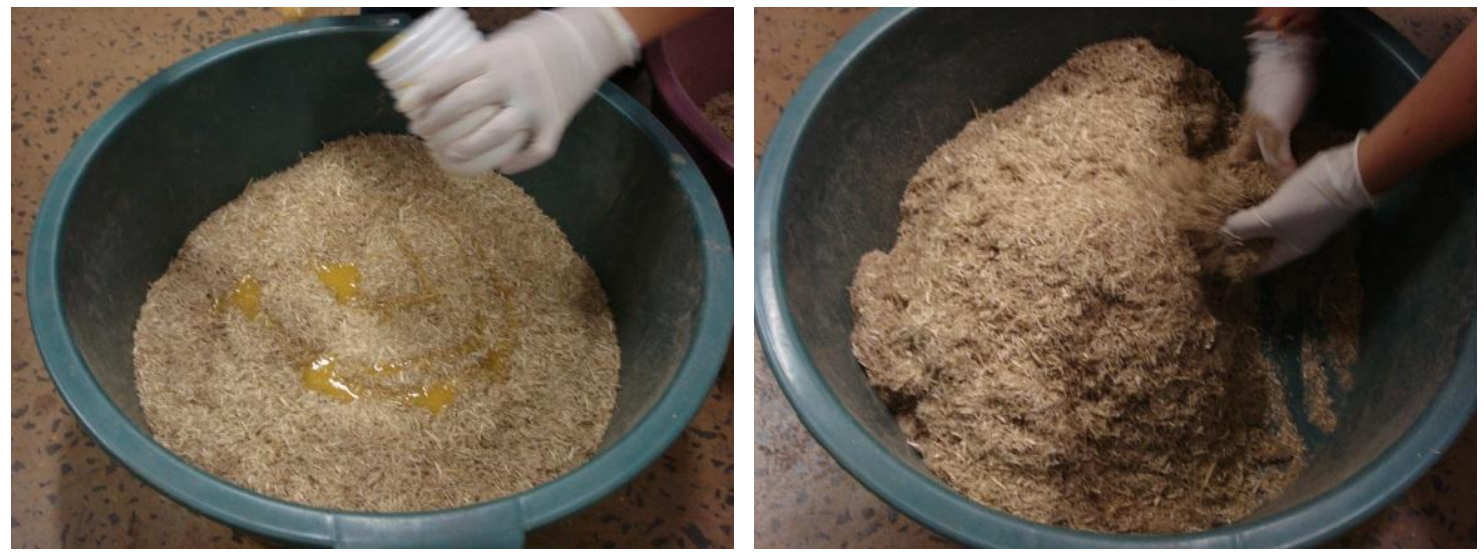

Figura 10 - Aplicação e pré-mistura da resina ao bagaço de cana-de-açúcar.
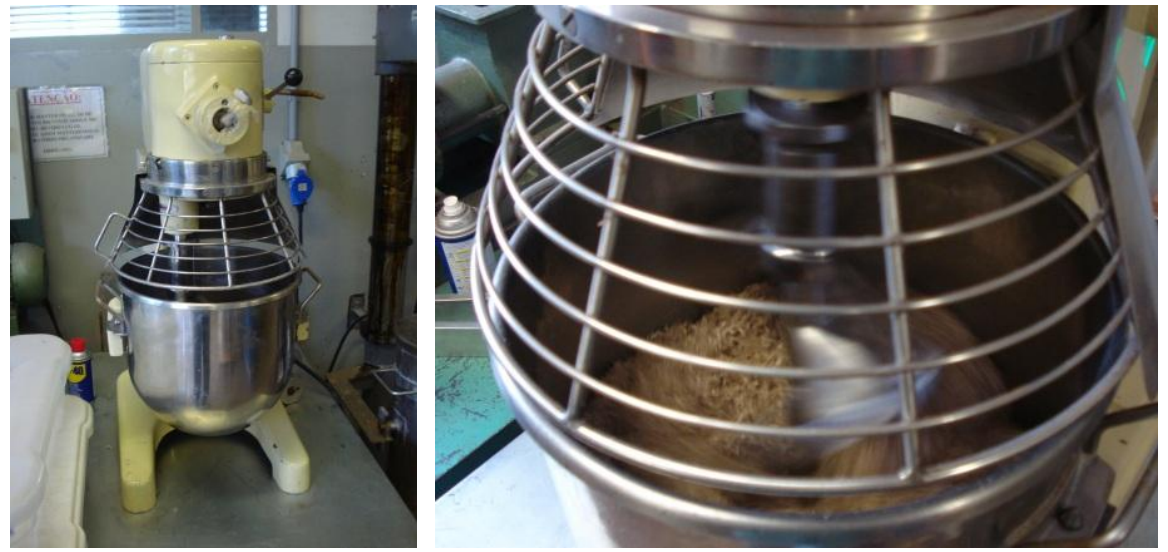

Figura 11 - Vista geral do batedor planetário e homogeneização.

Após a mistura, o resíduo com a resina devidamente distribuída, foi acondicionado em um molde formador com dimensões de $40 \times 40 \times 10 \mathrm{~cm}$, sendo formado o colchão de partículas (Figura 12), submetido a uma prensa hidráulica com aquecimento, por um período de $10 \mathrm{~min}$, pressão de $5 \mathrm{MPa}$ e temperatura de $100^{\circ} \mathrm{C}$ (Figura 13). Após o processo de prensagem, os painéis produzidos (Figura 14) permaneceram por $72 \mathrm{~h}$ em processo de estabilização.
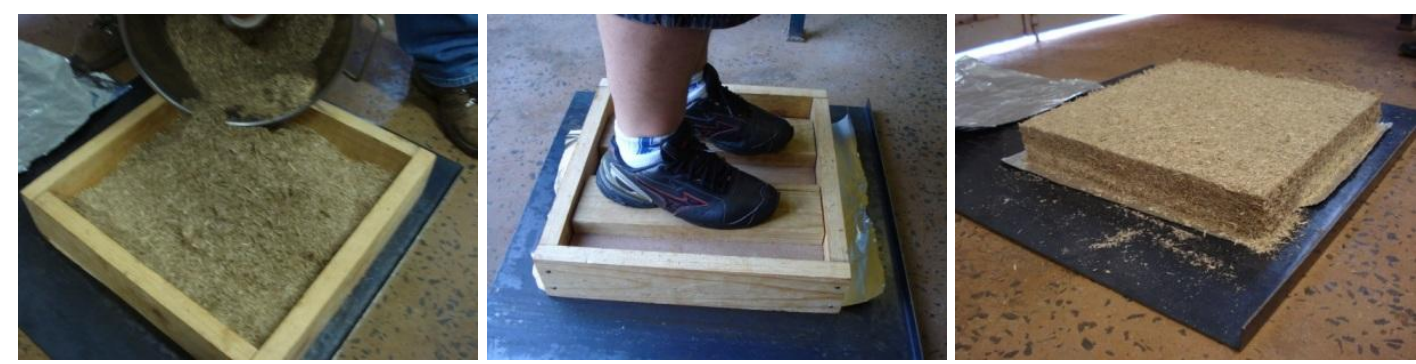

Figura 12 - Moldagem, pré-prensagem e formação do colchão de bagaço de cana de açúcar e resina. 

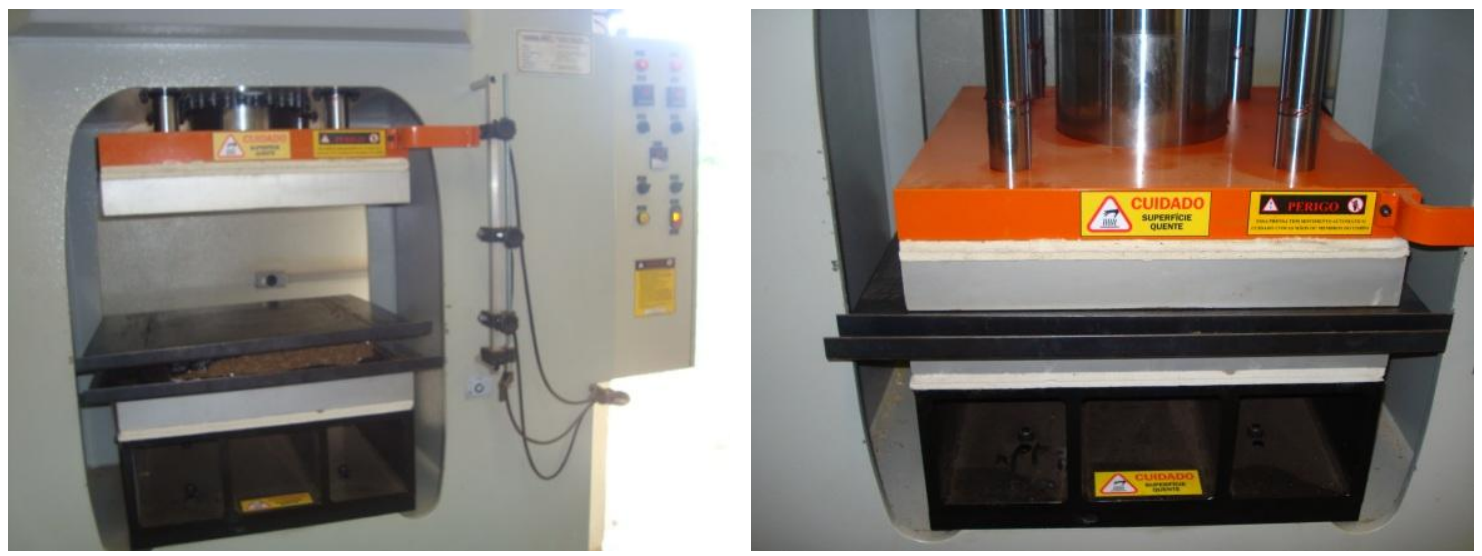

Figura 13 - Prensagem a quente com prensa hidráulica do colchão de bagaço e resina.
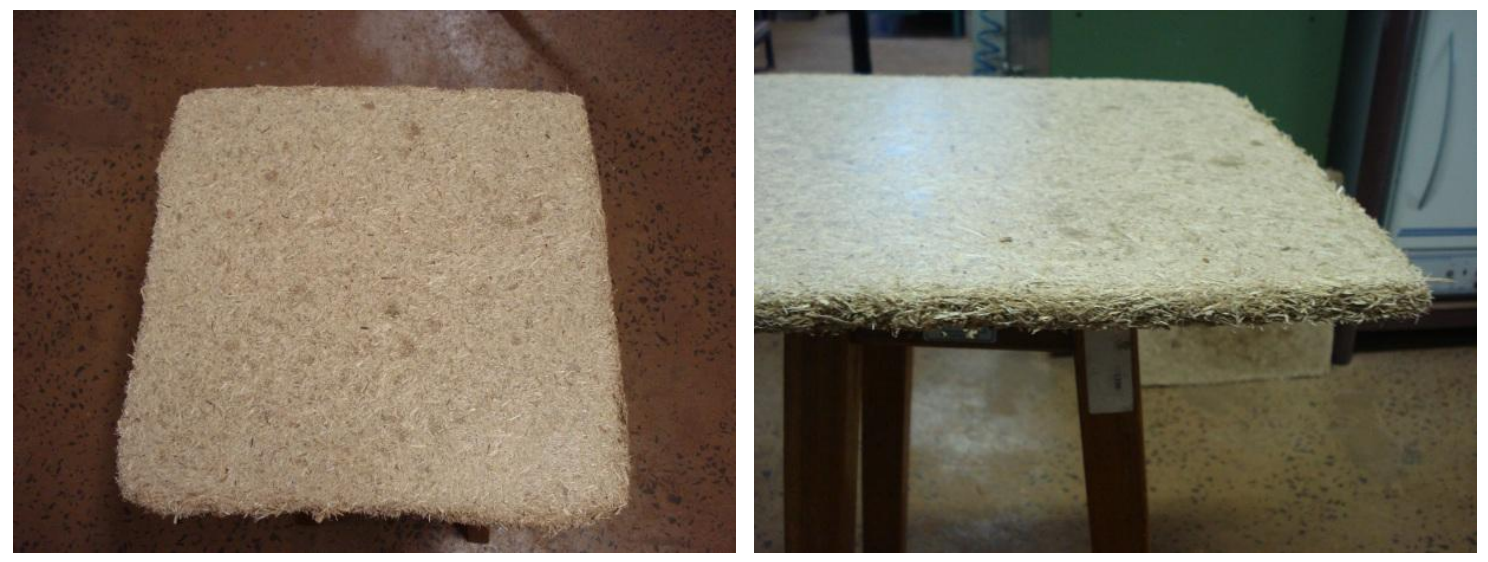

Figura 14 - Chapas após prensagem.

\subsection{Caracterização das chapas de bagaço de cana-de-açúcar e resina poliuretana bi} componente à base de óleo de mamona

Neste item estão descritos os procedimentos de ensaios para a caracterização físico-mecânica das chapas de partículas. Foram realizados ensaios seguindo os preceitos da norma ABNT NBR 14810-3 (2006) - Chapas de madeira aglomerada - Métodos de ensaio, determinando as seguintes propriedades: densidade, inchamento, absorção, módulo de ruptura e módulo de elasticidade na flexão estática e adesão interna (resistência à tração perpendicular). Os resultados obtidos foram comparados com aqueles indicados pelas normas ABNT NBR 14810-2 (2006) - Chapas de madeira aglomerada - Requisitos e ANSI 
A208.1 (1999) - Particleboard. A obtenção dos CP, para os ensaios físico-mecânicos, foi realizada utilizando uma serra esquadrejadeira de disco (Figura 15).

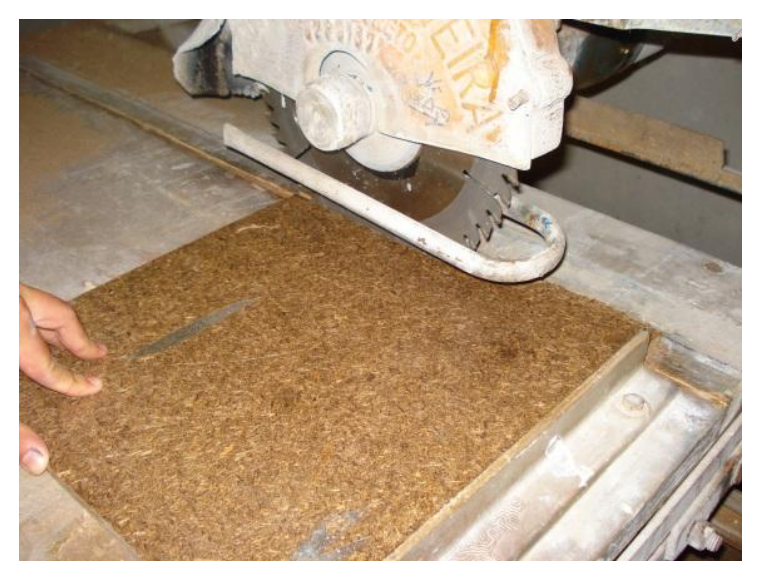

Figura 15 - Obtenção dos CP na serra de disco.

\subsubsection{Densidade}

Foram confeccionados CP com dimensões de 50 × 50 × $10 \mathrm{~mm}$. A determinação da espessura dos $\mathrm{CP}$ foi realizada com paquímetro digital, com resolução de $0,01 \mathrm{~mm}$. Para a pesagem foi utilizada balança analítica, com resolução de 0,01 g. O cálculo da densidade foi realizado por meio da eq. (2):

$$
\mathrm{D}=\frac{\mathrm{M}}{\mathrm{V}} * 1000000
$$

Onde:

$\mathrm{D}=$ densidade do $\mathrm{CP}$ em $\mathrm{kg} / \mathrm{m}^{3}$;

$\mathrm{M}=$ massa do $\mathrm{CP}$ em g;

$\mathrm{V}=$ volume do $\mathrm{CP}$ em $\mathrm{mm}^{3}$. 


\subsubsection{Inchamento em espessura}

Para os ensaios de inchamento em espessura (IE), foram confeccionados CP com dimensões de $25 \times 25 \times 10 \mathrm{~mm}$ e determinada a espessura com paquímetro digital, com resolução de $0,01 \mathrm{~mm}$ (Figura 16). Foi preparado um recipiente com água em temperatura ambiente (Figura 17), de modo que todos os CP ficassem submersos. Após 2 e 24 horas de imersão os CP foram retirados do recipiente, sendo removido o excesso de água com papel absorvente (Figura 17) e determinada a espessura (E1) (Figura 18). O IE foi determinado por meio da eq. (3):

$$
\mathrm{I}=\frac{E_{1}-E_{0}}{E_{0}} * 100
$$

Onde:

$\mathrm{I}=$ inchamento em espessura do CP (\%);

$E_{1}=$ espessura do CP após o período de imersão, em mm;

$E_{0}=$ espessura do $\mathrm{CP}$ antes da imersão, em $\mathrm{mm}$.
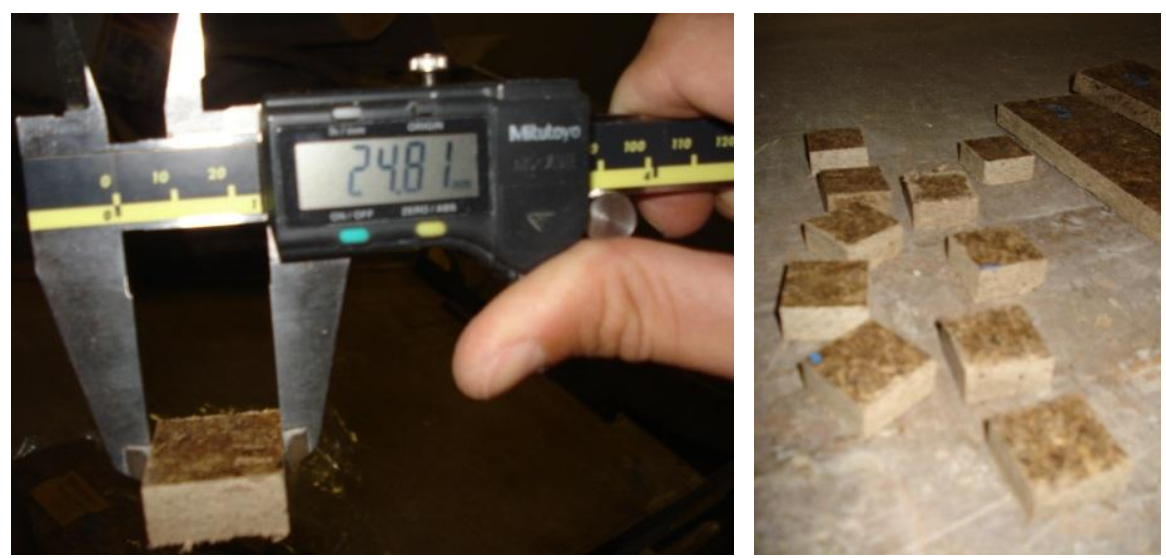

Figura 16 - Medição e CP para ensaios. 

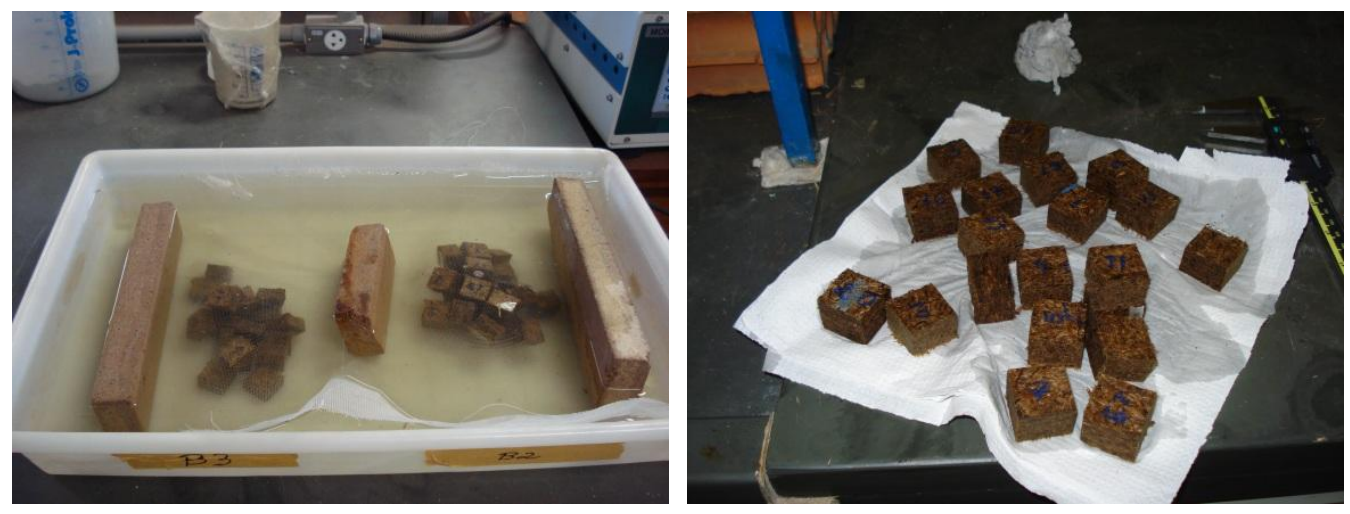

Figura 17 - CP submersos e secando para as medições.

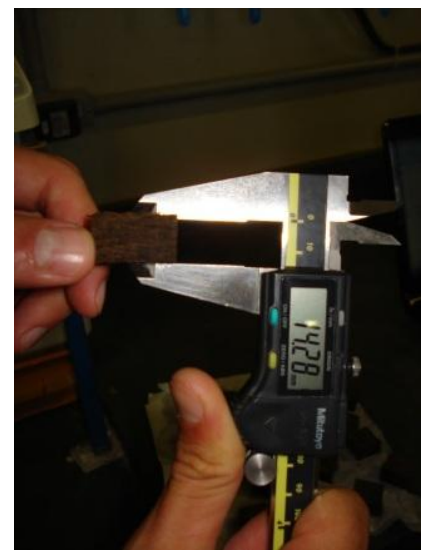

Figura 18 - Medição para inchamento.

\subsubsection{Absorção de água}

Para os ensaios de absorção de água (AA), foram confeccionados CP com dimensões de $25 \times 25 \times 10 \mathrm{~mm}$, sendo a massa determinada em balança analítica, com resolução de $0,01 \mathrm{~g}$. Foi preparado um recipiente com água em temperatura ambiente, de modo que todos os CP ficaram submersos. Após 2 e 24 horas de imersão, os CP foram retirados do recipiente e removido o excesso de água com papel absorvente, sendo pesados novamente. O cálculo para a absorção de água foi feito por meio da eq. (4):

$$
\mathrm{A}=\frac{M_{1}-M_{0}}{M_{0}} * 100
$$


Onde:

$$
\begin{aligned}
& \mathrm{A}=\text { absorção de água (\%); } \\
& M_{1}=\text { peso do } \mathrm{CP} \text { após o período de imersão, em g; } \\
& M_{0}=\text { peso do CP antes da imersão, em } \mathrm{g} .
\end{aligned}
$$

\subsubsection{Módulo de ruptura (MOR) e módulo de elasticidade à flexão (MOE)}

Para os ensaios de flexão estática foram confeccionados CP com dimensões de 250 x 50 x 10 mm. A dimensão da seção transversal foi determinada com paquímetro digital com resolução de 0,01 $\mathrm{mm}$. Os ensaios para determinação das propriedades $\mathrm{MOR}$ e MOE, foram realizados em uma maquina universal de ensaios mecânicos, da marca EMIC, modelo DL 30.000 (Figura 19).

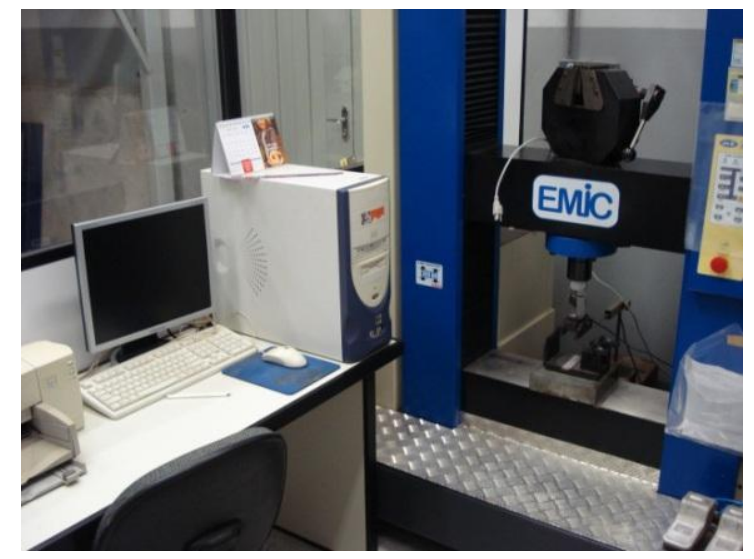

Figura 19 - Máquina universal de ensaios mecânicos com extensômetro externo.

Os CP foram posicionados sobre dois apoios da máquina universal de ensaios (Figura 20), sendo o comprimento do vão de $220 \mathrm{~mm}$, fazendo com que o dispositivo para aplicar a carga coincidisse com o centro do CP. A velocidade de ensaio foi de $6 \mathrm{~mm} / \mathrm{min}$ (Tabela 2, pág. 16, NBR 14810-3 (2006)).

Para a determinação do MOR e o MOE, foram utilizadas eq. (5) e eq. (6):

$$
\operatorname{MOR}=1,5 * \frac{(P * \mathrm{D})}{\mathrm{B} *(\mathrm{E})^{2}}
$$


Onde:

MOR = módulo de ruptura, em MPa;

$P=$ carga de ruptura, em N;

$\mathrm{D}$ = distância entre apoios do aparelho, em mm;

$\mathrm{B}=$ largura do $\mathrm{CP}$, em $\mathrm{mm}$;

$\mathrm{E}=$ espessura, em $\mathrm{mm}$.

$$
\mathrm{MOE}=\frac{\left(P_{1} * \mathrm{D}^{3}\right)}{d * 4 * B *(E)^{3}}
$$

Onde:

MOE = módulo de elasticidade, em MPa;

$P_{1}=$ carga no limite proporcional, em $\mathrm{N}$;

$\mathrm{D}$ = distância entre apoios do aparelho, em mm;

$d$ = deflexão, expressa em $\mathrm{mm}$, correspondente à força $\mathrm{P}$;

$B=$ largura do $\mathrm{CP}$, em $\mathrm{mm}$;

$E=$ espessura, em $\mathrm{mm}$.

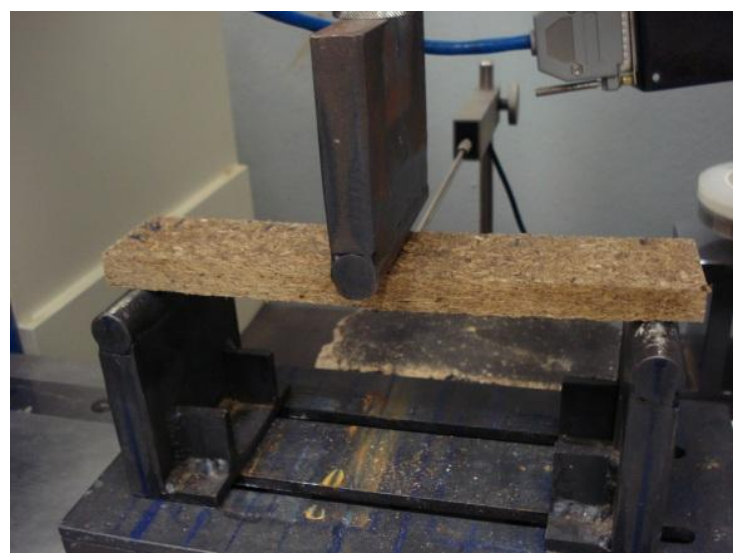

Figura 20 - CP submetido a ensaio de flexão a três pontos. 


\subsubsection{Tração perpendicular às fibras (TP)}

Para obtenção da adesão interna (Al), por meio do ensaio de tração perpendicular (TP), foram confeccionados CP com dimensões de $50 \times 50 \times 10 \mathrm{~mm}$ e determinadas as dimensões das seções transversais, com paquímetro digital com resolução de 0,01 $\mathrm{mm}$. Os $\mathrm{CP}$ foram fixados nos blocos de tração, sendo posteriormente posicionados no suporte de ensaio (Figuras 21 e 22). O ensaio foi realizado em uma maquina universal de ensaios mecânicos, da marca EMIC, modelo DL 30.000A, com velocidade de ensaio de $4 \mathrm{~mm} / \mathrm{min}$ (Figura 23). Para determinar o valor da TP, foi utilizada a eq. (7):

$$
\mathrm{T}=\frac{\mathrm{P}}{\mathrm{S}}
$$

Onde:

$\mathrm{T}$ = resistência à tração perpendicular, em MPa;

$\mathrm{P}=$ carga de ruptura, em $\mathrm{N}$;

$S=$ área da superfície do $\mathrm{CP}$, em $\mathrm{mm}^{2}$.
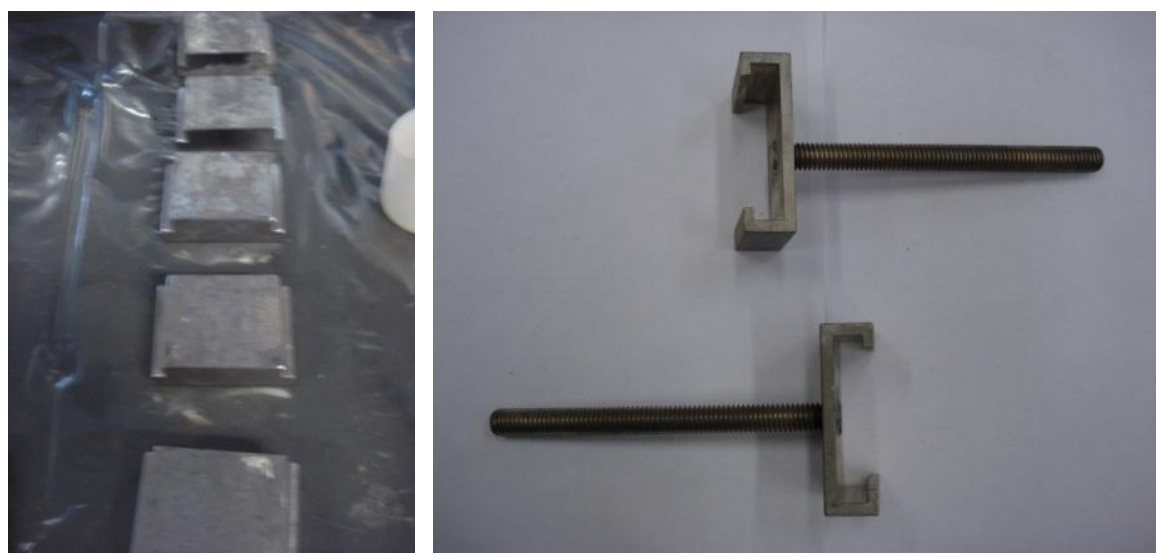

Figura 21 - Blocos de tração e suporte para ensaio de TP. 

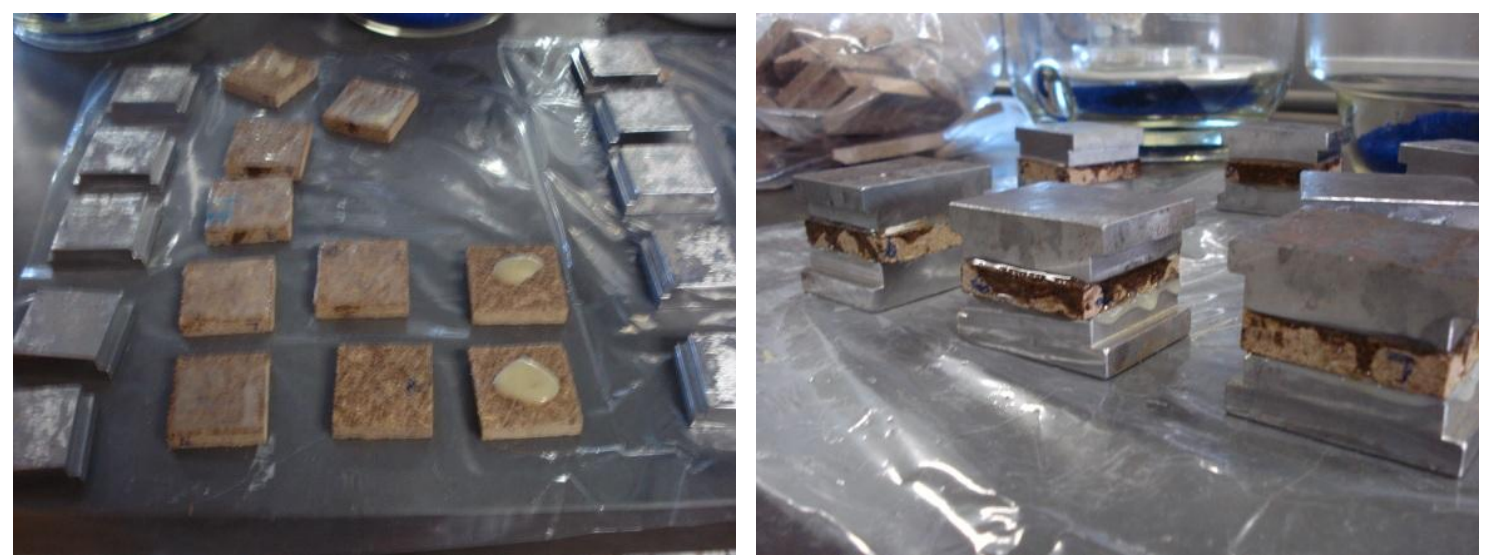

Figura 22 - Colagem dos CP e conjunto CP mais bloco de tração.

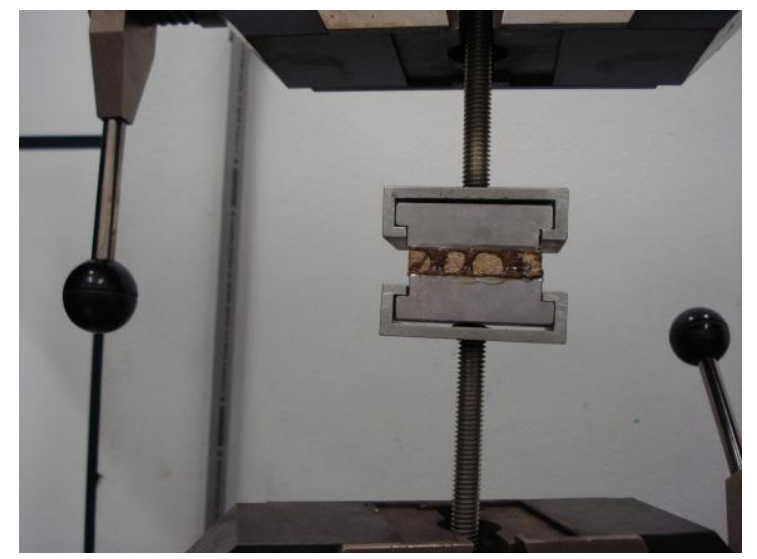

Figura 23 - Momento do ensaio.

3.4.6 Envelhecimento das chapas de bagaço de cana-de-açúcar e resina poliuretana bi componente à base de óleo de mamona

Este item descreve os procedimentos de ensaio de envelhecimento natural e acelerado utilizados na avaliação da durabilidade das chapas de partículas de bagaço de cana-de-açúcar quando expostas a diferentes condições de temperatura e umidade.

Com a avaliação dos resultados das propriedades físico-mecânicas, foi determinado que as chapas com tamanho de partículas de até $8 \mathrm{~mm}$ eram superiores as de até $5 \mathrm{~mm}$. Portando para a realização da avaliação de durabilidade em envelhecimento natural e acelerado foi adotada as chapas com partículas de até $8 \mathrm{~mm}$. 


\subsubsection{Envelhecimento natural}

Expostos a todas as intempéries do clima, principalmente chuva e radiação solar, os CP permaneceram por 6 meses (184 dias) em bancada com inclinação de 30 graus em relação ao solo e face voltada ao norte, no campo de envelhecimento natural (Figura 24), localizado no Campo Agrostológico do Campus da FZEA/USP. Após esse período foram realizados ensaios mecânicos, a fim de verificar o comportamento do material após o tempo de exposição ao envelhecimento natural.

Foram expostos $12 \mathrm{CP}$, com dimensões de $250 \times 50 \times 10 \mathrm{~mm}$, sendo que em $5 \mathrm{CP}$ foi aplicada a mesma resina bi componente de mamona em sua superfície (Figura 25) com o objetivo avaliá-la como impermeabilizante e protetor superficial do material. Os outros $7 \mathrm{CP}$ foram expostos sem a aplicação de resina em sua superfície. A Tabela 4 apresenta informações sobre o período e quantidade de CP avaliados no ensaio de envelhecimento natural.

Tabela 4 - Informações do ensaio de envelhecimento natural.

\begin{tabular}{lccc}
\hline & Data de início & $\begin{array}{c}\text { Data de } \\
\text { término }\end{array}$ & Quantidade de CP \\
\hline CP com resina & $19 / 05 / 2011$ & $19 / 11 / 2011$ & 5 \\
CP sem resina & $10 / 05 / 2011$ & $10 / 11 / 2011$ & 7 \\
\hline
\end{tabular}
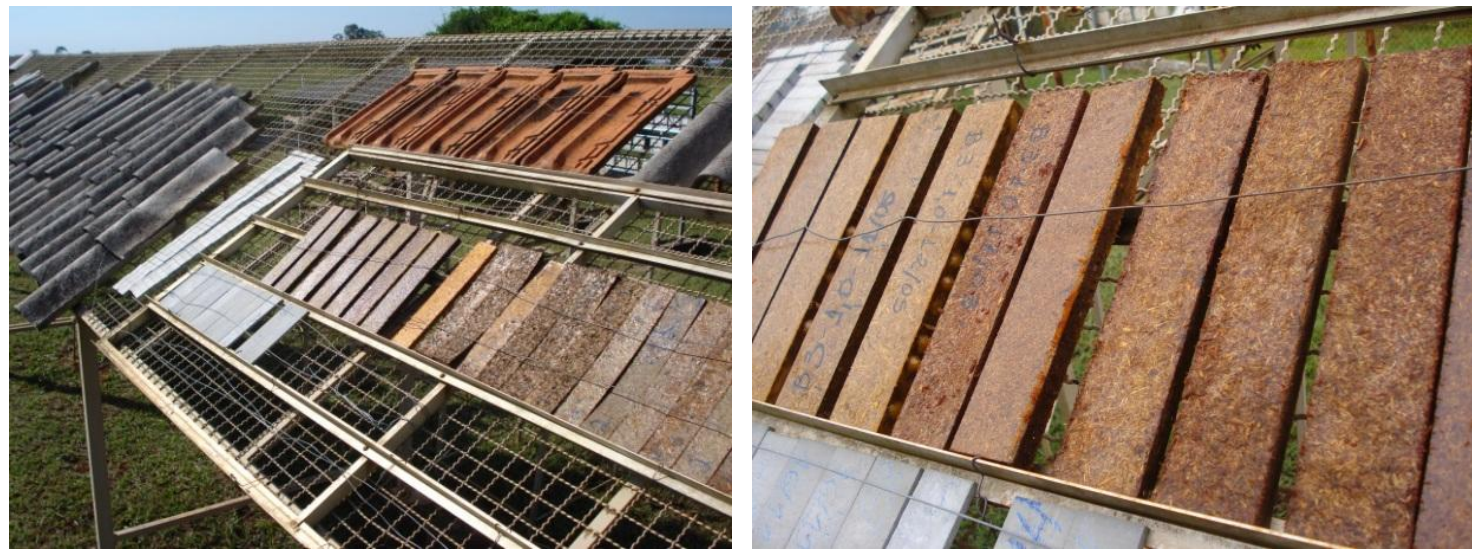

Figura 24 - Campo de envelhecimento natural e CP acondicionados. 


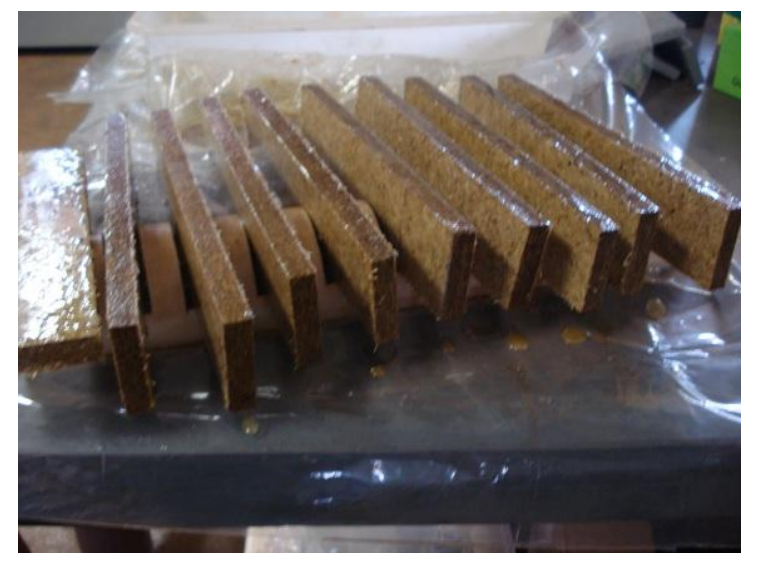

Figura 25 - CP em secagem após aplicação de resina.

Para a caracterização do ambiente físico, durante o período de 184 dias que os CP foram expostos, foram utilizados os dados aferidos pela estação climatológica da marca Davis, modelo Vantage Pro2 (Figura 26) e software registrador WeatherLink, localizada no Campus da FZEA/USP. Os dados coletados foram agrupados pelas estações correspondentes a todo o período e os dados estão apresentados na Tabela 5. De acordo com César (2002), os agentes não biológicos que mais degradam a madeira e chapas de partículas são os raios ultravioletas, que decompõem a lignina do material deixando as fibras soltas, sendo estas retiradas da superfície das peças de madeira pelo vento e pela chuva.

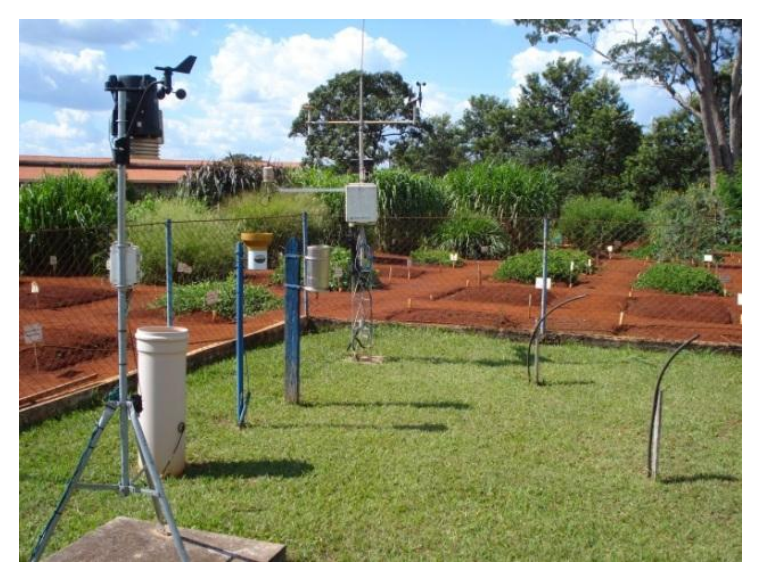

Figura 26 - Estação climatológica. 
Tabela 5 - Dados climatológicos do período, divididos pelas estações do ano.

\begin{tabular}{|c|c|c|c|c|c|c|c|c|}
\hline Estações & $\begin{array}{c}\text { Temp. } \\
\text { média } \\
\left({ }^{\circ} \mathrm{C}\right)\end{array}$ & $\begin{array}{c}\text { Temp. } \\
\text { máxima } \\
\left({ }^{\circ} \mathrm{C}\right)\end{array}$ & $\begin{array}{l}\text { Temp. } \\
\text { mínima } \\
\left({ }^{\circ} \mathrm{C}\right)\end{array}$ & $\begin{array}{l}\text { Umidade } \\
\text { externa } \\
\text { média (\%) }\end{array}$ & $\begin{array}{c}\text { Total } \\
\text { de } \\
\text { chuva } \\
(\mathrm{mm})\end{array}$ & $\begin{array}{l}\text { Radiação } \\
\text { solar } \\
\left(\mathrm{W} / \mathrm{m}^{2}\right)\end{array}$ & $\begin{array}{l}\text { Radiação } \\
\text { ultravioleta }\end{array}$ & $\begin{array}{c}\text { Radiação } \\
\text { ultravioleta } \\
\text { máxima }\end{array}$ \\
\hline Outono & 16,8 & 28,7 & 3,9 & 76,6 & 46,4 & 155,4 & 0,7 & 4,7 \\
\hline Inverno & 19,2 & 19,3 & 1,0 & 67,9 & 38,2 & 173,5 & 0,7 & 0,8 \\
\hline Primavera & 22,2 & 36,2 & 11,9 & 70,3 & 351,0 & 232,8 & 1,2 & 9,5 \\
\hline
\end{tabular}

\subsubsection{Envelhecimento acelerado}

Para o ensaio de envelhecimento acelerado foram utilizados $10 \mathrm{CP}$, com dimensões de $250 \times 50 \times 10 \mathrm{~mm}$, sendo aplicada a resina bi componente de mamona na superfície de 5 deles. Os CP foram submetidos a seis ciclos de envelhecimento acelerado, com base no documento normativo ASTM 1037:2006 - Standard test methods for evaluating properties of wood-based fiber and particle panel materials, tendo como variáveis a umidade relativa e a temperatura, de acordo com a Tabela 6. Os equipamentos utilizados foram: câmara climática (Figura 27), banho maria (Figura 27), estufa e freezer. Antes do início dos testes, os $\mathrm{CP}$ foram armazenadas por 48 horas à temperatura de $20 \pm 5^{\circ} \mathrm{C}$ e umidade relativa de $65 \pm 2 \%$, sob condições normais de laboratório. Figura 28 mostra os CP submetidos às etapas do ciclo de envelhecimento. 
Tabela 6 - Etapas e descrição dos ciclos de envelhecimento.

\begin{tabular}{ccccc}
\hline Ciclo & Descrição & Temperatura $\left({ }^{\circ} \mathrm{C}\right)$ & Tempo $(\mathrm{h})$ & Equipamento utilizado \\
\hline Etapa 1 & Imersão em água & $49 \pm 2$ & 1 & Banho maria \\
Etapa 2 & Vapor de água & $93 \pm 3$ & 3 & Banho maria \\
Etapa 3 & Congelamento & $-12 \pm 3$ & 20 & Freezer \\
Etapa 4 & Calor em ar seco & $99 \pm 2$ & 3 & Estufa \\
Etapa 5 & Vapor de água & $93 \pm 2$ & 3 & Banho maria \\
Etapa 6 & Calor em ar seco & $99 \pm 2$ & 18 & Estufa \\
\hline Acondicionamento & 65\% de umidade & $20 \pm 3$ & 48 & Câmara climática \\
\hline
\end{tabular}
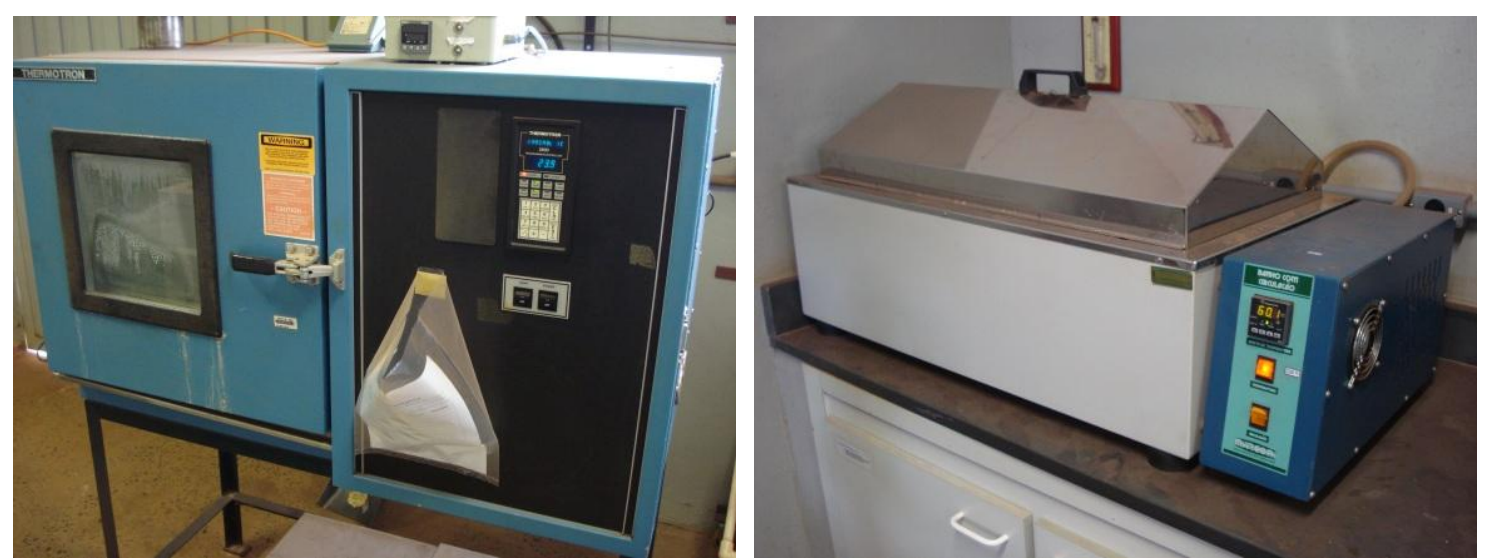

Figura 27 - Câmara climática e banho maria. 


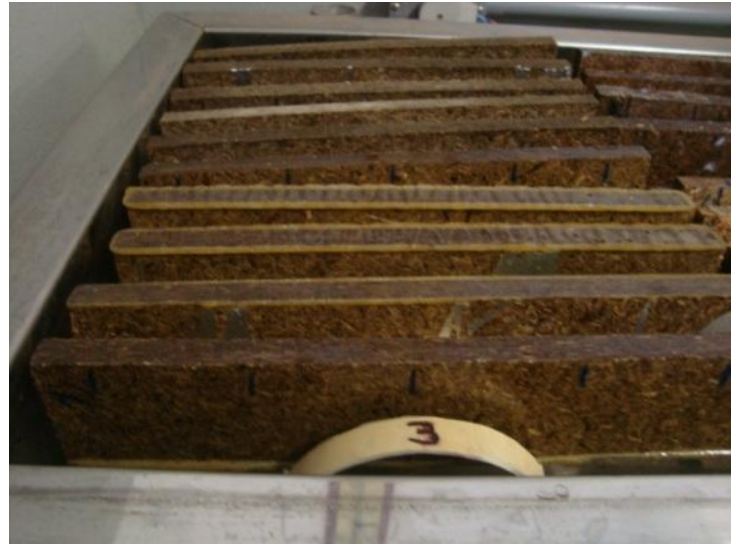

(a)

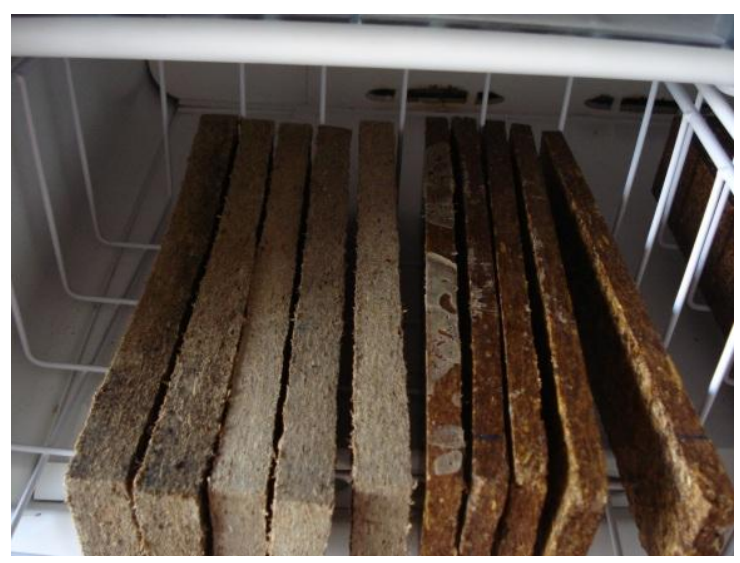

(c)

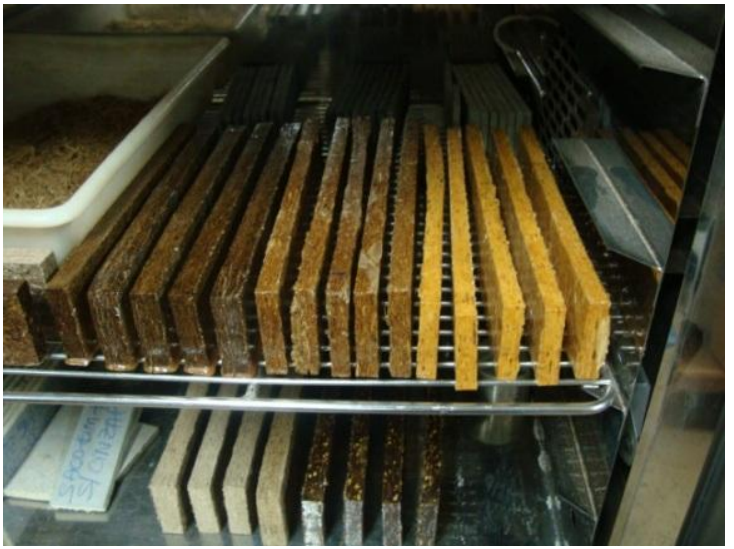

(b)

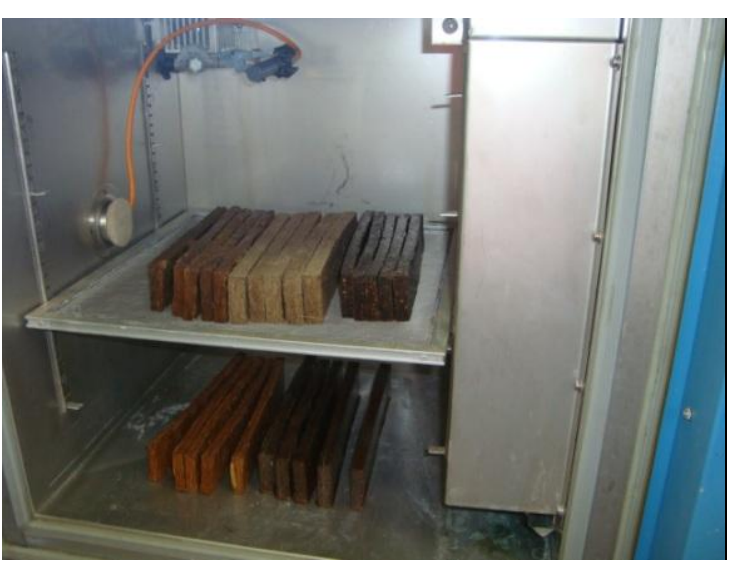

(d)

Figura 28 - CP durante as etapas dos ciclos de envelhecimento de vapor de água (a), calor em ar seco (b), congelamento (c) e acondicionamento (d).

Após o fim dos 6 ciclos, foram realizados ensaios mecânicos dos CP seguindo os mesmos procedimentos da norma ABNT 14810-3:2006, além de inspeção visual para identificar as mudanças superficiais nas amostras. Sendo que após cada ciclo foi realizado inspeções visuais para observar a decorrência de delaminação e deformações.

\subsubsection{Microscopia eletrônica de varredura (MEV)}

Com o objetivo de analisar a morfologia das chapas, distribuição das partículas e da resina, foram retiradas amostras com dimensões de aproximadamente $15 \times 15 \mathrm{~mm}$, dos CP de cada tratamento, para a realização da análise da imagem por MEV. As imagens de MEV foram obtidas em um microscópio da marca Hitachi e modelo Analytical TableTop 
Microscope TM3000 (Figura 29), do laboratório multiusuários do Departamento de Engenharia de Alimentos da Faculdade de Zootecnia e Engenharia de Alimentos (FZEA/USP).
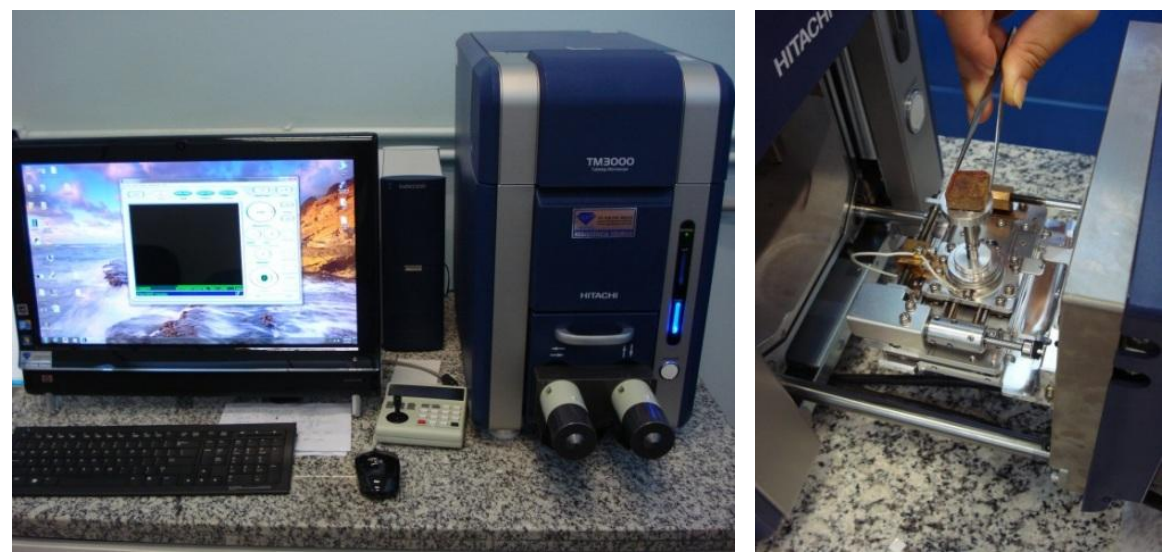

Figura 29 - Microscópio eletrônico de varredura e amostra sendo posicionada.

\subsubsection{Projeto do painel portante}

Neste item está descrito a metodologia para o dimensionamento das chapas, utilizadas na composição do painel portante e suas dimensões. Também o desenvolvimento do projeto de centro de manejo em 3D, utilizando software computacional.

\subsubsection{Dimensionamento das chapas}

As chapas para utilização no protótipo de painel de fechamento lateral foram dimensionadas seguindo as diretrizes de resistência dos materiais, conforme descrito nas eq. (8) a eq. (10) .

$$
\sigma=\frac{M}{W}
$$


Onde:

$\sigma=$ tensão;

$\mathrm{M}=$ momento fletor;

$\mathrm{W}=$ módulo de resistência.

$$
\mathrm{M}=\frac{\mathrm{p} * \mathrm{l}}{4}
$$

Onde:

$M=$ momento fletor;

$\mathrm{p}=$ massa do bovino (447 kg (ROSA et. Al (2001));

l = comprimento máximo da chapa $(52 \mathrm{~cm})$.

$$
\mathrm{W}=\frac{1}{6} \mathrm{~b} * \mathrm{e}^{2}
$$

Onde:

W = módulo de resistência;

$\mathrm{b}=$ base da chapa $(52 \mathrm{~cm})$;

$\mathrm{e}=$ espessura da chapa $(2 \mathrm{~cm})$.

Considerando que a capacidade de produção da prensa termo hidráulica esta limitada a formação de chapas com dimensão de $55 \times 55 \mathrm{~cm}$, a chapa que compõe o painel de fechamento lateral foi dimensionada com base nessa geometria limite, utilizando as equações 8 a 10. Por esse procedimento de cálculo, foi determinada espessura mínima para as chapas, igual a 1,8 cm. A Figura 30 apresenta o processo de fabricação dessas chapas de partículas. 


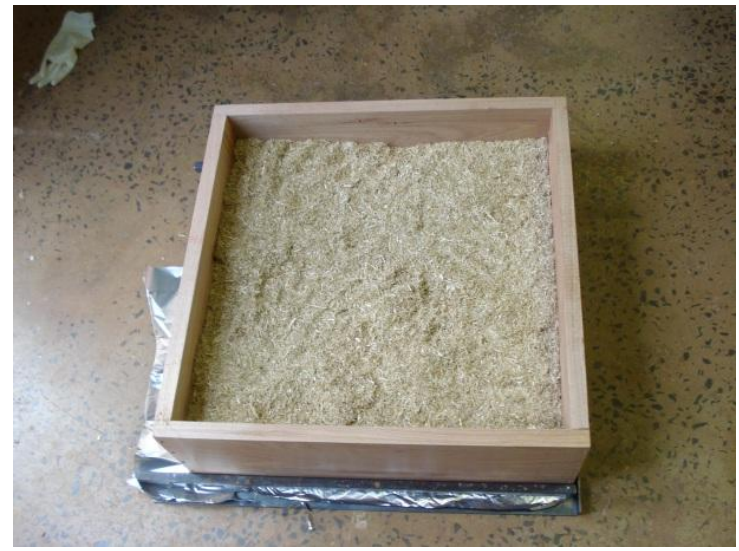

(a)

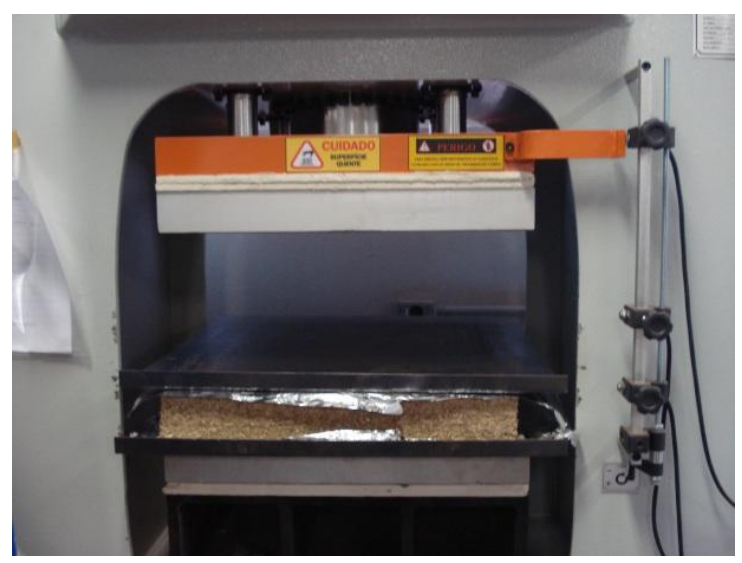

(c)

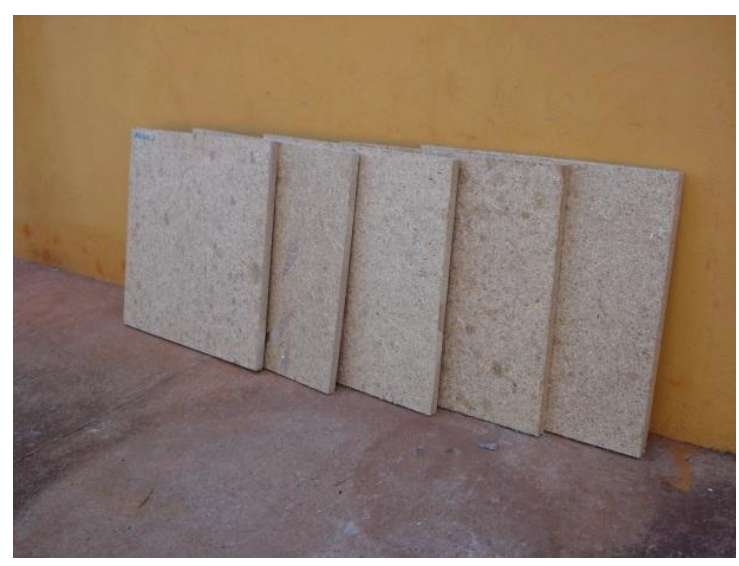

(e)

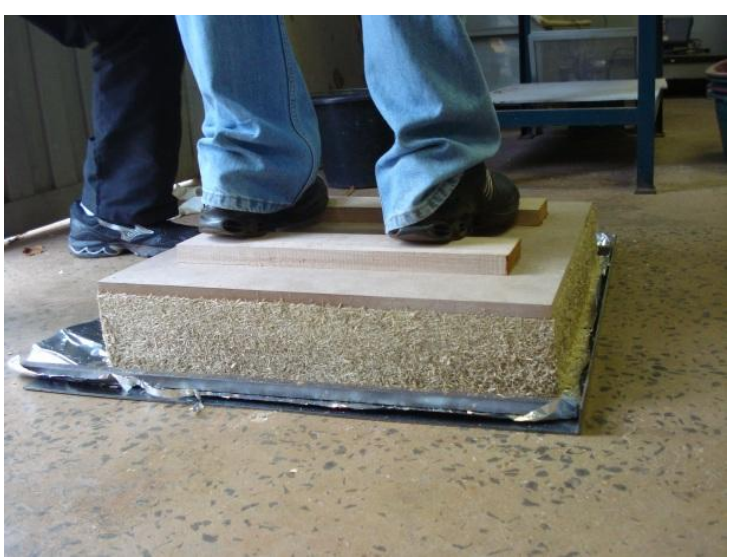

(b)

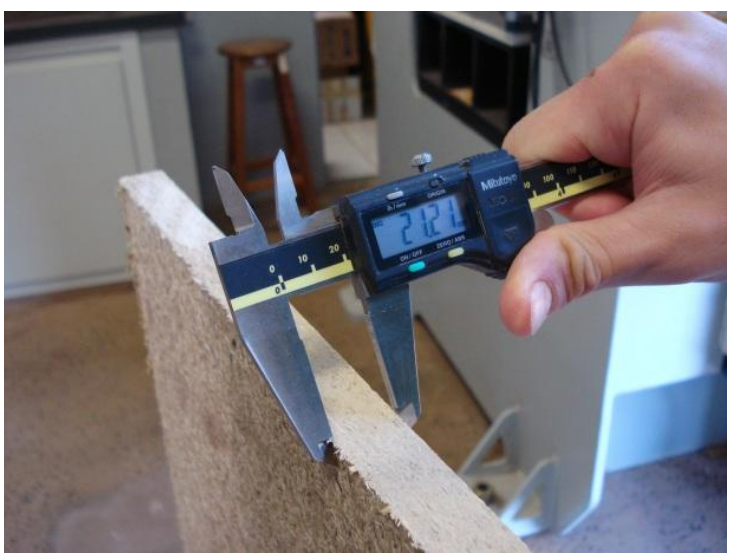

(d)

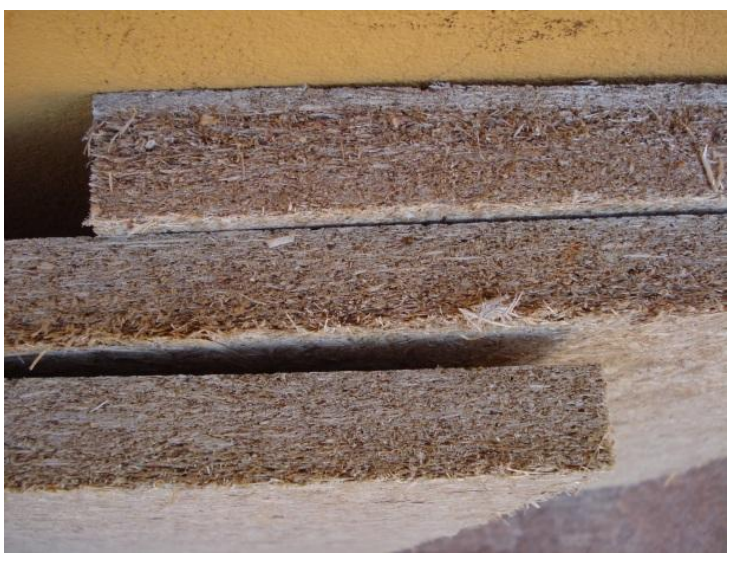

(f)

Figura 30 - Processo de fabricação das chapas de partículas, com formação do colchão ((a) e (b)), momento da prensagem com aquecimento (c), detalhe da espessura da chapa (d) e chapas produzidas ((e) e (f)). 


\subsubsection{Modelo 3D do protótipo aplicado como painel de fechamento lateral}

Com o objetivo de se ilustrar o protótipo do painel de fechamento lateral aplicado, como o proposto, em paredes laterais de brete e seringa em centro de manejo para bovinos, foi realizado o modelo em três dimensões utilizando o software Google SketchUp 8.

Para o modelo em três dimensões foram utilizadas as reais dimensões do painel portante e de centros de manejo para bovinos.

O modelo de centro de manejo para bovinos idealizado foi baseado nos conceitos estabelecidos por Grandin (1997), que diz que bretes, seringas, dispositivos de contenção e rampas de embarque em caminhões devem ter suas laterais totalmente fechadas para manter os bovinos calmos, pois previnem que os animais vejam o movimento de pessoas e outras distrações do outro lado da cerca, assim movendo-se mais facilmente através das instalações.

Para bretes, Grandin (1997) cita duas razões principais pela qual se torna mais eficiente a construção em curva, do que em linha reta como é feito tradicionalmente. A primeira é de que em curva, impede dos animais de verem o caminhão, no caso de estarem sendo conduzidos para o embarcadouro, ou de verem tronco de contenção até que estejam quase nele. A segunda é em relação a um dos comportamentos bovino, que é a tendência natural dos animais moverem em circulo em volta das pessoas. Portanto o raio interno do brete recomendado, para centros de manejo para confinamentos ou fazendas, é de 3,5 a 6 m (GRANDIN, 1980; VOWLES E HOLLIER, 1982).

O comprimento mínimo um brete para manejar um grande número de animais deve ser de 9 m (GRANDIN, 1983), sendo um meio circulo com 3,5 a $5 \mathrm{~m}$ de raio o comprimento ideal. A largura recomendada entre as paredes, sem inclinação, é de 66 a 71 $\mathrm{cm}$ para animais adultos. Essa dimensão deve variar dependendo do tamanho dos bovinos e altura das paredes deve ser de até $1,83 \mathrm{~cm}$. O brete deve possuir uma passarela por toda sua extensão, para as pessoas que manejam os animais sejam forçadas a permanecerem no ângulo correto da visão dos animais (GRANDIN, 1980). 


\subsubsection{Ensaio de impacto de corpo mole}

Com o objetivo de simular o efeito do impacto de um bovino no painel portante de madeira de reflorestamento e chapa de partículas de bagaço de cana-de-açúcar, foi realizado ensaio de impacto de corpo mole seguindo preceitos da normativa ABNT MB3256:1990 - Divisórias leves internas moduladas - Verificação a resistência a impactos. Essa norma foi utilizada, pois o painel em estudo é análogo a painéis divisórias.

O ensaio de impacto de corpo mole foi realizado no Hall Tecnológico da Escola Politécnica da Universidade de São Paulo (Poli/USP). Para a realização do ensaio foi utilizado um pórtico com estrutura em aço, saco de couro e dispositivo para registro gráfico dos deslocamentos transversais.

O pórtico possuía duas vigas móveis (com deslocamento na vertical), em aço preenchidas com concreto, que foram ajustadas para que o vão entre elas fosse de $2,20 \mathrm{~m}$, onde foi posicionado o protótipo. A fixação do protótipo no pórtico foi por parafusamento em suas extremidades, realizada na base de concreto das vigas de aço (Figura 31).
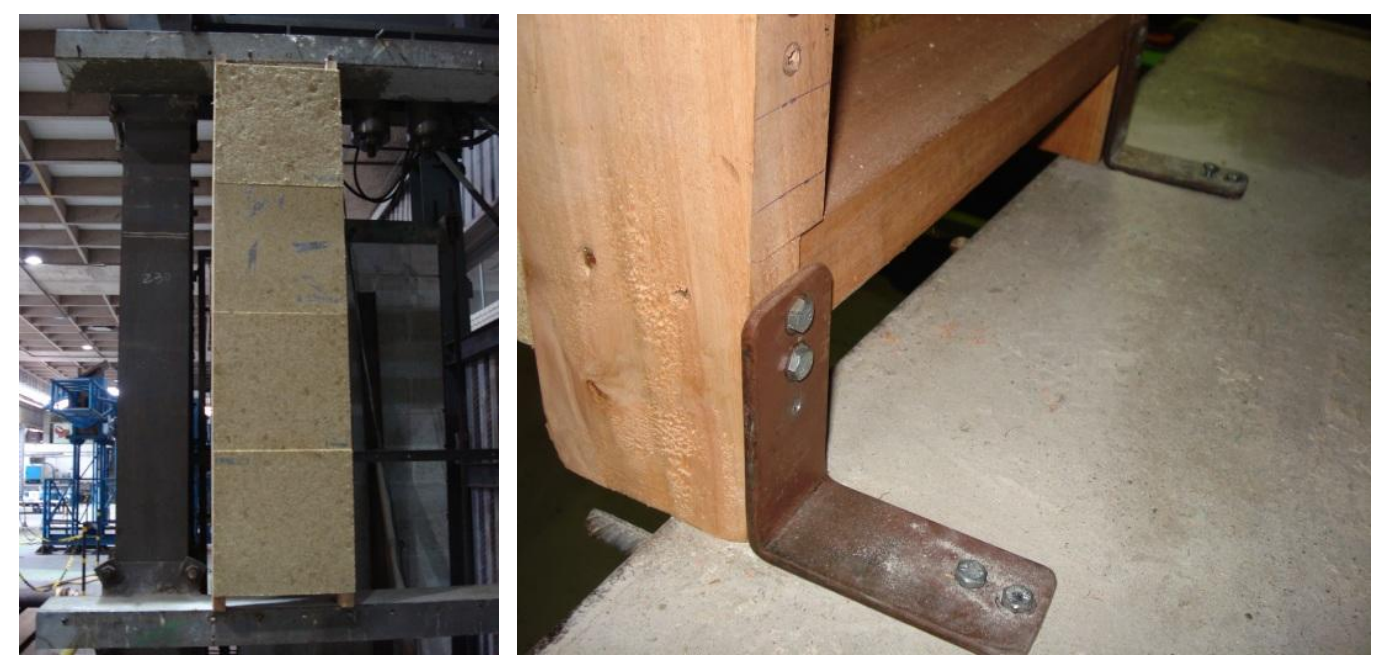

Figura 31 - Pórtico para a fixação do painel de fechamento, detalhe da fixação do painel no pórtico.

O saco de couro com dimensões de $350 \mathrm{~mm}$ de diâmetro e altura de $900 \mathrm{~mm}$, que foi usado como o corpo mole, foi preenchido com uma mistura de areia e serragem para que chegasse ao peso de $40 \mathrm{~kg}$ (Figura 32). 


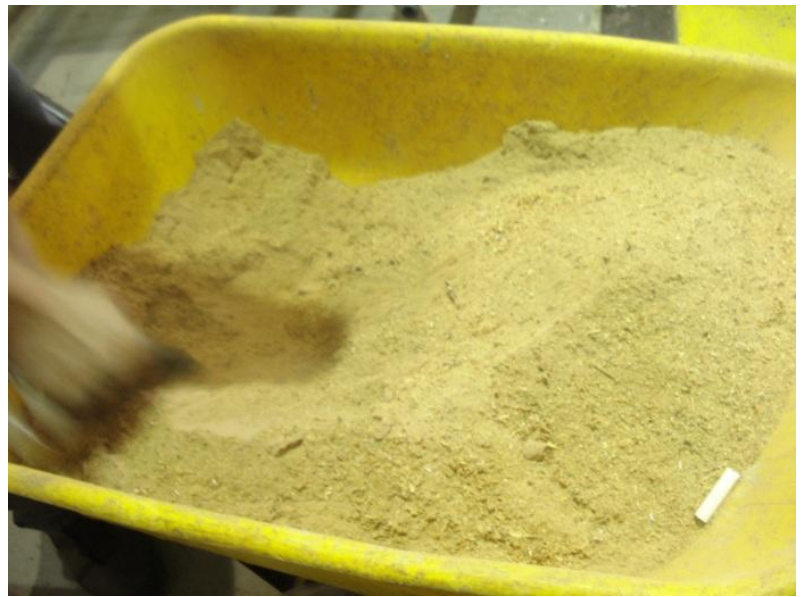

(a)

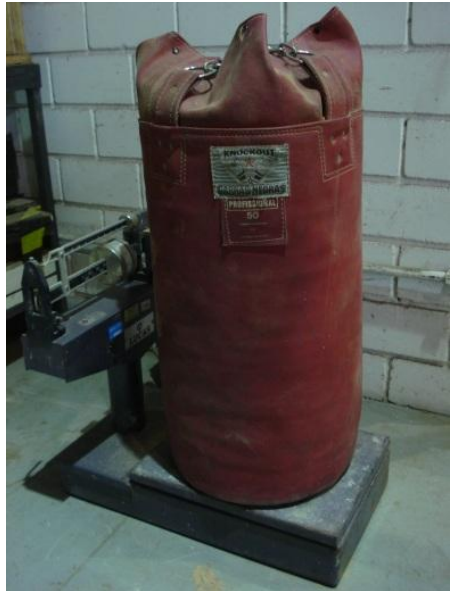

(b)

Figura 32 - Mistura de serragem e areia para enchimento do saco (a) e pesagem do saco (b).

Para o registro dos deslocamentos transversais, foi fixado o dispositivo na face posterior do protótipo (Figura 33). O mesmo ficou posicionado no centro de massa do protótipo, mesma linha do centro de impacto do corpo mole.
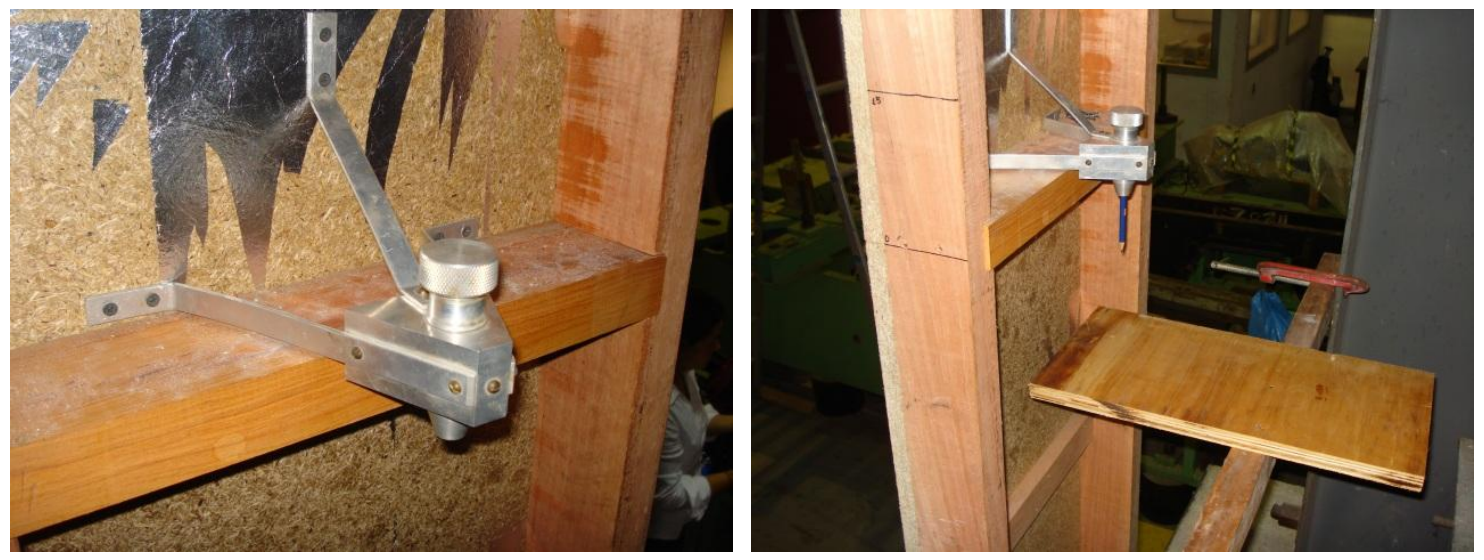

Figura 33 - Dispositivo para registro dos deslocamentos transversais.

Com o protótipo devidamente fixado ao pórtico e o saco de couro com as dimensões e peso corretos, foi realizado a fixação e posicionamento do corpo mole de modo que seu centro ficasse alinhado ao centro do protótipo, sendo o local de impacto (Figura 34). 

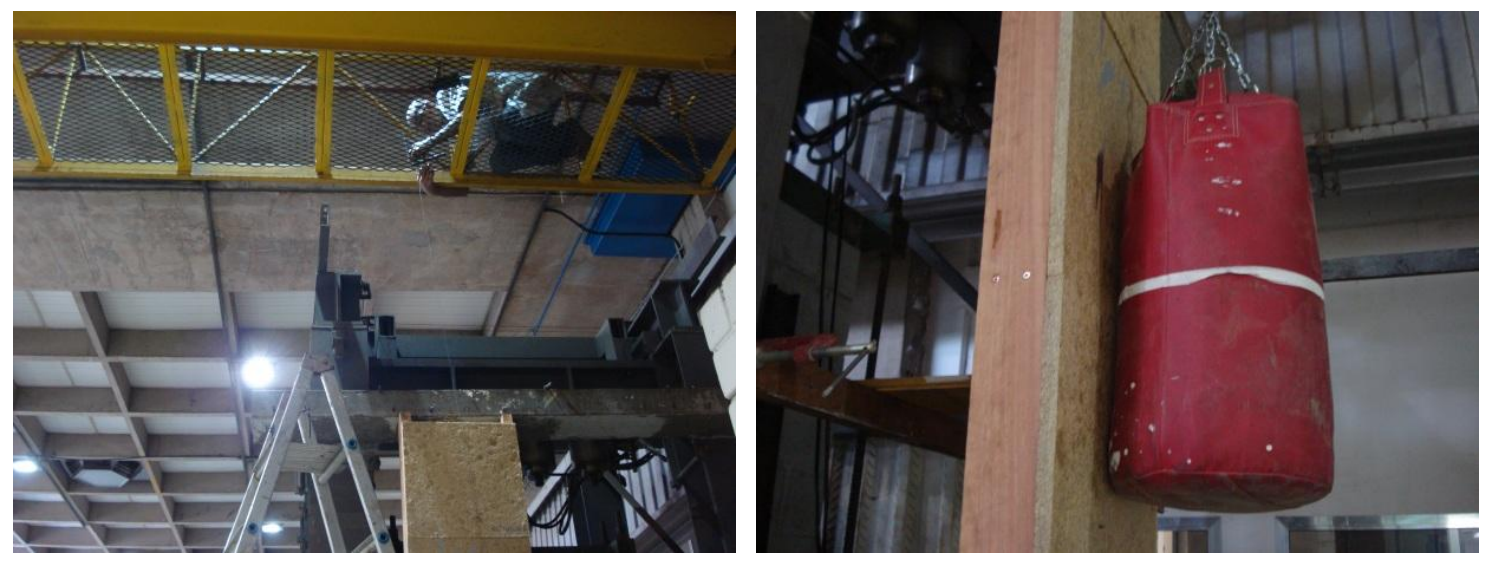

Figura 34 - Fixação do corpo mole e alinhamento com o centro do protótipo.

Como parâmetros para o ensaio foram aplicadas no protótipo diferentes intensidades de forças (energia) e aferido o deslocamento horizontal e possíveis alterações sofridas pelo elemento construtivo. A Tabela 7 apresenta a altura inicial do corpo-mole e a energia correspondente. Vale ressaltar que foi aplicada uma energia de até $720 \mathrm{~J}$, correspondente a altura de $1,80 \mathrm{~m}$.

Tabela 7 - Altura e energia de cada impacto correspondente à massa do saco de areia.

\begin{tabular}{ccc}
\hline $\mathbf{m}(\mathbf{k g})$ & $\mathbf{h}(\mathbf{m})$ & $\mathbf{E}(\mathbf{J})$ \\
\hline 40 & 0,15 & 60 \\
40 & 0,30 & 120 \\
40 & 0,45 & 180 \\
40 & 0,60 & 240 \\
40 & 0,90 & 360 \\
40 & 1,20 & 480 \\
40 & 1,80 & 720 \\
\hline
\end{tabular}

Na proposta do ensaio, foi considerado que o valor da energia causada pelo animal, que simulasse o impacto do mesmo, em uma situação real no modelo idealizado seria de até 670,5 J a uma altura de impacto de até $0,15 \mathrm{~m}$, considerando o peso adulto médio equivalente a $447 \mathrm{~kg}$ de uma matriz da raça Nelore, de acordo com Rosa et al. (2001) que coletou dados de 34 rebanhos, de 11 diferentes regiões brasileiras, num total de 6.867 vacas. 


\subsection{Análises estatísticas}

\subsubsection{Análises entre chapas de bagaço das duas usinas}

Para verificar a influência da qualidade do bagaço de cana-de-açúcar das duas Usinas, nas características físico-mecânicas (MOR, MOE e densidade) foi montado um experimento de acordo com o delineamento inteiramente casualizado (DIC), correspondendo a um fator (Usinas) com dois níveis (Usina A e Usina B). Foram utilizadas 10 unidades experimentais por cada tratamento (norma ABNT NBR 14810-3:2006), perfazendo um total de 20 unidades experimentais.

O modelo estatístico adotado para análise desses dados foi de acordo com a eq. (11):

$$
y_{i j}=\mu+t_{i}+e_{i j}
$$

Onde:

$y=$ valor observado das variáveis MOR, MOE e densidade, referente ao i-ésimo nível do fator Usina na j-ésima repetição;

$\mu=$ média geral;

$t_{i}=$ efeito do i-ésimo nível do fator Usina nas variáveis MOR, MOE e densidade.

$e_{i j}=$ efeito residual.

Para a variável inchamento foi montado dois experimentos de acordo com delineamento inteiramente casualizado (DIC), sendo um deles para o período de 2 horas e o outro para o período de 24 horas. O experimento correspondeu a um fator (Usinas) com dois níveis (Usina A e Usina B). Foram utilizadas 10 unidades experimentais por cada tratamento (norma ABNT NBR 14810-3:2006), perfazendo um total de 20 unidades experimentais.

O modelo estatístico adotado nos experimentos para efetuar a análise desses dados foi utilizado a eq. (12): 


$$
y_{i j}=\mu+t_{i}+e_{i j}
$$

Onde:

$y=$ valor observado da variável inchamento, referente ao i-ésimo nível do fator Usina na j-ésima repetição;

$\mu=$ média geral;

$t_{i}=$ efeito do i-ésimo nível do fator Usina na variável inchamento.

$e_{i j}=$ efeito residual.

Para a variável absorção foi montado dois experimentos de acordo com delineamento inteiramente casualizado (DIC), sendo um deles para o período de 2 horas e o outro para o período de 24 horas. O experimento correspondeu a um fator (Usina) com dois níveis (Usina A e Usina B). Foram utilizadas 10 unidades experimentais por cada tratamento (norma ABNT NBR 14810-3:2006), perfazendo um total de 20 unidades experimentais.

O modelo estatístico adotado nos experimentos para efetuar a análise desses dados foi utilizado a eq. (13):

$$
y_{i j}=\mu+t_{i}+e_{i j}
$$

Onde:

$y=$ valor observado da variável absorção, referente ao i-ésimo nível do fator Usina na j-ésima repetição;

$\mu=$ média geral;

$t_{i}=$ efeito do i-ésimo nível do fator Usina na variável absorção.

$e_{i j}=$ efeito residual.

O software utilizado para a interpretação dos dados foi o SISVAR, versão 5.3. 


\subsubsection{Análises físico-mecânicas}

Para verificar a influência do tamanho das partículas nas características físicomecânicas (MOR, MOE, Al e densidade) foi montado um experimento de acordo com o delineamento inteiramente casualizado (DIC), correspondendo a um fator (tamanho de partícula) com dois níveis ( $5 \mathrm{~mm}$ e $8 \mathrm{~mm}$ ). Foram utilizadas 10 unidades experimentais por cada tratamento (norma ABNT NBR 14810-3:2006), perfazendo um total de 20 unidades experimentais.

O modelo estatístico adotado para análise desses dados foi de acordo com a eq. (14):

$$
y_{i j}=\mu+t_{i}+e_{i j}
$$

Onde:

$y=$ valor observado das variáveis $\mathrm{MOR}, \mathrm{MOE}, \mathrm{Al}$ e densidade, referente ao i-ésimo nível do fator tamanho de partícula na j-ésima repetição;

$\mu=$ média geral;

$t_{i}=$ efeito do i-ésimo nível do fator tamanho de partícula nas variáveis $\mathrm{MOR}, \mathrm{MOE}, \mathrm{Al}$ e densidade.

$e_{i j}=$ efeito residual.

Para a variável inchamento foi montado dois experimentos de acordo com delineamento inteiramente casualizado (DIC), sendo um deles para o período de 2 horas e o outro para o período de 24 horas. O experimento correspondeu a um fator (tamanho de partícula) com dois níveis (5 mm e $8 \mathrm{~mm}$ ). Foram utilizadas 10 unidades experimentais por cada tratamento (norma ABNT NBR 14810-3:2006), perfazendo um total de 20 unidades experimentais.

O modelo estatístico adotado nos experimentos para efetuar a análise desses dados foi utilizado a eq. (15): 


$$
y_{i j}=\mu+t_{i}+e_{i j}
$$

Onde:

$y=$ valor observado da variável inchamento, referente ao i-ésimo nível do fator tamanho de partícula na j-ésima repetição;

$\mu=$ média geral;

$t_{i}=$ efeito do i-ésimo nível do fator tamanho de partícula na variável inchamento.

$e_{i j}=$ efeito residual.

Para a variável absorção foi montado dois experimentos de acordo com delineamento inteiramente casualizado (DIC), sendo um deles para o período de 2 horas e o outro para o período de 24 horas. 0 experimento correspondeu a um fator (tamanho de partícula) com dois níveis ( $5 \mathrm{~mm}$ e $8 \mathrm{~mm}$ ). Foram utilizadas 10 unidades experimentais por cada tratamento (norma ABNT NBR 14810-3:2006), perfazendo um total de 20 unidades experimentais.

O modelo estatístico adotado nos experimentos para efetuar a análise desses dados foi utilizado a eq. (16):

$$
y_{i j}=\mu+t_{i}+e_{i j}
$$

Onde:

$y$ = valor observado da variável absorção, referente ao i-ésimo nível do fator tamanho de partícula na j-ésima repetição;

$\mu=$ média geral;

$t_{i}=$ efeito do i-ésimo nível do fator tamanho de partícula na variável absorção.

$e_{i j}=$ efeito residual. 


\subsubsection{Análises de envelhecimento (natural e acelerado)}

Para verificar a influência da resina aplicada como proteção do material nas características mecânicas (MOR e MOE) foi montado um experimento de acordo com o delineamento inteiramente casualizado (DIC), correspondendo a um fator (resina) com dois níveis (sem resina e com resina). Foram utilizadas 5 unidades experimentais por cada tratamento, perfazendo um total de 10 unidades experimentais para ambos os envelhecimentos.

O modelo estatístico adotado para análise desses dados foi de acordo com a eq. (17):

$$
y_{i j}=\mu+t_{i}+e_{i j}
$$

Onde:

$y_{i j}=$ valor observado das variáveis MOR e MOE, referente ao i-ésimo nível do fator resina na j-ésima repetição;

$\mu=$ média geral;

$t_{i}=$ efeito do i-ésimo nível do fator resina nas variáveis MOR e MOE;

$e_{i j}=$ efeito residual.

Para os três experimentos, os dados qualitativos foram analisados por meio do teste $\mathrm{F}$ quando ANOVA foi significativa, sendo ambos testados a $\mathrm{P}<0,05$. $\mathrm{O}$ software utilizado para a interpretação dos dados foi o SISVAR, versão 5.3 


\section{Resultados e discussão}

Este item apresenta resultados da caracterização da matéria prima fibrosa (análise bromatológica, dimensão, densidade, microscopia óptica das partículas) que compreendem a caracterização físico-química e morfológica do bagaço de cana-de-açúcar; caracterização das chapas de partículas de bagaço de cana-de-açúcar e resina poliuretana bi componente à base de óleo de mamona produzidas com diferentes tamanhos de partículas (dimensões de até 8 e $5 \mathrm{~mm}$ ), por meio das propriedades físico-mecânicas, de durabilidade e micro estruturais; da análise do comportamento estrutural do painel portante em madeira de reflorestamento e chapas de partículas e proposta de aplicação do mesmo em centro de manejo para bovinos.

Os resultados obtidos das propriedades físico-mecânicas das chapas de partículas foram comparados aos requisitos das normas ABNT NBR 14810-2:2006 - Chapas de madeira aglomerada - Requisitos e ANSI A208.1:1999 - Particleboard.

\subsection{Caracterização da matéria prima fibrosa}

Neste item serão apresentados os resultados das análises química, física e morfológica do bagaço de cana-de-açúcar do bagaço de cana-de-açúcar.

\subsubsection{Análise bromatológica}

Conforme Bledzki e Gassan (1999), a composição química das fibras está relacionada com suas propriedades mecânicas, sendo sensível a diversos fatores, tais como condições climáticas e de plantio, idade e parte da planta de onde são extraídas, como outros fatores relacionados ao desenvolvimento da planta. $\mathrm{Na}$ análise bromatológica realizadas, do bagaço de cana-de-açúcar das diferentes usinas, como nos resultados das 
propriedades físico-mecânicos das chapas produzidas, pode-se observar esse comportamento, assim como será demostrado outros fatores relevantes em relação a qualidade da matéria prima.

De acordo com as informações apresentadas na Tabela 8 é possível identificar a presença de material mineral na quantia de 51,58\% na amostra da Usina A, uma diferença de $45,48 \%$ em relação à amostra da Usina B. Esse resultado indica a existência de terra misturada ao bagaço de cana-de-açúcar, uma vez que o solo é composto predominantemente de matéria mineral.

Foi observada a existência de quantidade de fibra bruta mais elevada no bagaço proveniente da Usina B. A existência desses compostos minerais e a presença de menor quantidade de fibra bruta foram responsáveis pelo baixo valor nas propriedades mecânicas das chapas produzidas com essa matéria prima, conforme apresentado na Tabela 8. Essa avaliação demonstra a necessidade de utilizar um resíduo limpo para garantir qualidade às chapas de partícula aglomeradas.

A Figura 35 apresenta as chapas produzidas com os dois tipos de bagaço (Usina A e Usina B). Pela característica superficial é possível observar diferença na coloração dos materiais produzidos, sendo as chapas mais escuras produzidas com bagaço contaminado.

Tabela 8 - Análise bromatológica do bagaço de cana-de-açúcar.

\begin{tabular}{ccccccc}
\hline Amostra & MS & MM & PB & FB & EE & ENN \\
\hline Usina A & 98,99 & 51,58 & 1,80 & 19,32 & 0,21 & 27,09 \\
Usina B & 98,03 & 6,10 & 1,59 & 47,10 & 0,51 & 44,70 \\
\hline
\end{tabular}

*MS (matéria seca); MM (matéria mineral); PB (proteína bruta); FB (fibra bruta); EE (extrato etéreo); ENN (extrativo não nitrogenado).

**Resultados expressos na matéria seca a $100 \%$. 


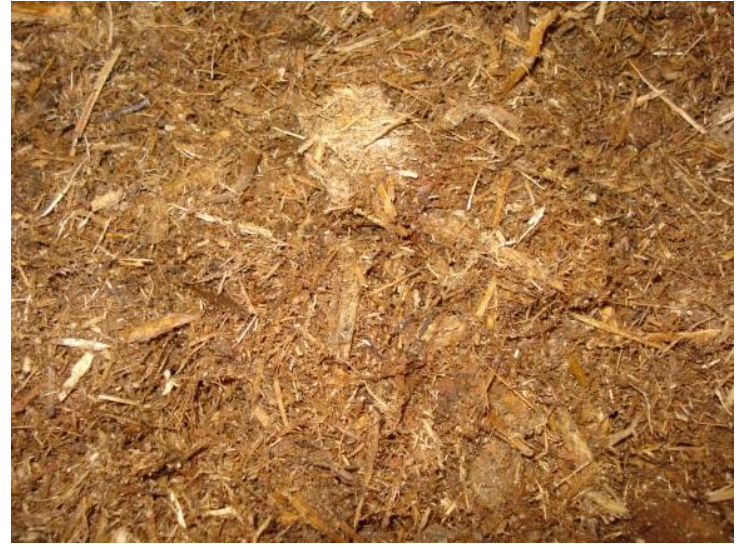

(a)

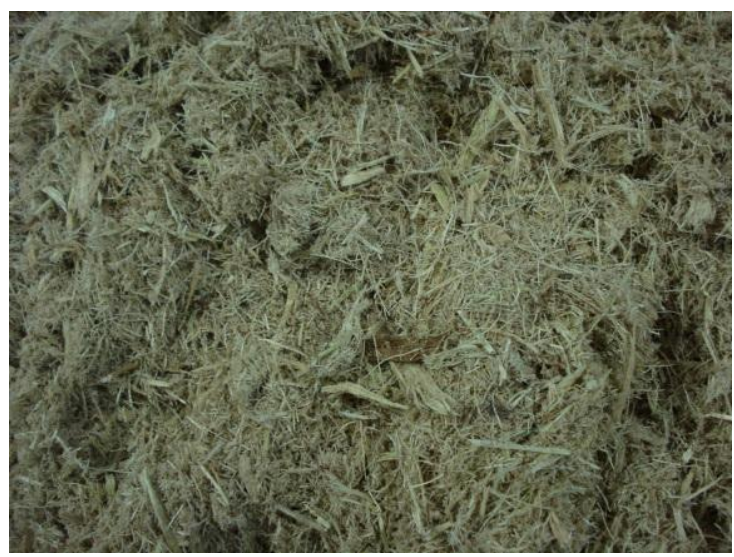

(c)

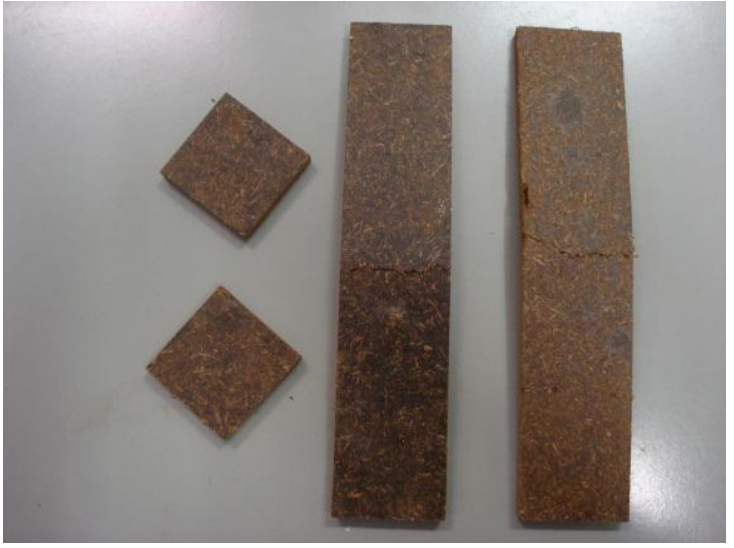

(b)

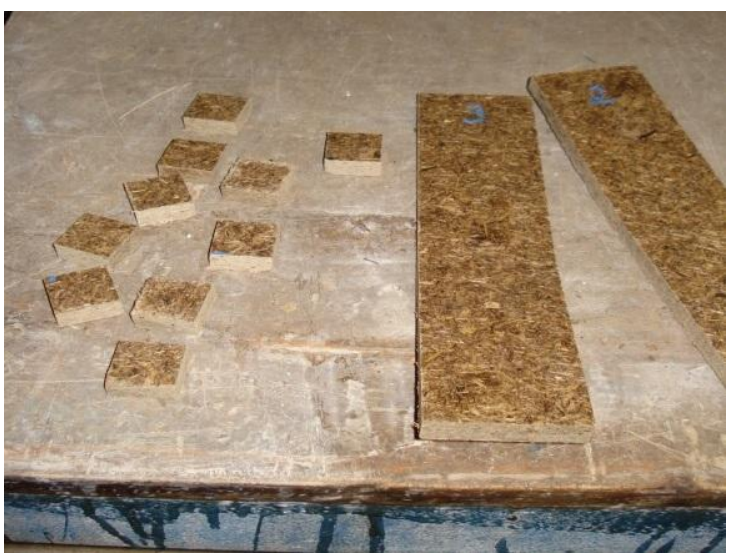

(d)

Figura 35 - Bagaço de cana-de-açúcar (a) e chapas produzidas com esse material proveniente da usina A (b); bagaço de cana-de-açúcar (c) e chapas produzidas com esse material proveniente da usina $B(d)$.

\subsubsection{Dimensão das partículas}

A Tabela 9 apresenta as dimensões médias para comprimento e espessura das partículas brutas de bagaço de cana-de-açúcar, determinada por meio do equipamento estereoscópio em cem amostras. Apresenta também a razão de aspecto, que possibilita a caracterização da forma, definida pela razão dos valores médios do comprimento e espessura. 
Tabela 9 - Valor médio e desvio padrão das dimensões das partículas.

\begin{tabular}{cc}
\hline Morfologia & \\
\hline Comprimento (mm) & $23,94 \pm 10,94$ \\
Espessura (mm) & $1,89 \pm 1,50$ \\
Razão de aspecto & 12,66 \\
\hline
\end{tabular}

Através das dimensões de comprimento, espessura e a razão de aspecto, pode-se definir as partículas de bagaço de cana-de-açúcar como de formato anisotrópicas, em outras palavras, aquelas no qual o comprimento é muito maior do que a espessura.

\subsubsection{Densidade das partículas}

O resultado para a densidade das partículas, determinada por meio do multipicnômetro de gás hélio foi de valor médio de $1,41 \pm 0,26 \mathrm{~g} / \mathrm{cm}^{3}$.

\subsubsection{Microscopia óptica das partículas}

A Figura 36 apresenta imagens com as medidas de largura indicadas nas imagens. 0 resultado de microscopia óptica demonstra que as partículas do bagaço de cana-de-açúcar, possuem irregularidade em relação à sua morfologia e dimensões, além de confirmar como apresentado no Item 4.1.2, a definição das partículas como de formato anisotrópicas. 


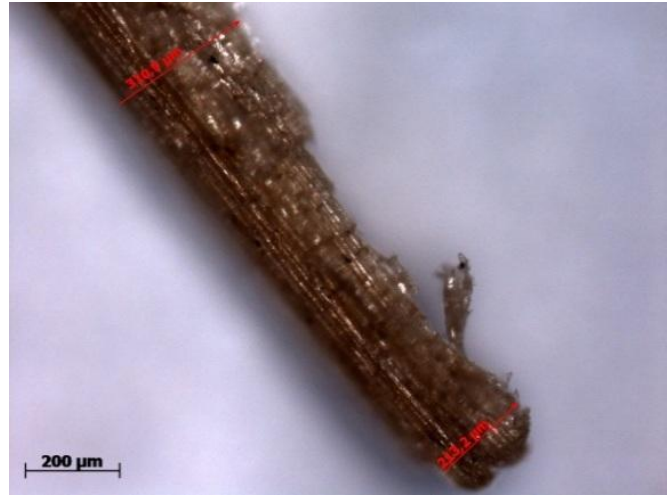

(a)

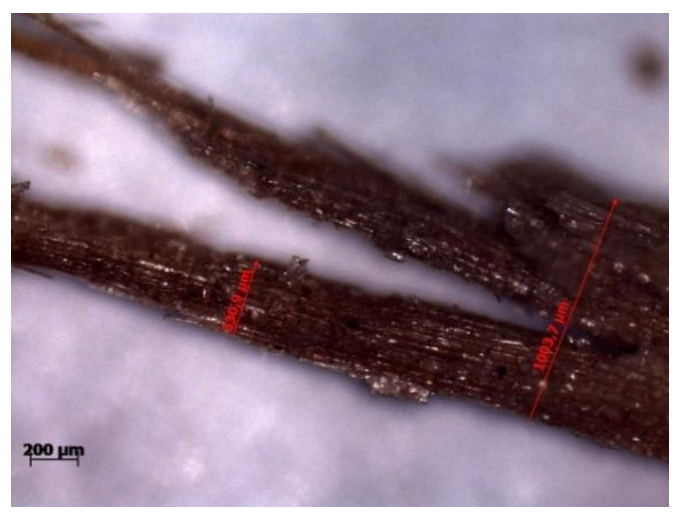

(c)

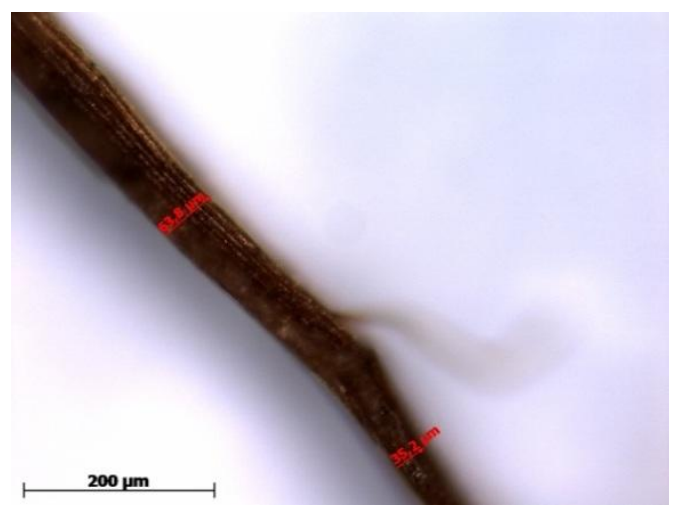

(e)

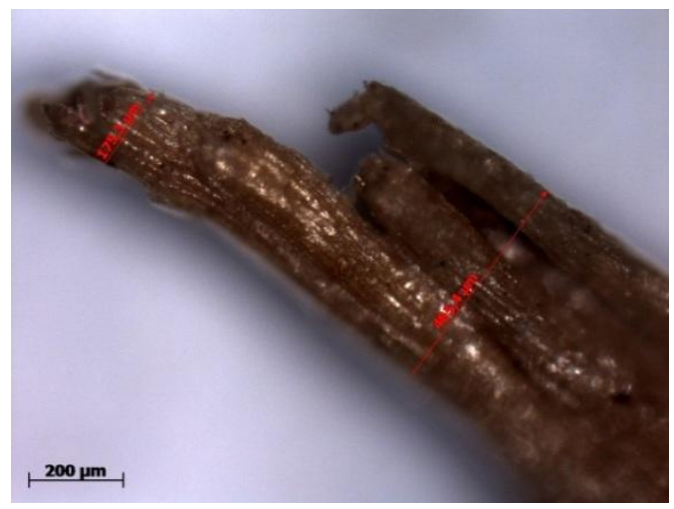

(g)

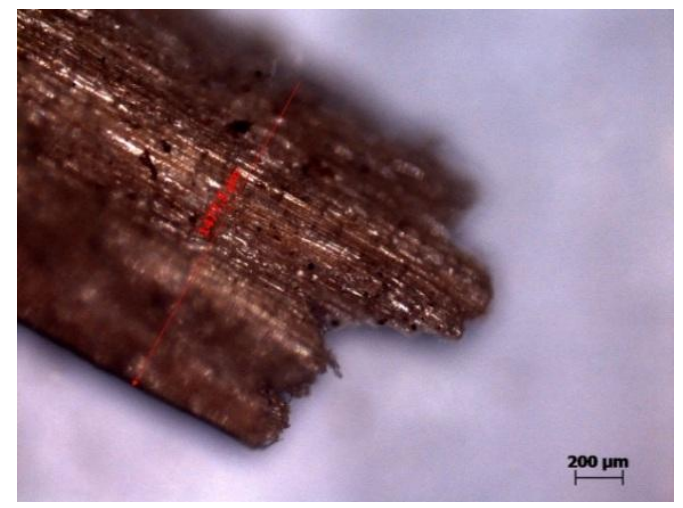

(b)

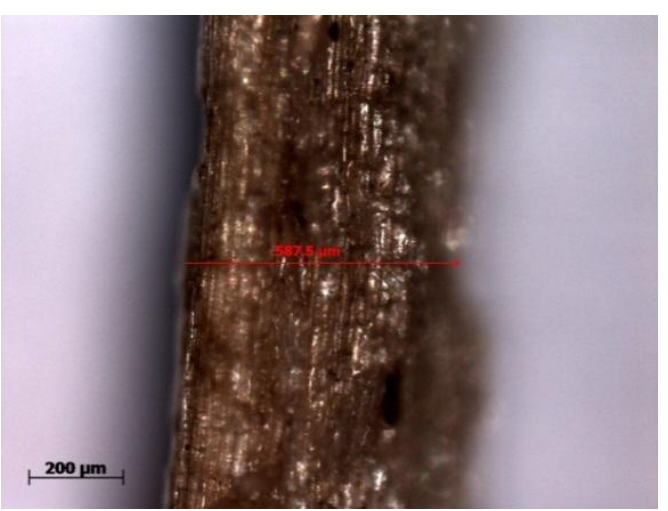

(d)

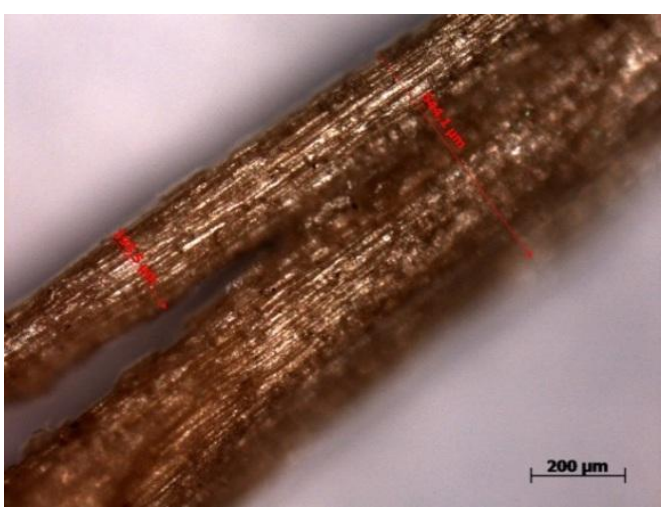

(f)

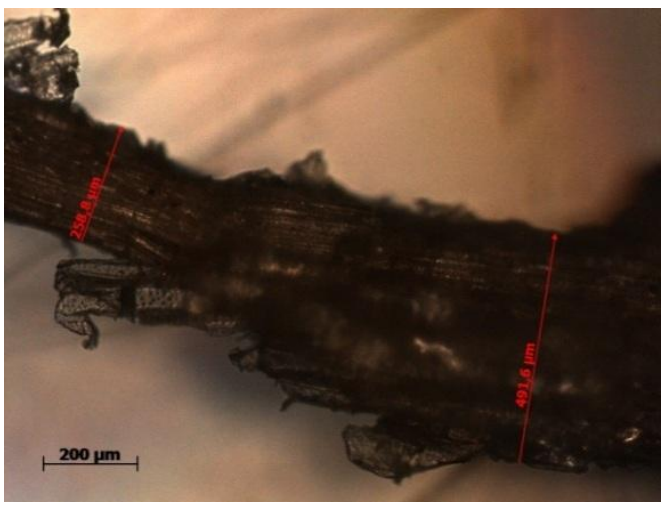

(h)

Figura 36 - Imagens microscópicas ópticas de partículas de bagaço de cana-de-açúcar. 
4.2 Caracterização das chapas de bagaço de cana-de-açúcar e resina poliuretana bi componente à base de óleo de mamona

Neste item serão apresentados resultados das propriedades físico-mecânicas das chapas produzidas com o bagaço de cana-de-açúcar proveniente das diferentes usinas (Usina A e B), que demonstram a justificativa da realização de análise bromatológica, das propriedades físico-mecânicas e comparação das chapas produzidas com dois tamanhos de partículas diferentes (dimensões de até 8 e $5 \mathrm{~mm}$ ).

\subsubsection{Comparativo entre as chapas produzidas com o bagaço das diferentes usinas}

$\mathrm{Na}$ Tabela 10 são apresentados os valores médios das propriedades físicomecânicas das chapas produzidas com partículas provenientes das Usinas A e B. Nota-se uma diferença significativa $(p<0,05)$ entre as propriedades físico-mecânicas das chapas. As chapas produzidas, com o bagaço de ambas as usinas, foram fabricadas com partículas de dimensão de até $8 \mathrm{~mm}$ com base em estudos preliminares por Fiorelli et. al (2011).

Tabela 10 - Valores médios de propriedades físico-mecânicas das chapas das duas Usinas.

\begin{tabular}{|c|c|c|c|}
\hline \multicolumn{2}{|c|}{ Prop. Físico-mecânicas } & Usina A & Usina B \\
\hline \multicolumn{2}{|c|}{$\begin{array}{c}\text { Densidade }\left(\mathrm{kg} / \mathrm{m}^{3}\right) \\
\text { CV (\%) }\end{array}$} & $\begin{array}{l}1265 a \\
(10,0)\end{array}$ & $\begin{array}{l}947 \mathrm{~b} \\
(5,5)\end{array}$ \\
\hline \multirow{2}{*}{$\begin{array}{l}\text { Inchamento (\%) } \\
\text { CV (\%) }\end{array}$} & $2 \mathrm{~h}$ & $\begin{array}{l}2,7 \mathrm{a} \\
(34,3)\end{array}$ & $\begin{array}{l}5,8 \mathrm{~b} \\
(20,9)\end{array}$ \\
\hline & $24 \mathrm{~h}$ & $\begin{array}{c}7,2 \mathrm{a} \\
(28,9)\end{array}$ & $\begin{array}{l}20,0 \mathrm{~b} \\
(13,8)\end{array}$ \\
\hline \multirow{2}{*}{$\begin{array}{c}\text { Absorção (\%) } \\
\text { CV (\%) }\end{array}$} & $2 \mathrm{~h}$ & $\begin{array}{c}4,0 \mathrm{a} \\
(47,9)\end{array}$ & $\begin{array}{l}5,6 \mathrm{a} \\
(8,8)\end{array}$ \\
\hline & $24 \mathrm{~h}$ & $\begin{array}{l}12,9 a \\
(26,6)\end{array}$ & $\begin{array}{l}20,1 \mathrm{~b} \\
(15,2)\end{array}$ \\
\hline \multicolumn{2}{|c|}{$\begin{array}{l}\text { MOR (MPa) } \\
\text { CV (\%) }\end{array}$} & $\begin{array}{c}8,8 \mathrm{a} \\
(27,3)\end{array}$ & $\begin{array}{l}22,6 b \\
(6,32)\end{array}$ \\
\hline \multicolumn{2}{|c|}{$\begin{array}{l}\text { MOE (MPa) } \\
\text { CV (\%) }\end{array}$} & $\begin{array}{l}1244 \mathrm{a} \\
(36,0)\end{array}$ & $\begin{array}{l}2848 b \\
(7,29)\end{array}$ \\
\hline
\end{tabular}

*Médias seguidas das mesmas letras na linha, não diferem $(p<0,05)$ pelo Teste F. 
Para as propriedades físicas, as chapas da Usina A apresentaram valores médios experimentais superiores em relação às chapas com bagaço proveniente da Usina B. Este fato pode ser explicado pela menor quantidade de fibra bruta do bagaço coletado na Usina A, uma diferença de $27,78 \%$ em relação ao bagaço da Usina B, como pode ser observado na Tabela 8 do Item 4.1.1. Com a menor quantidade de material lenhoso que contem alta porosidade, faz com a capacidade de absorção de água e consequentemente, o inchamento em espessura, seja reduzido.

Em relação às propriedades mecânicas, para MOR e MOE obtiveram-se médias experimentais significativamente superiores para as chapas produzidas com bagaço da Usina B, sendo de $61,07 \%$ para MOR e de $56,33 \%$ para MOE.

Outro fato que pode ser observado são os altos valores e diferença do CV (\%) para as chapas produzidas com o bagaço de cana-de-açúcar da Usina A em relação às produzidas com o da Usina B. Isso demonstra uma alta heterogeneidade nas chapas produzidas com o bagaço de cana-de-açúcar da Usina A, o que pode justificar também os baixos valores das propriedades mecânicas.

Portanto fica constatado que a pureza e qualidade da matéria prima empregada para a confecção das chapas, esta diretamente ligada à qualidade final do material, principalmente as relacionadas com as propriedades mecânicas.

\subsubsection{Propriedades físicas}

Neste item são apresentados os valores médios das propriedades físicas (densidade, inchamento e absorção) das chapas fabricadas com diferentes dimensões de partículas (dimensões de até 5 e $8 \mathrm{~mm}$ ) e a comparação, por meio de análise descritiva e inferencial das propriedades, entre as mesmas. 


\subsubsection{Densidade aparente}

- Análise descritiva dos dados

A Tabela 11 apresenta análise descritiva para a variável densidade aparente. Como medida de tendência central foi utilizada a média aritmética e como medidas de dispersão foram adotados desvio padrão e coeficiente de variação (CV).

Tabela 11 - Densidade aparente média de chapas de partículas com bagaço de cana de diferentes comprimentos.

\begin{tabular}{ccc}
\hline Densidade & $\mathbf{8} \mathbf{~ m m}$ & $\mathbf{5 ~} \mathbf{~ m m}$ \\
\hline Média $\left(\mathbf{k g} / \mathrm{m}^{\mathbf{3}}\right)$ & 947 & 883 \\
Desv. Padrão $\left(\mathbf{k g} / \mathrm{m}^{\mathbf{3}}\right)$ & 52,20 & 62,01 \\
CV (\%) & 5,51 & 7,02 \\
\hline
\end{tabular}

A chapas com partículas de até $8 \mathrm{~mm}$ apresentaram maior média para densidade aparente em relação às de até $5 \mathrm{~mm}$. Em relação às medidas de dispersão, as chapas de partículas de $8 \mathrm{~mm}$ apresentaram CV (\%) menor do que as de até $5 \mathrm{~mm}$, demonstrando maior homogeneidade para a variável densidade aparente. Apesar dos CV (\%) serem baixos, demonstra a existência de certa heterogeneidade nas chapas (dimensões de até 8 e $5 \mathrm{~mm}$ ). A Figura 37 representa a dispersão dos conjuntos de dados da variável densidade aparente, ilustrando a dispersão dos dados. 


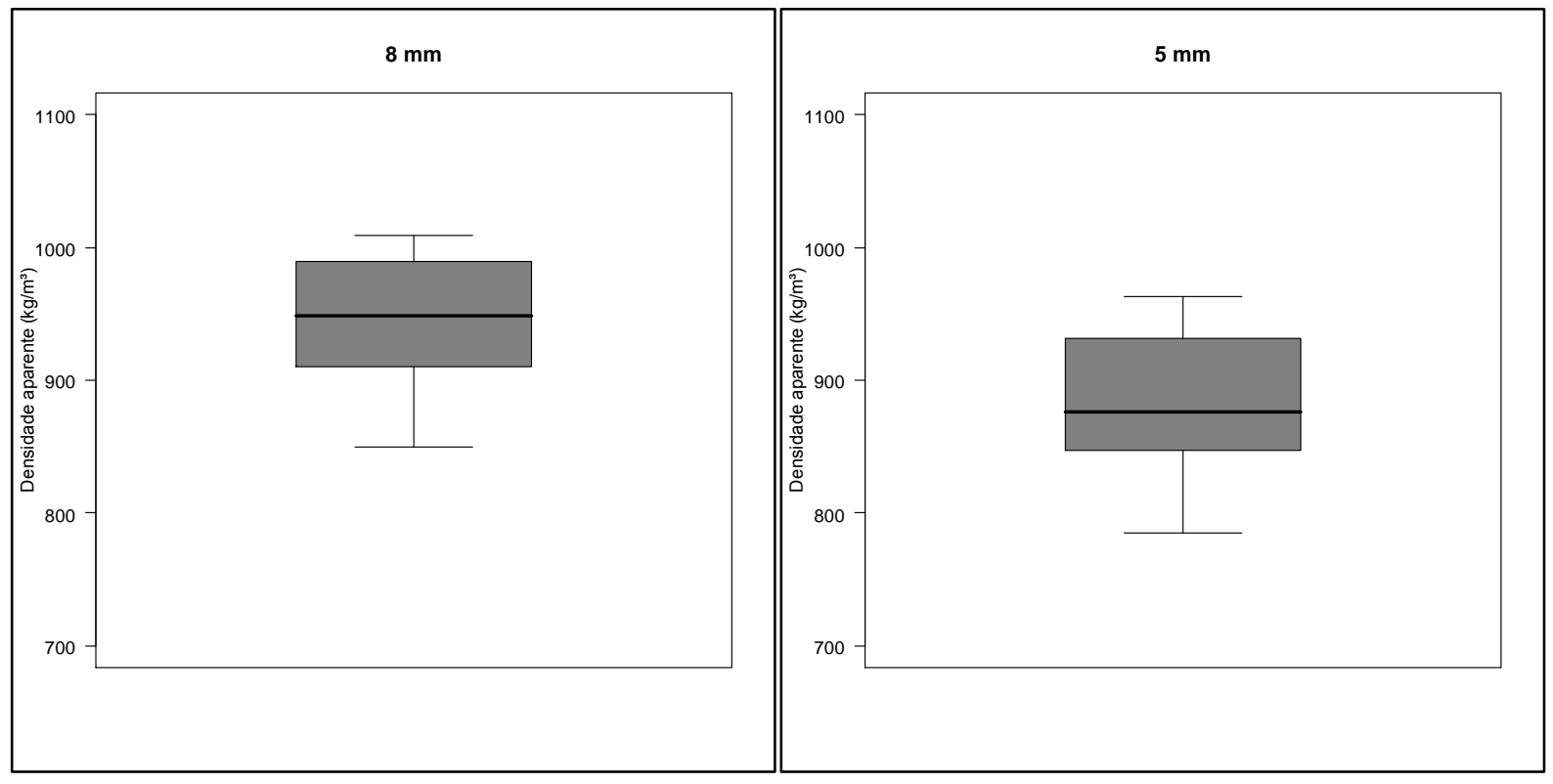

Figura 37 - Gráficos Boxplot da densidade aparente de chapas de partículas com diferentes tamanhos.

A Figura 38 sumariza a comparação dos valores médios experimentais (densidade aparente) com os valores preconizados pelas normas ANSI A208.1:1999, para chapas da classe H-1 (valor acima de 800 kg/m³), e NBR 14810-2:2006 (valor entre 551 a 750 kg/m³).

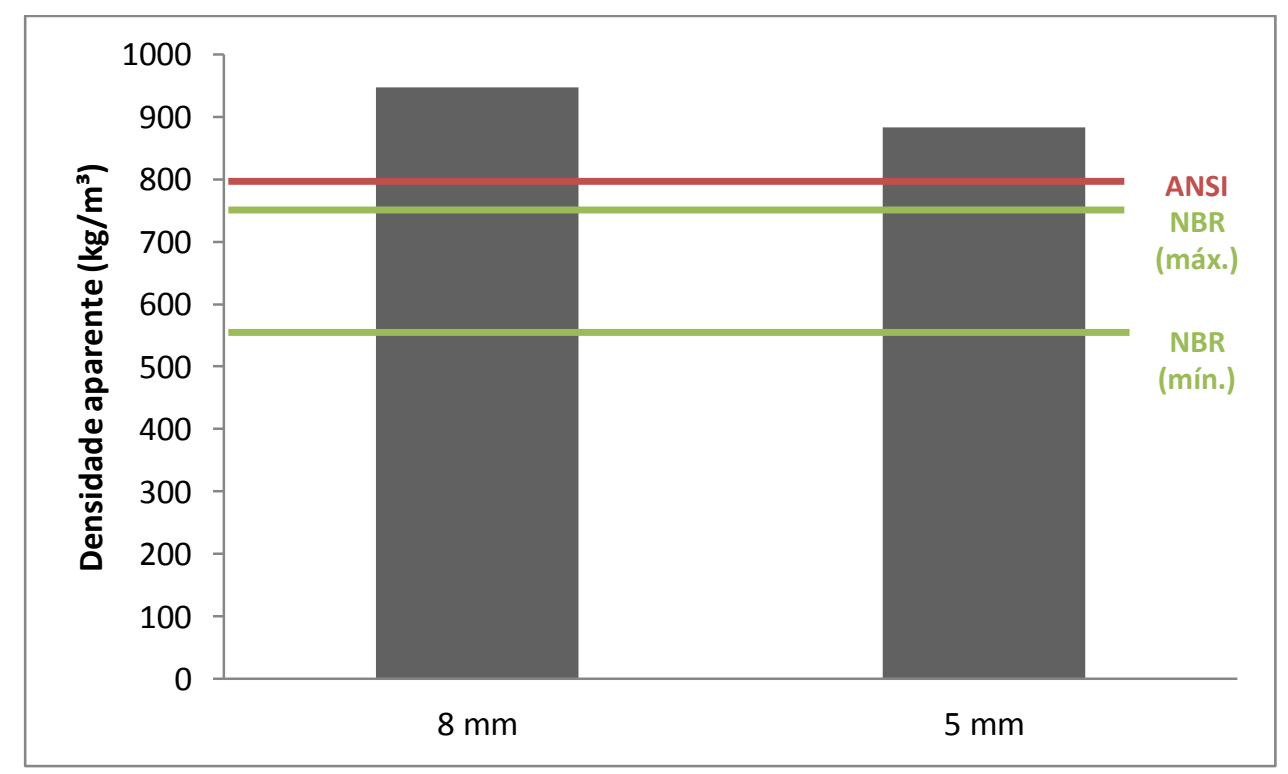

Figura 38 - Gráfico comparativo entre os valores médios experimentais e as normas.

Pelas informações ilustradas na Figura 38, é possível observar que as chapas desenvolvidas com partículas de bagaço de cana-de-açúcar apresentaram valores médios de 
densidade aparente superiores aos recomendados pelas normas. Em relação a ANSI A208.1:1999 as chapas com dimensões de partículas de até 8 e $5 \mathrm{~mm}$ apresentaram respectivamente, valores $18,37 \%$ e $10,37 \%$ superiores. Para a norma NBR 14810-2:2006, as chapas com dimensões de partículas de até 8 e $5 \mathrm{~mm}$ apresentaram, respectivamente, valores $45,58 \%$ e $35,74 \%$ superiores. É possível observar uma diferença de $6,76 \%$ na densidade das chapas produzidas com partículas com comprimento de até $5 \mathrm{~mm}$ em comparação àquelas com partículas de até $8 \mathrm{~mm}$.

De acordo com norma ANSI A208.1-1999, chapas de partícula acima de $800 \mathrm{~kg} / \mathrm{m}^{3}$ são classificados como de alta densidade. Neste caso os resultados obtidos com os dois tamanhos de partículas, mostram valores $947 \mathrm{~kg} / \mathrm{m}^{3}$ e $883 \mathrm{~kg} / \mathrm{m}^{3}$ para chapas com partículas de dimensões de até 8 e $5 \mathrm{~mm}$, respectivamente. Dentro desse contexto, é possível classificar as chapas de partícula à base de bagaço de cana-de-açúcar e resina poliuretana bi componente, como de alta densidade. Esses valores ficaram acima dos preconizados pela norma ABNT 14810-2006, de 551-750 kg/m³.

A densidade nominal calculada para as chapas foi de $1.000 \mathrm{~kg} / \mathrm{m}^{3}$, sendo que os valores de densidade aparente para ambos os tratamentos ( $8 \mathrm{~mm}$ e $5 \mathrm{~mm}$ ) ficaram um pouco a baixo do valor calculado, sendo mais evidente para as chapas produzidas com partículas de até $5 \mathrm{~mm}$. Esse menor valor obtido para a densidade aparente, em comparação a calculada, e o comportamento divergente entre os valores experimentais da densidade aparente com as normas pode ser atribuído às perdas de material durante as etapas de fabricação (pesagem das partículas, mistura das partículas com a resina e formação do colchão) à variação da densidade da matéria-prima empregada na confecção e ao maior volume da mesma empregada na confecção das chapas do que o utilizado pelas normas. Esse comportamento foi relevante, pois existe uma correlação direta entre densidade e as propriedades mecânicas das chapas. Saldanha e Iwakiri (2009) definem a densidade dos painéis sendo dos parâmetros mais importantes na produção de painéis, pois possuem influência altamente significativa sobre as propriedades físicas e mecânicas.

\section{- Análise inferencial}

A Tabela 12 apresenta análise de variância (ANOVA) para a variável densidade aparente. Observa-se, que o P-valor foi menor que 0,05, podendo afirmar que existe efeito de tratamento ( $8 \mathrm{~mm}$ e $5 \mathrm{~mm}$ ). Com base no teste $\mathrm{F}$ a $5 \%$ de probabilidade, pode-se afirmar 
que existe diferença significativa do valor médio experimental da densidade aparente do tratamento $8 \mathrm{~mm}\left(947 \mathrm{~kg} / \mathrm{m}^{3}\right)$ com o valor médio experimental da densidade aparente do tratamento $5 \mathrm{~mm}\left(883 \mathrm{~kg} / \mathrm{m}^{3}\right)$.

Tabela 12 - ANOVA da densidade aparente de chapas de partículas com bagaço de cana de diferentes comprimentos.

\begin{tabular}{cccccc}
\hline FV & GL & SQ & QM & Fc & P-valor \\
\hline Tratamento & 1 & 20352,20 & 20352,20 & 6,184 & $0,0229^{*}$ \\
erro & 18 & 59241,60 & 3291,20 & & \\
Total corrigido & 19 & 79593,80 \\
\hline \multicolumn{5}{c}{ *valor significativo a $p<0,05}$.
\end{tabular}

\subsubsection{Inchamento}

\section{- Análise descritiva}

A Tabela 13 apresenta a análise descritiva para a variável inchamento 2 h e 24 h. Como medida de tendência central foi utilizada a média aritmética e como medidas de dispersão foram utilizados o desvio padrão e coeficiente de variação (CV).

Tabela 13 - Inchamento médio, em 2 h e 24 h, de chapas de partículas com bagaço de cana de diferentes comprimentos.

\begin{tabular}{ccccc}
\hline Inchamento & \multicolumn{2}{c}{$\mathbf{8} \mathbf{~ m m}$} & \multicolumn{3}{c}{$\mathbf{~} \mathbf{~ m m}$} \\
\hline & $\mathbf{2 ~ h}$ & $\mathbf{2 4} \mathbf{~}$ & $\mathbf{2 ~ h}$ & $\mathbf{2 4} \mathbf{~}$ \\
Média (\%) & 5,8 & 20,0 & 20,1 & 42,0 \\
Desv. Padrão (\%) & 1,21 & 2,75 & 10,95 & 9,74 \\
CV (\%) & 20,9 & 13,8 & 54,51 & 23,19 \\
\hline
\end{tabular}

A chapas com partículas de até $8 \mathrm{~mm}$ apresentaram menores valores médios experimentais para a variável inchamento ( 2 h e 24 h) em relação as chapas com partículas de até $5 \mathrm{~mm}$. Em relação às medidas de dispersão, as chapas de partículas de até $8 \mathrm{~mm}$ apresentaram CV (\%) menor do que as de até $5 \mathrm{~mm}$, demonstrando maior homogeneidade para a variável inchamento ( 2 e 24 h). A Figura 39 representa a dispersão dos conjuntos de 
dados da variável Inchamento em 2 e 24 h, onde observa-se a tendência de estabilização da capacidade de absorção de água no período de 24 h, que justifica o menor inchamento.
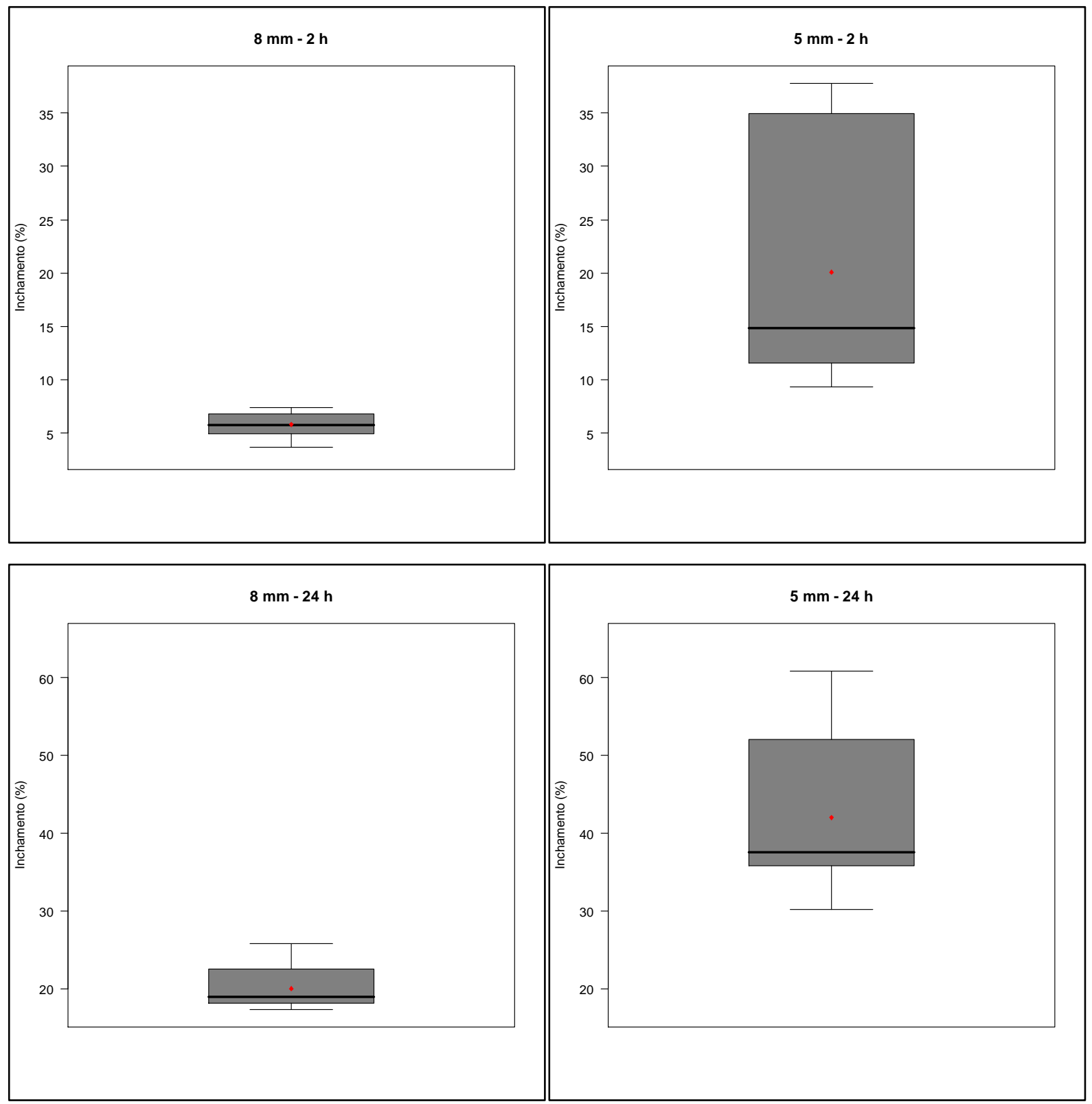

Figura 39 - Gráficos Boxplot de inchamento, em 2 h e 24 h, de chapas de partículas com diferentes tamanhos.

A Figura 40 compara os valores médios experimentais (inchamento - $2 \mathrm{~h}$ e $24 \mathrm{~h}$ ) com os valores preconizados pelas normas ANSI A208.1:1999, para chapas da classe H-1 (8\% - 24 h), e NBR 14810-2:2006 (8\% - 2 h). 


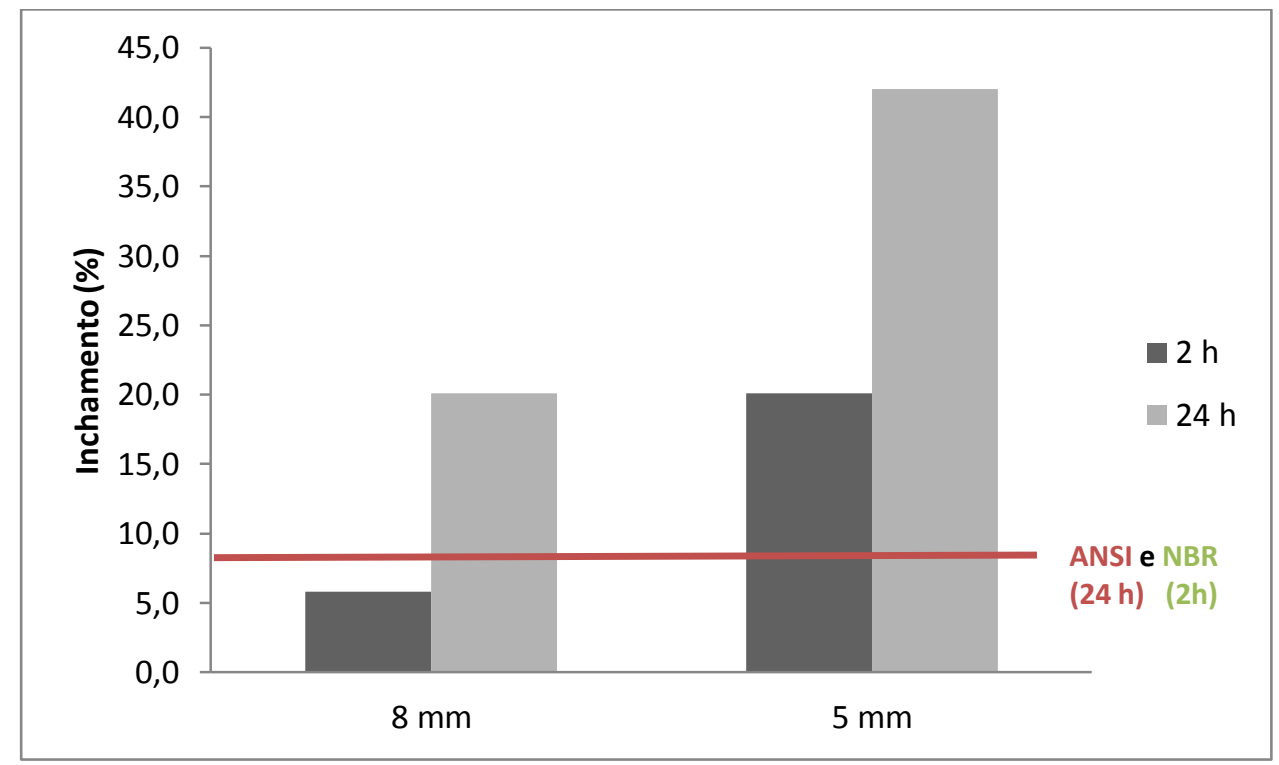

Figura 40 - Gráfico comparativo entre os valores médios experimentais e as normas.

A norma ANSI A208.1:1999 tem valor limite para inchamento a 8\% somente para o período de 24 h. Visualiza-se na Figura 40, que as chapas experimentais, exibiram valores médios experimentais que ficaram acima $(12 \%$ - $8 \mathrm{~mm}$ e $34 \%-5 \mathrm{~mm})$ ao requerido por essa norma. A norma NBR 14810-2:2006 exige valor para inchamento de 8\% somente para o período de $2 \mathrm{~h}$. Nota-se na Figura 40 que somente as chapas com partículas de até $8 \mathrm{~mm}$ apresentaram valor compatível (2,2\% menor) a essa norma, com as chapas com partículas de até $5 \mathrm{~mm}$ ficando a cima do valor limite (12,1\% maior).

Os resultados experimentais obtidos para as chapas com partículas de até $8 \mathrm{~mm}$ demonstraram-se superiores quando comparados com os apresentados por Fiorelli et al. (2011) que encontrou valores para inchamento em 2 h de 19,6\% e para 24 h de 25,07\%. Assim como para Ashori et al. (2009), que obteve valores para $2 \mathrm{~h}$ de até $14,2 \%$ e para $24 \mathrm{~h}$ de até $23,5 \%$.

Xu et al. (2009) encontrou valores para inchamento em $24 \mathrm{~h}$, entre 10,1\% e 42,1\%, sendo o intervalo em que os resultado experimentais para as chapas com os dois tamanhos de partículas ( $8 \mathrm{~mm}$ e $5 \mathrm{~mm}$ ) se inserem.

Comparando os resultados obtidos com os de Iwakari et al. (2005), que trabalhou com chapas de madeira aglomerada, com densidade nominal também de $1.000 \mathrm{~kg} / \mathrm{m}^{3} \mathrm{e}$ como aglomerante utilizada a resina uréia-formaldeído, ficou constatada os bons resultados deste trabalho para inchamento em 24 h, sendo obtido pelo autor o valor de 43,97\% para 
esta propriedade, e de $20,0 \%$ e $40,0 \%$ para as chapas de bagaço de cana-de-açúcar com dimensões de partículas de até 8 e $5 \mathrm{~mm}$, respectivamente.

\section{- Análise inferencial}

A Tabela 14 apresenta a análise de variância (ANOVA) para a variável inchamento para o período de $2 \mathrm{~h}$. Observa-se, que o P-valor foi menor que 0,05, podendo afirmar que existe efeito de tratamento $(8 \mathrm{~mm}$ e $5 \mathrm{~mm}$ ). De acordo com o teste $\mathrm{F}$ a $5 \%$ de probabilidade, pode-se afirmar que o valor médio experimental do tratamento $8 \mathrm{~mm}(5,8 \%)$ foi significativamente menor que o valor médio experimental do tratamento $5 \mathrm{~mm}(20,1 \%)$.

Tabela 14 - ANOVA de inchamento em $2 \mathrm{~h}$ de chapas de partículas com bagaço de cana de diferentes comprimentos.

\begin{tabular}{cccccc}
\hline FV & GL & SQ & QM & Fc & P-valor \\
\hline Tratamento & 1 & 1019,59 & 1019,59 & 15,16 & $0,0011^{*}$ \\
erro & 18 & 1210,43 & 67,24 & & \\
Total corrigido & 19 & 2230,02 \\
\hline \multicolumn{5}{c}{ *valor significativo a $\mathrm{p}<0,05}$.
\end{tabular}

A Tabela 15 apresenta a análise de variância (ANOVA) para a variável inchamento para o período de $24 \mathrm{~h}$. Observa-se, que o P-valor foi menor que $p<0,05$, podendo afirmar que existe efeito de tratamento $(8 \mathrm{~mm}$ e $5 \mathrm{~mm}$ ). Com base no teste $\mathrm{F}$ a $5 \%$ de probabilidade, existe diferença significativa entre o valor médio experimental do tratamento $8 \mathrm{~mm}(20,0 \%)$

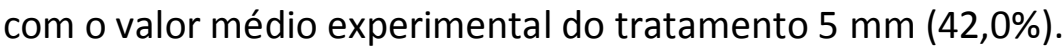

Tabela 15 - ANOVA de inchamento em 24 h de chapas de partículas com bagaço de cana de diferentes comprimentos.

\begin{tabular}{cccccc}
\hline FV & GL & SQ & QM & Fc & P-valor \\
\hline Tratamento & 1 & 2422,20 & 2422,20 & 42,81 & $0,0000^{*}$ \\
erro & 18 & 1018,22 & 56,56 & & \\
Total corrigido & 19 & 3440,42 & & \\
\hline \multicolumn{5}{c}{ *valor significativo a p<0,05. }
\end{tabular}




\subsubsection{Absorção}

\section{- Análise descritiva dos dados}

A Tabela 16 apresenta a análise descritiva para a variável absorção 2 h e 24 h. Como medida de tendência central foi utilizada a média aritmética e como medidas de dispersão foi o desvio padrão e coeficiente de variação (CV).

Tabela 16 - Absorção média, em 2 h e 24 h, de chapas de partículas com bagaço de cana de diferentes comprimentos.

\begin{tabular}{ccccc}
\hline Absorção & \multicolumn{2}{c}{$\mathbf{8} \mathbf{~ m m}$} & \multicolumn{3}{c}{$\mathbf{~} \mathbf{m m}$} \\
\hline & $\mathbf{2} \mathbf{h}$ & $\mathbf{2 4} \mathbf{~}$ & $\mathbf{2} \mathbf{~}$ & $\mathbf{2 4} \mathbf{~}$ \\
Média (\%) & 5,6 & 20,1 & 20,8 & 53,2 \\
Desv. Padrão (\%) & 0,49 & 3,05 & 12,52 & 10,62 \\
CV (\%) & 8,8 & 15,2 & 60,08 & 19,96 \\
\hline
\end{tabular}

A chapas com partículas de até $8 \mathrm{~mm}$ apresentaram menores valores médios experimentais para a variável absorção ( 2 h e 24 h) em relação as chapas com partículas de até $5 \mathrm{~mm}$. Em relação às medidas de dispersão, as chapas de partículas de até $8 \mathrm{~mm}$ apresentaram maior variação na chapa do que as de até $5 \mathrm{~mm}$. A Figura 41 representa a dispersão dos conjuntos de dados da variável absorção em 2 e 24 h. Visualiza-se que a dispersão dos dados, para as chapas de partículas de até $8 \mathrm{~mm}$ demostraram comportamento inverso as chapas com partículas de até $5 \mathrm{~mm}$, ou seja, enquanto o CV (\%) aumentou para as chapas com partículas de até $8 \mathrm{~mm}(2$ a $24 \mathrm{~h}$ ) decresceu para as com partículas de até $5 \mathrm{~mm}$. 

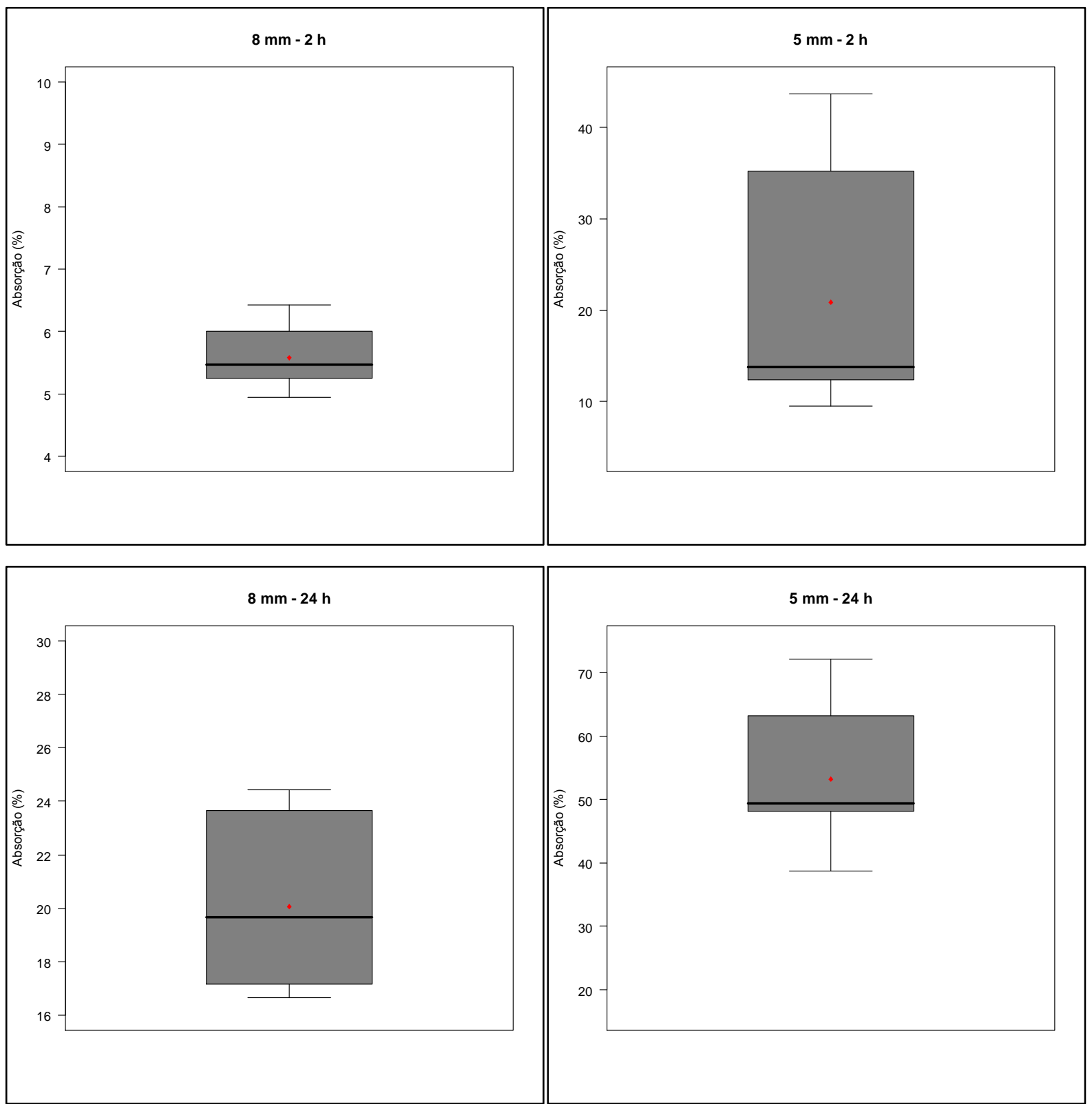

Figura 41 - Gráficos Boxplot de absorção, em 2 h e 24 h, de chapas de partículas com diferentes tamanhos.

A Figura 42 sumariza a comparação dos valores médios experimentais (absorção - 2 h e 24 h), não sendo efetuada a comparação com nenhum documento normativo (ANSI A208.1:1999 e NBR 14810-2:2006), pelo fato, deles não possuírem requerimento para essa variável. Observou novamente superioridade das chapas com partículas com comprimento de até $8 \mathrm{~mm}$, apresentando uma diferença de valores médios de 15,2\% e 33,1\% para absorção em $2 \mathrm{~h}$ e $24 \mathrm{~h}$ respectivamente, em relação as chapas com partículas de até $5 \mathrm{~mm}$. 


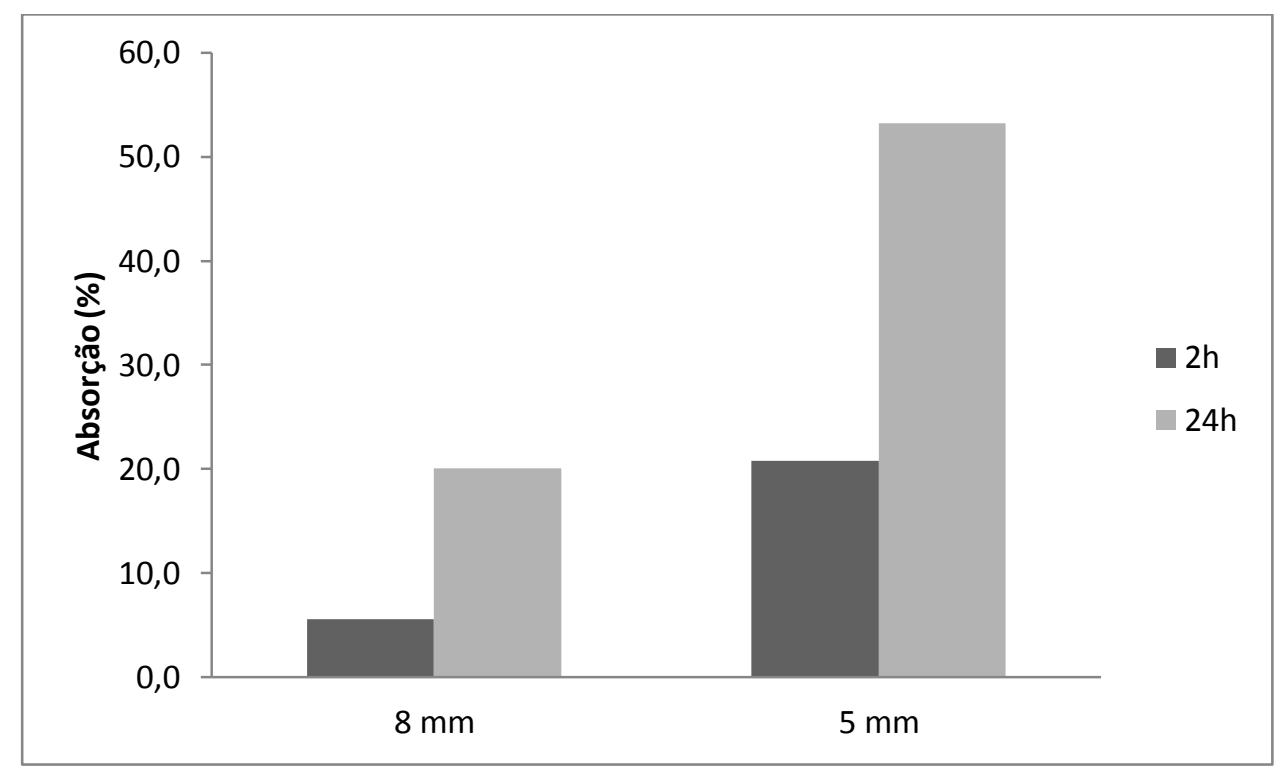

Figura 42 - Gráfico comparativo entre os valores médios experimentais.

Os resultados experimentais para absorção, tanto para as chapas com partículas de até $8 \mathrm{~mm}$ quanto para as de até $5 \mathrm{~mm}$, mostraram valores superiores quando comparados com os encontrados por Xu et al. (2009), de valor máximo de 57,1\% para $24 \mathrm{~h}$, e de Ashori et al. (2009) com valores de até $62,2 \%$ para 2 h e de até $92,7 \%$ para 24 h.

\section{- Análise inferencial}

A Tabela 17 apresenta a análise de variância (ANOVA) para a variável absorção para o período de $2 \mathrm{~h}$. Observa-se, que o P-valor foi menor que 0,05 , podendo afirmar que existe efeito de tratamento ( $8 \mathrm{~mm}$ e $5 \mathrm{~mm}$ ). De acordo com o teste $\mathrm{F}$ a $5 \%$ de probabilidade, podese afirmar que o valor médio experimental de $8 \mathrm{~mm}(5,6 \%)$ foi significativamente menor que o valor médio experimental de $5 \mathrm{~mm}(20,8 \%)$.

Tabela 17 - ANOVA de absorção em $2 \mathrm{~h}$ de chapas de partículas com bagaço de cana de diferentes comprimentos.

\begin{tabular}{cccccc}
\hline FV & GL & SQ & QM & Fc & P-valor \\
\hline Tratamento & 1 & 1167,39 & 1167,39 & 13,37 & $0,0018^{*}$ \\
erro & 18 & 1570,82 & 87,26 & & \\
Total corrigido & 19 & 2738,21 \\
\hline \multicolumn{5}{c}{ *valor significativo a $\mathrm{p}<0,05}$.
\end{tabular}


A Tabela 18 apresenta a análise de variância (ANOVA) para a variável absorção para o período de $24 \mathrm{~h}$. Observa-se, que o P-valor foi menor que 0,05 , podendo afirmar que existe efeito de tratamento $(8 \mathrm{~mm}$ e $5 \mathrm{~mm}$ ). Com base no teste $\mathrm{F}$ a $5 \%$ de probabilidade, existe diferença significativa entre o valor médio experimental do tratamento $8 \mathrm{~mm}(20,1 \%)$ com o valor médio experimental do tratamento $5 \mathrm{~mm}(53,2 \%)$.

Tabela 18 - ANOVA de absorção em 24 h de chapas de partículas com bagaço de cana de diferentes comprimentos.

\begin{tabular}{cccccc}
\hline FV & GL & SQ & QM & Fc & P-valor \\
\hline Tratamento & 1 & 5484,67 & 5484,67 & 81,47 & $0,0000^{*}$ \\
erro & 18 & 1211,76 & 67,32 & & \\
Total corrigido & 19 & 6696,43 \\
\hline \multicolumn{5}{c}{ *valor significativo a $p<0,05}$.
\end{tabular}

\subsubsection{Propriedades mecânicas}

Neste item são apresentados os valores médios das propriedades mecânicas (módulo de ruptura, módulo de elasticidade e adesão interna) das chapas fabricadas com diferentes dimensões de partículas (de até 5 e $8 \mathrm{~mm}$ ) e a comparação, por meio de análise descritiva e inferencial das propriedades, entre as mesmas.

\subsubsection{Módulo de ruptura (MOR)}

\section{- Análise descritiva}

A Tabela 19 apresenta a análise descritiva para a variável MOR. Como medida de tendência central foi utilizada a média aritmética e como medidas de dispersão foi o desvio padrão e coeficiente de variação (CV). 
Tabela 19 - MOR médio de chapas de partículas com bagaço de cana de diferentes comprimentos.

\begin{tabular}{ccc}
\hline MOR & $\mathbf{8} \mathbf{~ m m}$ & $\mathbf{5 ~} \mathbf{m m}$ \\
\hline Média (MPa) & 22,60 & 21,22 \\
Desv. Padrão (MPa) & 1,43 & 2,28 \\
CV (\%) & 6,32 & 10,76 \\
\hline
\end{tabular}

A chapas com partículas de até $8 \mathrm{~mm}$ apresentaram maiores valores médios experimentais para a variável MOR em relação as chapas com partículas de até $5 \mathrm{~mm}$. Em relação às medidas de dispersão, as chapas com partículas de até $8 \mathrm{~mm}$ apresentaram CV (\%) menor do que as de até $5 \mathrm{~mm}$, demonstrando maior homogeneidade para a variável MOR. A Figura 43 representa a dispersão dos conjuntos de dados da variável MOR, onde observa-se que as chapas com partículas de até $5 \mathrm{~mm}$ tendem a ter uma maior heterogeneidade para essa variável.

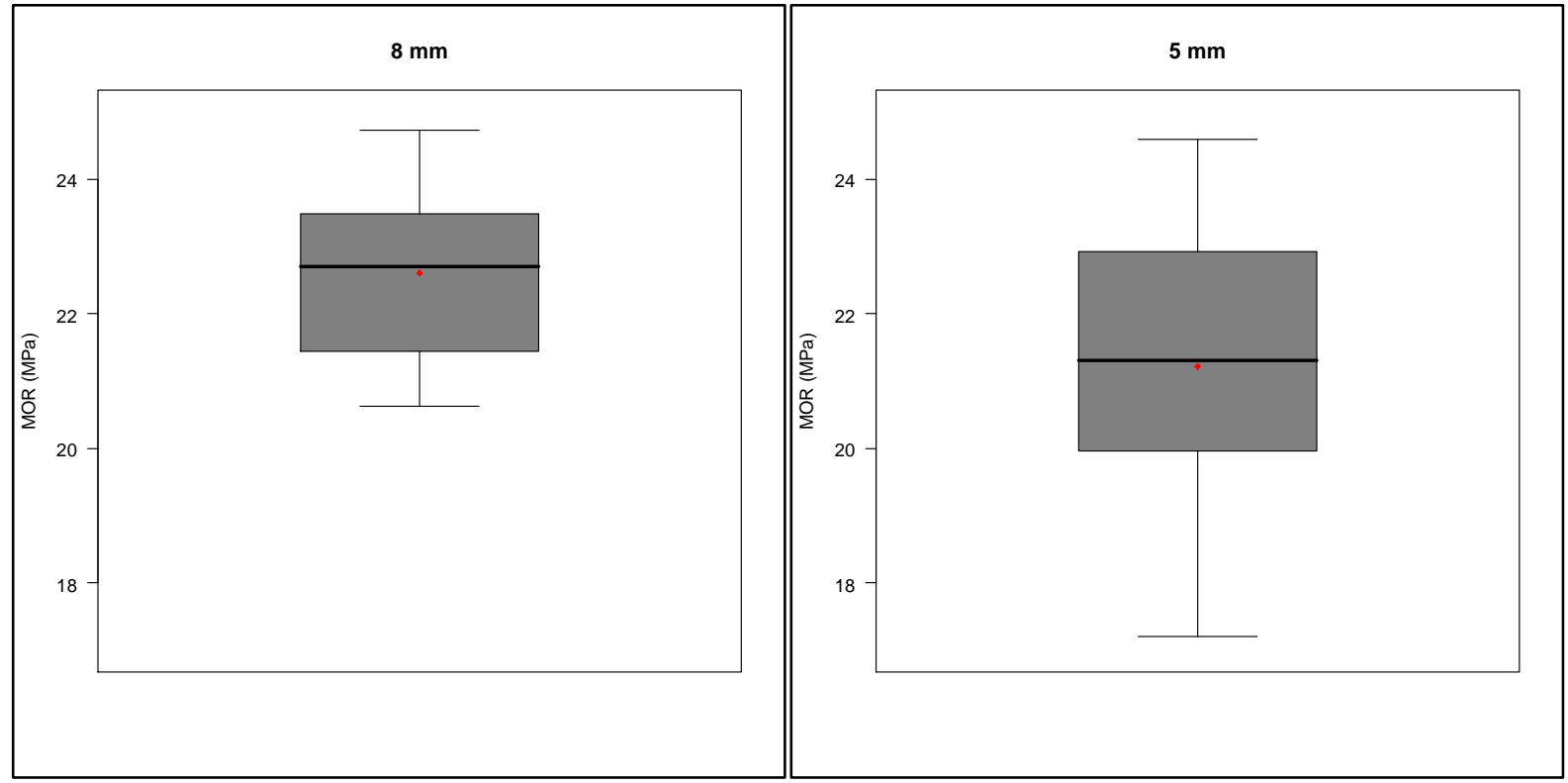

Figura 43 - Gráficos Boxplot do MOR de chapas de partículas com diferentes tamanhos.

A Figura 44 sumariza a comparação dos valores médios experimentais (MOR) com os valores preconizados pelas normas ANSI A208.1:1999, para chapas da classe H-1 (16,5 MPa), e NBR 14810-2:2006 (18 MPa). Visualiza-se, que os valores médios experimentais das chapas $(8 \mathrm{~mm}$ e $5 \mathrm{~mm}$ ) foram maiores que os preconizados pelas normas. Para a propriedade mecânica MOR, foram obtidos resultados de 22,60 MPa para chapas com 
partículas de até $8 \mathrm{~mm}$ e 21,22 MPa para chapas com partículas de até $5 \mathrm{~mm}$. A normativa ANSI 208.1:1999 estabelece valor, para painéis de alta densidade, de 16,5 MPa e a norma ABNT 14810:2006 recomenda valor acima de $18 \mathrm{MPa}$. Sendo assim, os valores experimentais obtidos atendem a recomendação desses documentos normativos.

Na Figura 44 é possível observar diferença de valores médios de 6,11\% entre as chapas produzidas com comprimentos de partículas diferentes, sendo os resultados das chapas com partículas de até $8 \mathrm{~mm}$ superiores aos da chapas com partículas de até $5 \mathrm{~mm}$.

Comparando os valores descritivos, frisados na Tabela 19, observa-se que as chapas com partículas de até $8 \mathrm{~mm}$ apresentaram valores mais adequados para sua aplicação, pois exibiu menor variação no conjunto de dados, o que é relevante para sua adequação a situação de recebimento da carga de impacto.

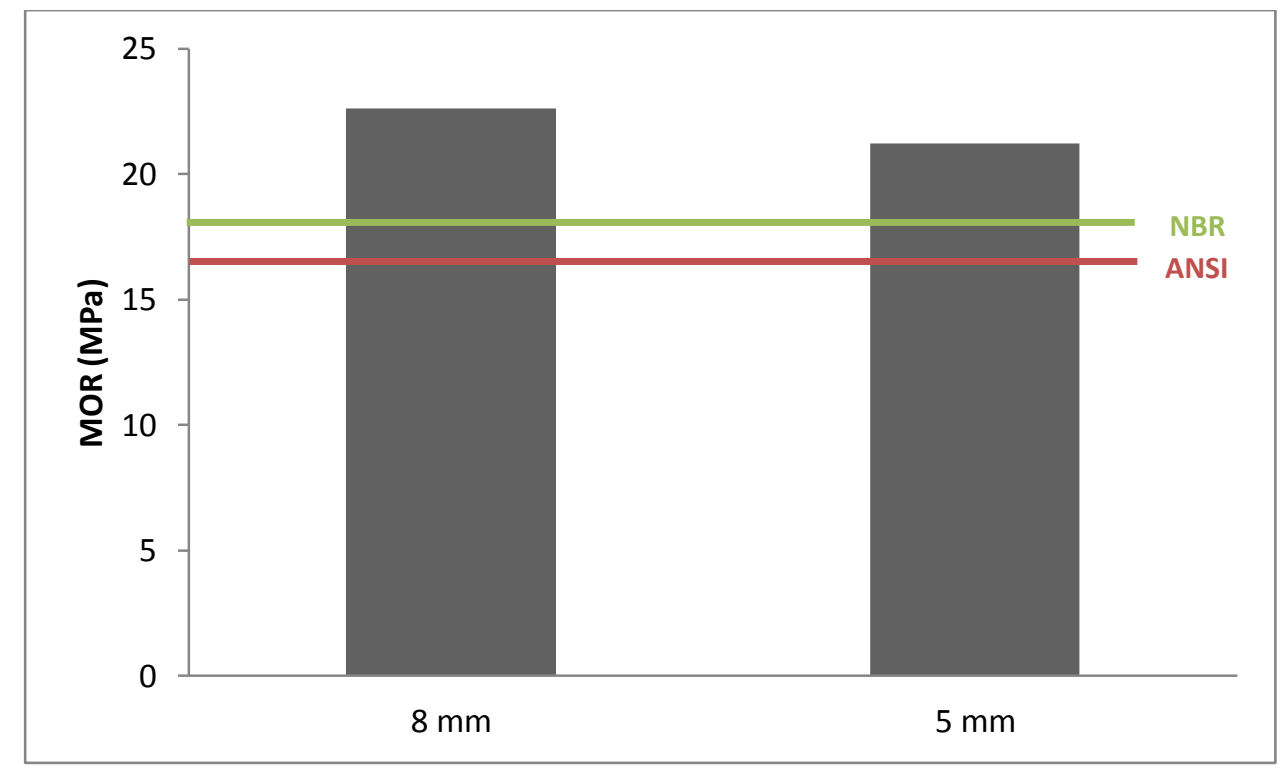

Figura 44 - Gráfico comparativo entre os valores médios experimentais e as normas.

Os resultados experimentais obtidos se assemelham aos apresentados por Xu et al. (2009); Fiorelli et al. (2011); Ashori et al. (2009), que trabalhando com chapas de partículas de bagaço de cana-de-açúcar, encontraram valores máximos para MOR de 26,7 MPa, 24,41 $\mathrm{MPa}$ e $28,6 \mathrm{MPa}$, respectivamente.

Comparando os resultados obtidos por Iwakari et al. (2005) para MOR de 22,57 MPa com os das chapas de partículas de bagaço de cana-de-açúcar deste trabalho, contatouse valores próximos entre os obtidos pelo autor e este trabalho. 


\section{- Análise inferencial}

A Tabela 20 apresenta a análise de variância (ANOVA) para a variável MOR. Observa-se, que o P-valor foi maior que 0,05 , podendo afirmar que não existe efeito significativo entre os tratamentos do estudo ( $8 \mathrm{~mm}$ e $5 \mathrm{~mm}$ ). Apesar de não existir diferença $(p<0,05)$ entre os tratamentos, a chapa de $8 \mathrm{~mm}$ exibiu maior valor médio experimental.

Tabela 20 - ANOVA de MOR de chapas de partículas com bagaço de cana de diferentes comprimentos.

\begin{tabular}{cccccc}
\hline FV & GL & SQ & QM & Fc & P-valor \\
\hline Tratamento & 1 & 8,45 & 8,45 & 2,23 & $0,1524^{\text {NS }}$ \\
erro & 18 & 68,10 & 3,78 & & \\
Total corrigido & 19 & 76,55 & & \\
\hline \multicolumn{5}{c}{ NS valor não significativo a p<0,05. }
\end{tabular}

\subsubsection{Módulo de elasticidade (MOE)}

\section{- Análise descritiva}

A Tabela 21 apresenta a análise descritiva para a variável MOE. Como medida de tendência central foi utilizada a média aritmética e como medidas de dispersão foi o desvio padrão e coeficiente de variação (CV).

Tabela 21 - MOE médio de chapas de partículas com bagaço de cana de diferentes comprimentos.

\begin{tabular}{ccc}
\hline MOE & $\mathbf{8} \mathbf{~ m m}$ & $\mathbf{5 ~} \mathbf{m m}$ \\
\hline Média (MPa) & 2848 & 2571 \\
Desv. Padrão (MPa) & 207,79 & 257,83 \\
CV (\%) & 7,29 & 10,03 \\
\hline
\end{tabular}

A chapas com partículas de até $8 \mathrm{~mm}$ apresentaram maiores valores médios experimentais para a variável MOE em relação as chapas com partículas de até $5 \mathrm{~mm}$. Em relação às medidas de dispersão, as chapas com partículas de até $8 \mathrm{~mm}$ apresentaram CV (\%) menor do que as de até $5 \mathrm{~mm}$, demonstrando maior homogeneidade para a variável 
MOE. A Figura 45 representa a dispersão dos conjuntos de dados da variável MOE, onde se observa que as chapas com partículas de até $5 \mathrm{~mm}$ tendem a ter uma maior heterogeneidade para essa variável, seguindo a mesma tendência para a propriedade MOR.

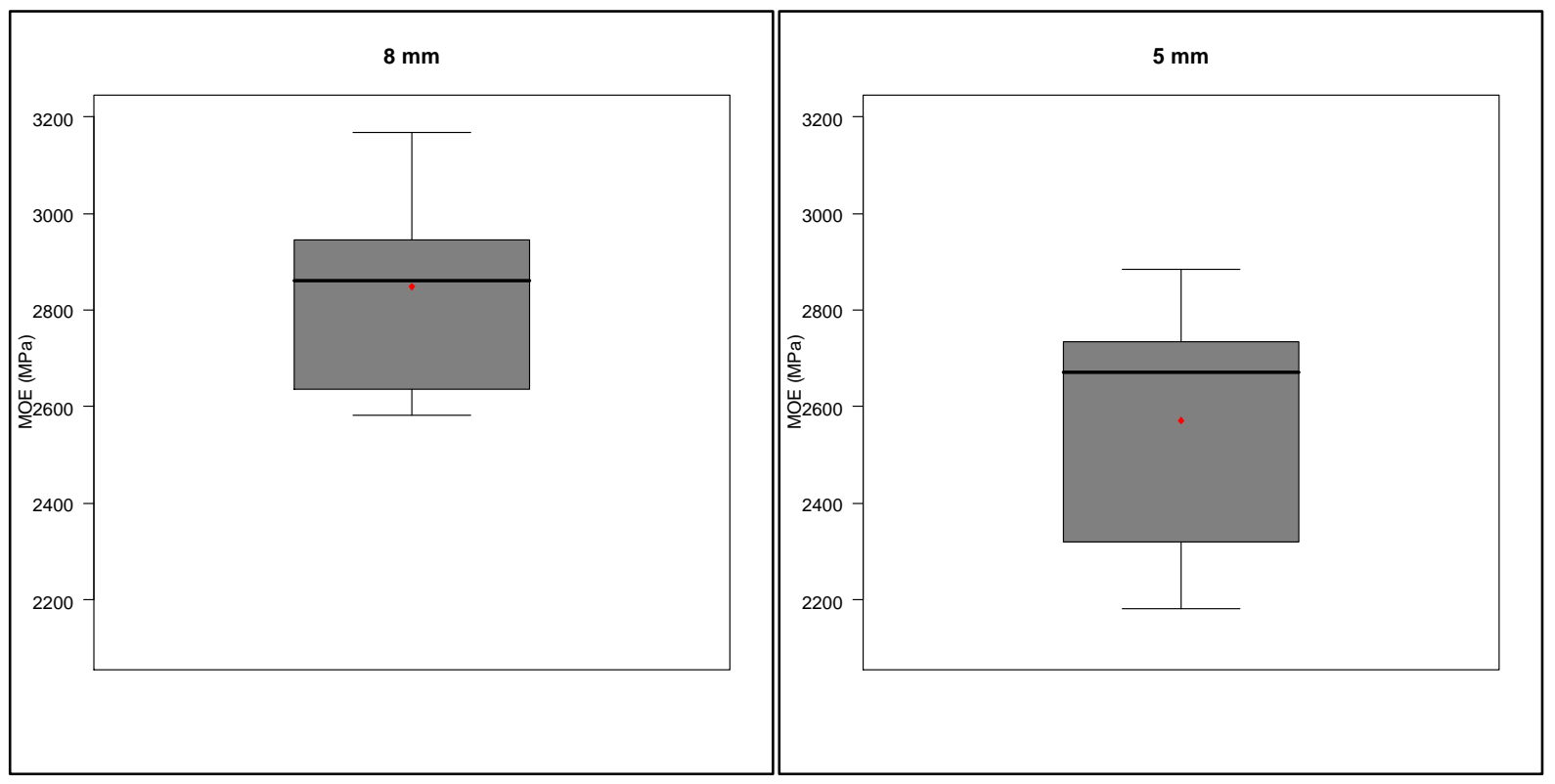

Figura 45 - Gráficos Boxplot do MOE de chapas de partículas com diferentes tamanhos.

A Figura 46 sumariza a comparação dos valores médios experimentais (MOE) com o valor preconizado pela norma ANSI A208.1:1999, para chapas da classe H-1 (2400 MPa). Observa-se que os valores médios experimentais, das chapas com partículas de até 8 e $5 \mathrm{~mm}$ (2848 MPa e $2571 \mathrm{MPa}$, respectivamente) foram superiores ao requerido pela norma.

As chapas produzidas com partículas de até $5 \mathrm{~mm}$ apresentaram valor médio 9,73\% inferior as chapas produzidas com partículas de até $8 \mathrm{~mm}$. 


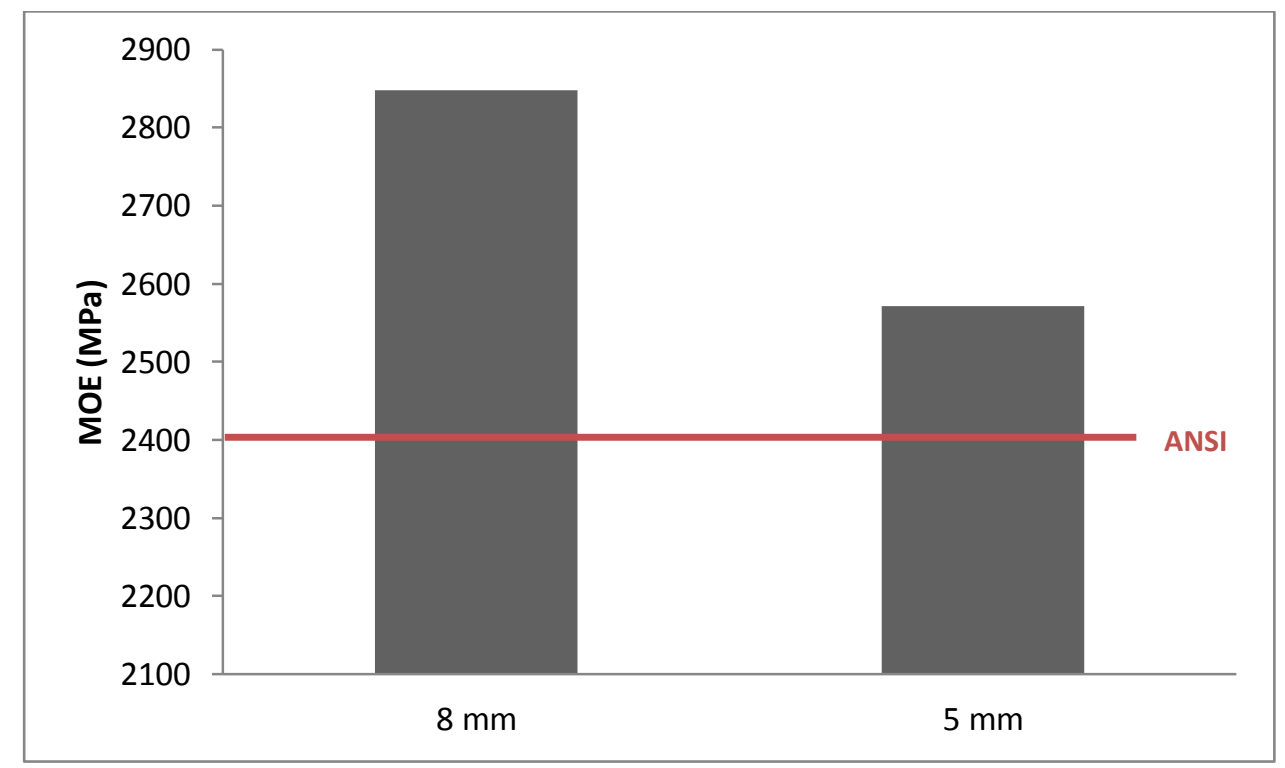

Figura 46 - Gráfico comparativo entre os valores médios experimentais e as normas.

Assim como para a propriedade MOR, os resultados experimentais obtidos para a propriedade MOE demonstram-se próximos aos encontrados por Xu et al. (2009); Fiorelli et al. (2011); Ashori et al. (2009), que trabalhando com chapas de partículas de bagaço de canade-açúcar, encontraram valores máximos para MOE de $3400 \mathrm{MPa}, 2432 \mathrm{MPa}$ e $2582 \mathrm{MPa}$, respectivamente.

Ao comparar os valores de MOE, com os de chapas de partículas de madeira aglomerada e mesma densidade nominal, obtido por Iwakari et al. (2005) de $2818 \mathrm{MPa}$, com os obtidos neste trabalho, observa-se que para as chapas de partículas de bagaço de canade-açúcar de partículas com dimensão de até $8 \mathrm{~mm}$ o resultado ficou muito próximo ao encontrado pelo autor, sendo que para as chapas com partículas com dimensões de até 5 $\mathrm{mm}$ o resultado foi inferior.

\section{- Análise inferencial}

A Tabela 22 apresenta a análise de variância (ANOVA) para a variável MOE. Observa-se, que o P-valor foi menor que 0,05, podendo afirmar que existe efeito de tratamento $(8 \mathrm{~mm}$ e $5 \mathrm{~mm}$ ). Com base no teste $\mathrm{F}$ a $5 \%$ de probabilidade, pode-se afirmar que existe diferença significativa entre os tratamentos ( $8 \mathrm{~mm}$ e $5 \mathrm{~mm}$ ). 
Tabela 22 - ANOVA de MOE de chapas de partículas com bagaço de cana de diferentes comprimentos.

\begin{tabular}{cccccc}
\hline FV & GL & SQ & QM & Fc & P-valor \\
\hline Tratamento & 1 & 384199,20 & 384199,20 & 7,008 & $0,0164^{*}$ \\
erro & 18 & 986876,00 & 54826,44 & & \\
Total corrigido & 19 & 1371075,20 \\
\hline \multicolumn{5}{c}{ *valor significativo a $p<0,05}$.
\end{tabular}

\subsubsection{Adesão interna (AI)}

\section{- Análise descritiva}

A Tabela 23 apresenta a análise descritiva para a variável Al. Como medida de tendência central foi utilizada a média aritmética e como medidas de dispersão foi o desvio padrão e coeficiente de variação (CV).

Tabela 23 - Al média de chapas de partículas com bagaço de cana de diferentes comprimentos.

\begin{tabular}{ccc}
\hline Al & $\mathbf{8} \mathbf{~ m m}$ & $\mathbf{5 ~} \mathbf{m m}$ \\
\hline Média (MPa) & 1,18 & 0,34 \\
Desv. Padrão (MPa) & 0,37 & 0,27 \\
CV (\%) & 31,64 & 78,96 \\
\hline
\end{tabular}

A chapas com partículas de até $8 \mathrm{~mm}$ apresentaram maior valor médio experimental para a variável $\mathrm{Al}$ em relação as chapas de até $5 \mathrm{~mm}$. Em relação às medidas de dispersão, as chapas de partículas ( $8 \mathrm{~mm}$ e $5 \mathrm{~mm}$ ) apresentaram alta variação. A Figura 47 representa a dispersão dos conjuntos de dados da variável Al. Nota-se a presença de outliers (valores extremamente altos ou baixos) em ambos os tratamentos ( $8 \mathrm{~mm}$ e $5 \mathrm{~mm}$ ), assim justifica-se o alto valor do CV (\%) diagnosticado para ambos os tratamentos.

A hipótese que pode explicar os altos valores dos CV (\%) é dada pela falta de homogeneidade da dispersão da resina nas partículas de bagaço de cana-de-açúcar durante o processo de produção das chapas, pois foi constatado alto CV $(32,05 \%$ - $8 \mathrm{~mm} ; 77,87 \%$ - 5 $\mathrm{mm})$. 
Os resultados, referentes à dispersão dos dados, demonstram a necessidade de possível melhoria no processo de aplicação e dispersão da resina, no momento da formação do colchão, uma vez que é de grande interesse materiais que apresentem boa homogeneidade em suas propriedades mecânicas.

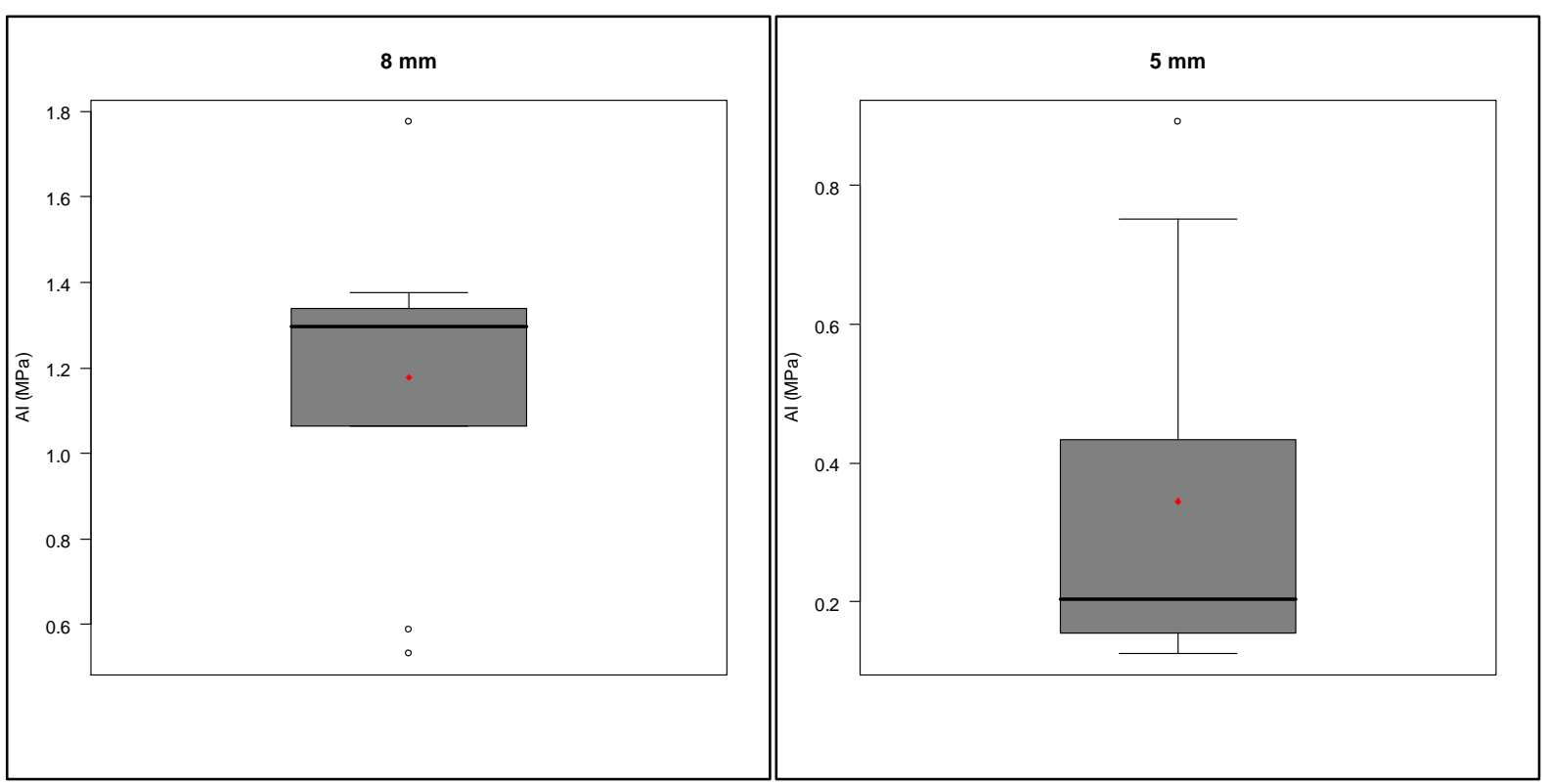

Figura 47 - Gráficos Boxplot da Al de chapas de partículas com diferentes tamanhos.

A Figura 48 sumariza a comparação dos valores médios experimentais dos tratamentos estudados ( $8 \mathrm{~mm}$ e $5 \mathrm{~mm}$ ) com os valores preconizados pelas normas ANSI A208.1:1999, para chapas da classe H-1 (0,9 MPa) e NBR 14810-2:2006 (0,4 MPa). Nota-se, que o valor médio experimental, das chapas com partículas de até $8 \mathrm{~mm}$, foi superior aos preconizados pelas normas. No entanto, para as chapas com partículas de até $5 \mathrm{~mm}$, o valor médio experimental não atendeu ao requerido por nenhuma das normas.

Comparando o valor médio entre as chapas das diferentes dimensões de partículas, temos uma diferença inferior de 71,19\% para as chapas com partículas de até $5 \mathrm{~mm}$. 


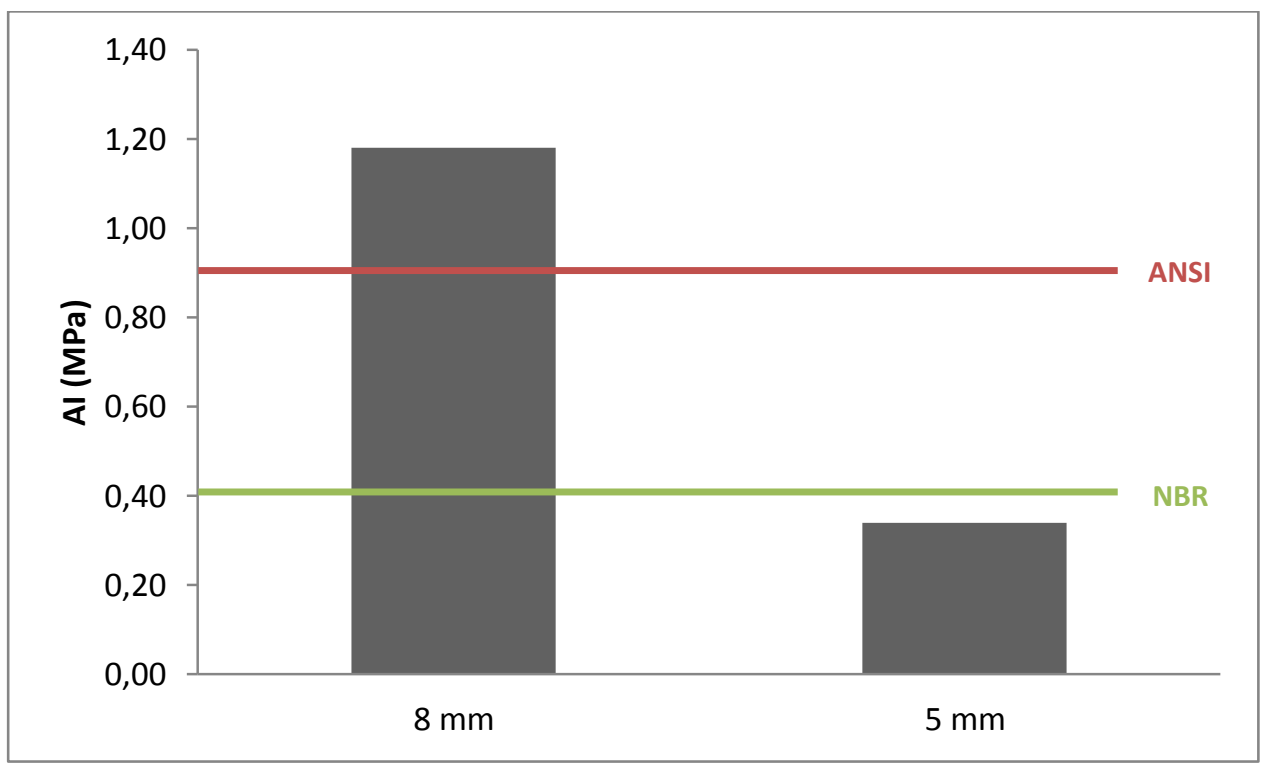

Figura 48 - Gráfico comparativo entre os valores médios experimentais e as normas.

Os resultados experimentais obtidos pata Al, para as chapas com partículas de até 8 mm, também se assemelham aos apresentados por Xu et al. (2009) e Fiorelli et al. (2011), que trabalhando com chapas de partículas de bagaço de cana-de-açúcar, encontraram valores máximos para $\mathrm{Al}$ de 1,02 $\mathrm{MPa}, 1,29 \mathrm{MPa}$ e, respectivamente.

Ashori et al. (2009) obteve resultados inferiores, quando comparados com as chapas com partículas de até $8 \mathrm{~mm}$, aos encontrados nesse trabalho, com valores para $\mathrm{Al}$ de 0,32 MPa, não seguindo a tendência para os valores das propriedades MOR e MOE, que tiveram valores próximos. Porém se assemelham aos valores de Al para as chapas com partículas de até $5 \mathrm{~mm}$ que foram de 0,34 MPa.

Comparando com chapas de partículas de madeira aglomerada e mesma densidade nominal, trabalhadas por Iwakari et al. (2005), que obteve o valor de 1,17 MPa para esta propriedade, observa-se um valor muito próximo obtido neste trabalho para as chapas de partículas de bagaço de cana-de-açúcar para as chapas com partículas com dimensão de até $8 \mathrm{~mm}$. Para as chapas com partículas com dimensão de até $5 \mathrm{~mm}$, o valor para Al foi muito inferior ao encontrado pelo autor.

\section{- Análise inferencial}

A Tabela 24 apresenta a análise de variância (ANOVA) para a variável TP. Observase, que o P-valor foi menor que 0,05 , podendo afirmar que existe efeito de tratamento (8 $\mathrm{mm}$ e $5 \mathrm{~mm})$. De acordo com o teste $F$, foi constatado diferença significativa $(p<0,05)$ entre o 
valor médio experimental de $8 \mathrm{~mm}(1,18 \mathrm{MPa})$ com o valor médio experimental de $5 \mathrm{~mm}$ (0,34 MPa).

Tabela 24 - ANOVA de TP de chapas de partículas com bagaço de cana de diferentes comprimentos.

\begin{tabular}{cccccc}
\hline FV & GL & SQ & QM & Fc & P-valor \\
\hline Tratamento & 1 & 4,05 & 4,05 & 29,16 & $0,0000^{*}$ \\
erro & 18 & 2,50 & 0,13 & & \\
Total corrigido & 19 & 6,55 & & & \\
\hline
\end{tabular}

*valor significativo a $p<0,05$.

\subsubsection{Conclusão dos resultados das propriedades físico-mecânicas ( $8 \mathrm{~mm}$ e $5 \mathrm{~mm}$ )}

Com base nos resultados obtidos, foi considerado utilizar partículas com comprimento de até $8 \mathrm{~mm}$ para a produção das próximas chapas para a continuidade do trabalho. Essa opção se deve aos valores superiores de propriedades físico-mecânicas em relação às chapas produzidas com partículas com comprimento de até $5 \mathrm{~mm}$ (Tabela 25).

Tabela 25 - Valores médios de propriedades físico-mecânicas de chapas de partículas com bagaço de cana de diferentes comprimentos.

\begin{tabular}{|c|c|c|c|}
\hline \multicolumn{2}{|c|}{ Prop. Físico-mecânicas } & $\mathbf{8 ~} \mathbf{~ m m}$ & $\mathbf{5 ~} \mathbf{~ m}$ \\
\hline \multicolumn{2}{|c|}{ Densidade $\left(\mathbf{k g} / \mathbf{m}^{\mathbf{3}}\right.$ ) } & 947 & 883 \\
\hline \multirow{2}{*}{ Inchamento (\%) } & $\mathbf{2 h}$ & 5,8 & 20,1 \\
\cline { 2 - 3 } & $\mathbf{2 4 h}$ & 20,0 & 42,0 \\
\hline \multirow{2}{*}{ Absorção (\%) } & $\mathbf{2 h}$ & 5,6 & 20,8 \\
\cline { 2 - 3 } & $\mathbf{2 4 h}$ & 20,1 & 53,2 \\
\hline \multicolumn{2}{|c|}{ MOR (MPa) } & 22,6 & 21,2 \\
\hline \multicolumn{2}{|c|}{ MOE (MPa) } & 2848 & 2571 \\
\hline \multicolumn{2}{|c|}{ Al (MPa) } & 1,18 & 0,34 \\
\hline
\end{tabular}

A realização da avaliação físico-mecânica foi essencial, pois permitiu o estabelecimento de diretrizes para a definição de qual material seria o mais indicado e que seria utilizado para o restante dos ensaios e próximos passos, como os testes de 
envelhecimento e a produção de chapas com dimensões maiores para o desenvolvimento do painel portante para utilização como fechamento lateral em centro de manejo para bovinos.

4.3 Envelhecimento das chapas de bagaço de cana-de-açúcar e resina poliuretana bi componente à base de óleo de mamona

\subsubsection{Envelhecimento natural}

Neste item serão apresentados os resultados para as propriedades mecânicas dos $\mathrm{CP}$, com e sem resina aplicada em sua superfície como proteção, das chapas com partículas de até $8 \mathrm{~mm}$ expostas as intempéries do clima pelo período de 6 meses.

Nas Figuras 49 e 50 são apresentados os CP das chapas expostas ao envelhecimento com resina aplicada em sua superfície e sem resina aplicada, respectivamente. Pode-se notar a grande diferença no aspecto entre os dois tratamentos, sendo que o com resina quase não sofreu alteração em seu aspecto.
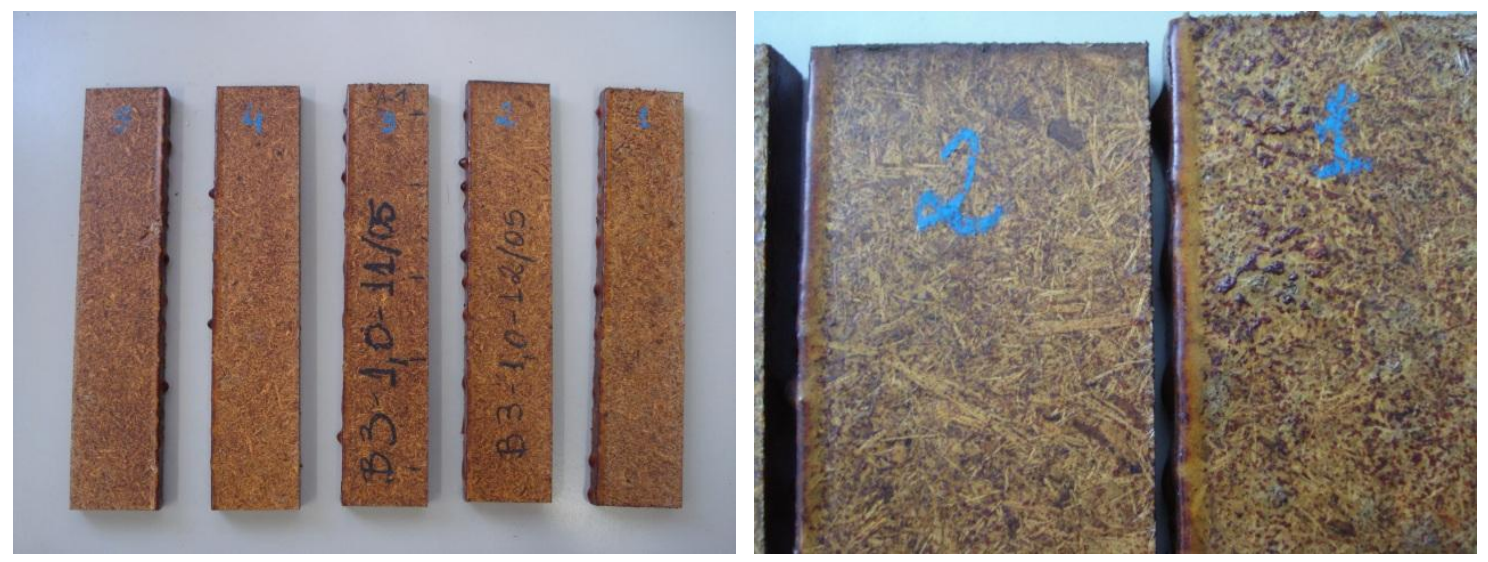

Figura 49 - CP com aplicação de resina após período de envelhecimento. 

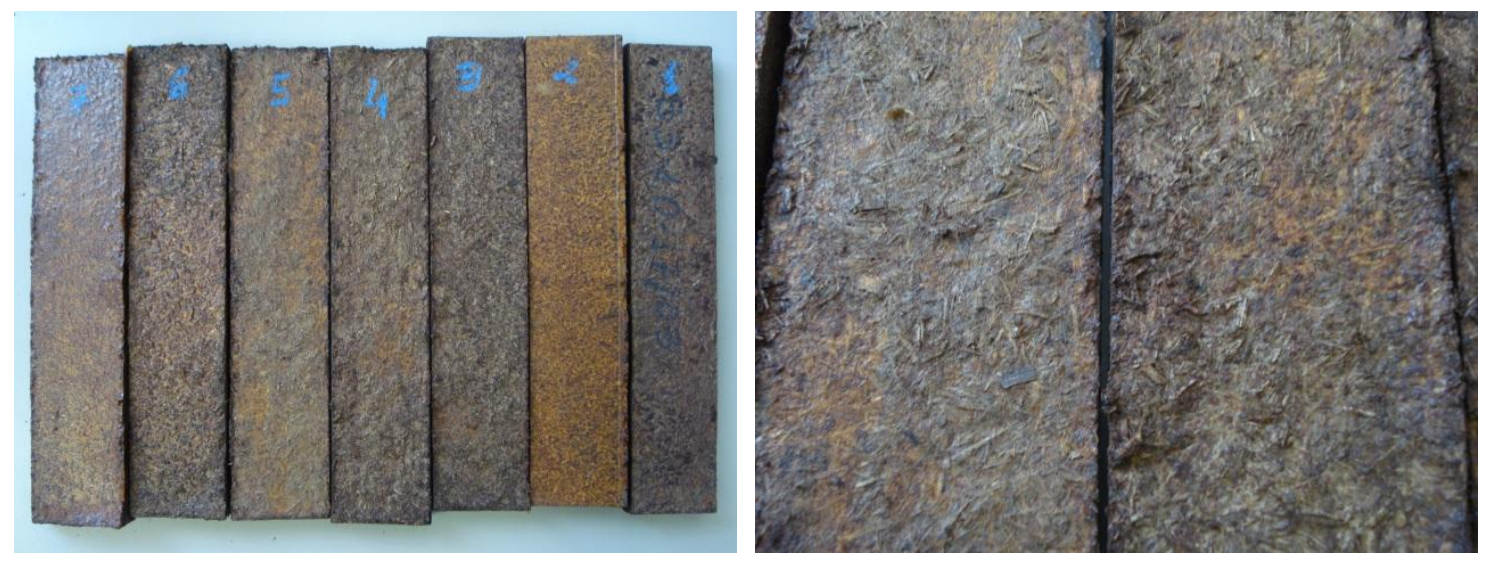

Figura 50 - CP sem aplicação de resina após período de envelhecimento.

Nas Figuras 51 e 52 pode ser observado a delaminação e deformações ocorridas nos $\mathrm{CP}$, sem aplicação de resina, após o período envelhecimento natural. Foi notável a interferência da aplicação da resina de mamona na superfície dos $C P$, sendo que aqueles com resina não apresentaram delaminação e deformação, além de propriedades mecânicas superiores aos painéis sem revestimento superficial como será apresentado nos itens a seguir.
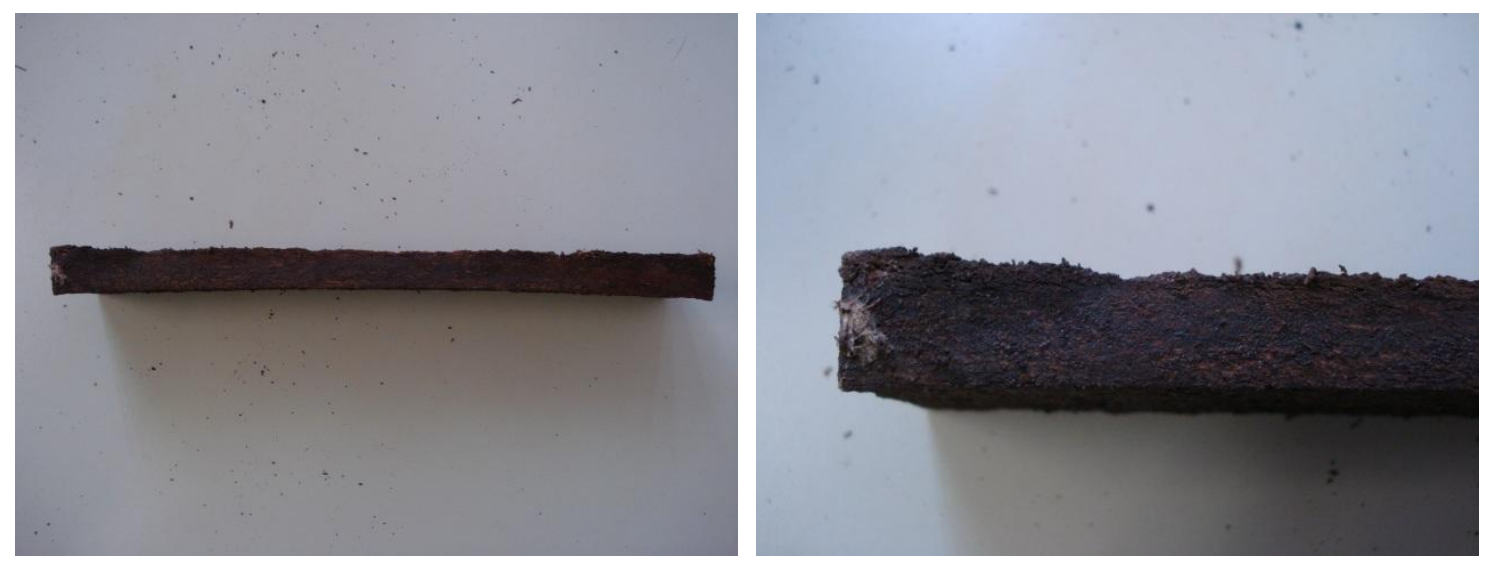

Figura 51 - CP sem aplicação de resina com grande alteração em seu aspecto. 

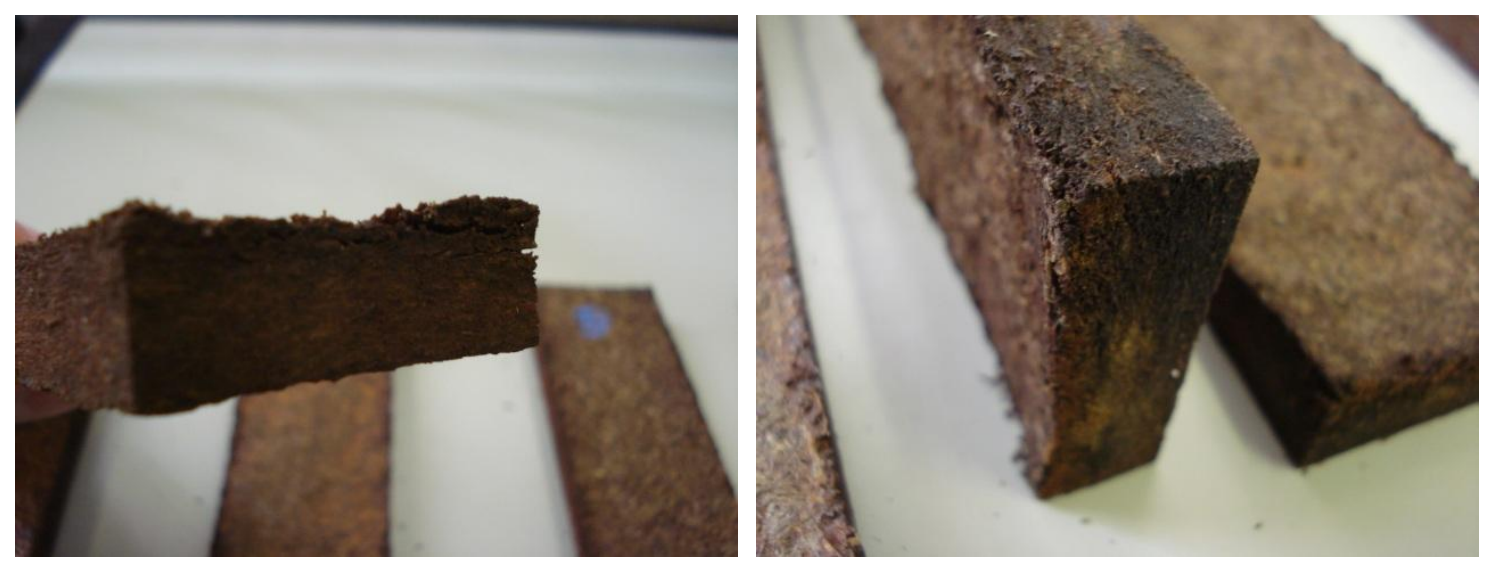

Figura 52 - CP sem resina com detalhe das delaminações ocorridas.

\subsubsection{Módulo de ruptura (MOR)}

\section{- Análise descritiva}

A Tabela 26 apresenta a análise descritiva para a variável MOR. Como medida de tendência central foi utilizada a média aritmética e como medidas de dispersão foi o desvio padrão e coeficiente de variação (CV).

Tabela 26 - MOR médio de chapas de partículas com bagaço de cana com e sem revestimento após envelhecimento natural.

\begin{tabular}{ccc}
\hline MOR & Com revestimento & Sem revestimento \\
\hline Média (MPa) & 17,14 & 6,12 \\
Desv. Padrão (MPa) & 4,12 & 1,11 \\
CV (\%) & 24,04 & 18,09 \\
\hline
\end{tabular}

As chapas com revestimento na superfície externa apresentaram maiores valores médios experimentais para a variável MOR em relação às chapas sem revestimento de resina. Em relação às medidas de dispersão, as chapas de partículas com revestimento aplicada na superfície apresentaram CV (\%) maior do que as sem revestimento, demonstrando menor homogeneidade para a variável MOR. Os CV (\%) das chapas (com revestimento e sem revestimento) exibiram uma alta heterogeneidade para esta característica mecânica. A Figura 53 representa a dispersão dos conjuntos de dados da 
variável MOR, onde se observa que as chapas com revestimento tendem a ter uma maior heterogeneidade para essa variável.

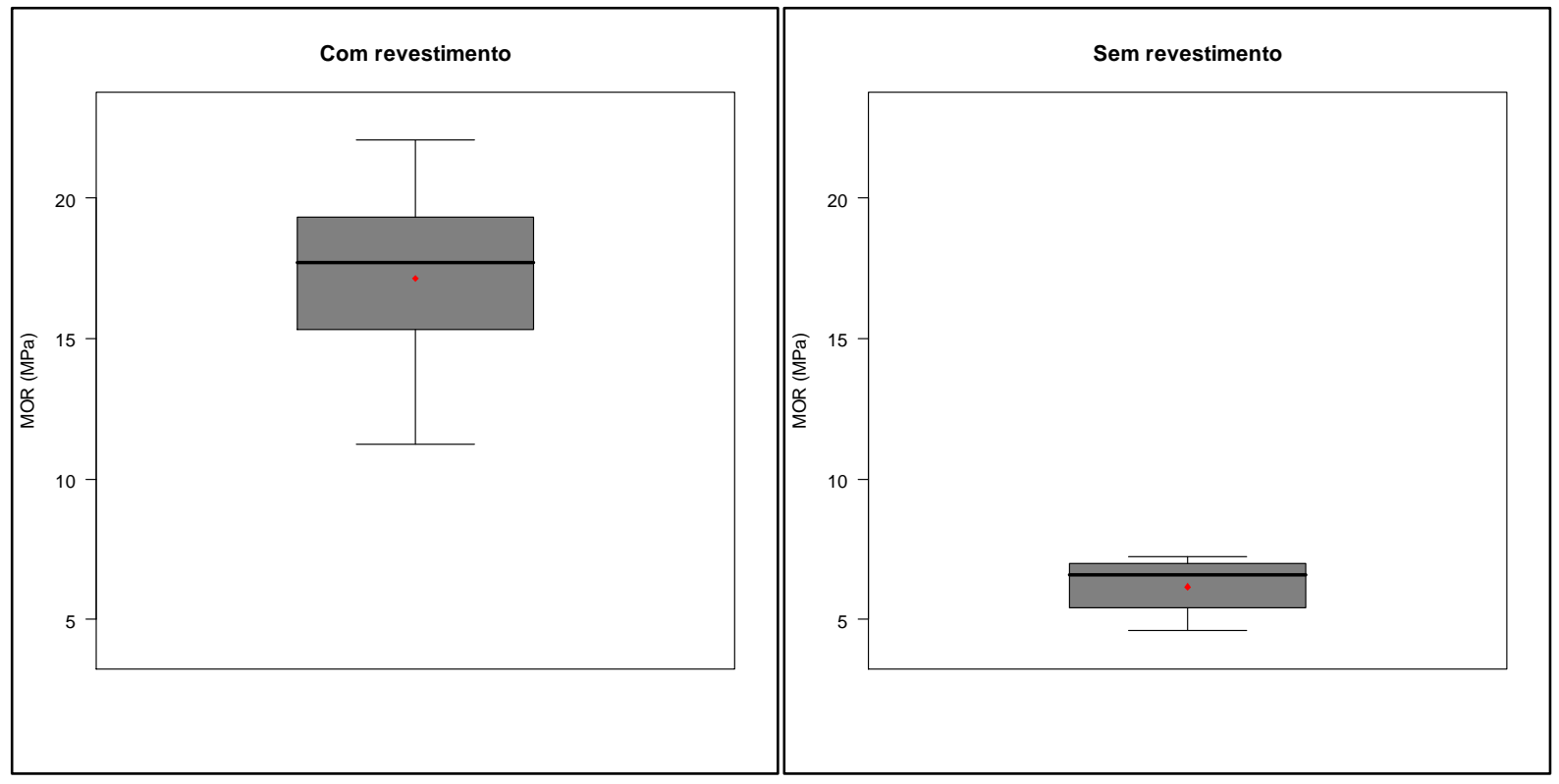

Figura 53 - Gráficos Boxplot do MOR de chapas de partículas com e sem revestimento de resina após envelhecimento natural.

A Figura 54 sumariza a comparação dos valores médios experimentais (MOR) entre os dois tratamentos. Onde se observa uma superioridade de $64,29 \%$ do valor médio das chapas com revestimento em relação ao valor médio das chapas sem revestimento.

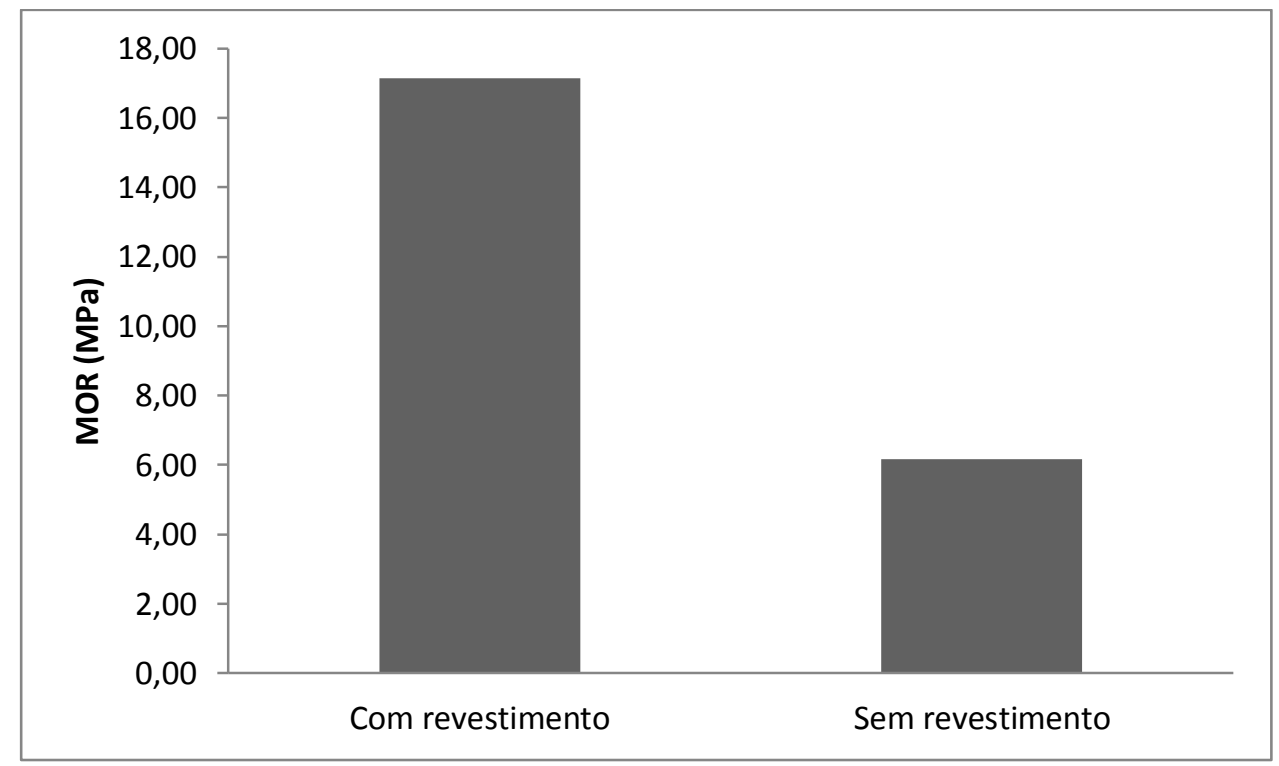

Figura 54 - Gráfico comparativo entre os valores médios experimentais. 


\section{- Análise inferencial}

A Tabela 27 apresenta a análise de variância (ANOVA) para a variável MOR. Observa-se, que o P-valor foi menor que 0,05, podendo afirmar que existe diferença significativa entre os tratamentos do estudo (com revestimento e sem revestimento).

Tabela 27 - ANOVA do MOR de chapas de partículas com bagaço de cana com e sem revestimento após envelhecimento natural.

\begin{tabular}{cccccc}
\hline FV & GL & SQ & QM & Fc & P-valor \\
\hline Tratamento & 1 & 301,40 & 301,40 & 33,11 & $0,0004^{*}$ \\
erro & 8 & 72,81 & 9,10 & & \\
Total corrigido & 9 & 374,21 \\
\hline \multicolumn{5}{c}{ *valor significativo a $\mathrm{p}<0,05}$.
\end{tabular}

\subsubsection{Módulo de elasticidade (MOE)}

\section{- Análise descritiva}

A Tabela 28 apresenta a análise descritiva para a variável MOE. Como medida de tendência central foi utilizada a média aritmética e como medidas de dispersão foi o desvio padrão e coeficiente de variação (CV).

Tabela 28 - MOE médio de chapas de partículas com bagaço de cana com e sem revestimento após envelhecimento natural.

\begin{tabular}{ccc}
\hline MOE & Com revestimento & Sem revestimento \\
\hline Média (MPa) & 2059 & 583 \\
Desv. Padrão (MPa) & 237,46 & 164,44 \\
CV (\%) & 11,53 & 28,22 \\
\hline
\end{tabular}

As chapas com revestimento na superfície externa apresentaram maiores valores médios experimentais para a variável $\mathrm{MOE}$ em relação às chapas sem revestimento de resina. Em relação às medidas de dispersão, as chapas de partículas com revestimento apresentaram CV (\%) menor do que as sem revestimento, demonstrando maior 
homogeneidade para a variável MOE. Os CV (\%) das chapas sem revestimento exibiram uma alta heterogeneidade para esta propriedade mecânica. A Figura 55 representa a dispersão dos conjuntos de dados da variável $\mathrm{MOE}$, onde se observa que as chapas com revestimento tendem a ter uma maior heterogeneidade para essa variável, da mesma forma que para a propriedade MOR.

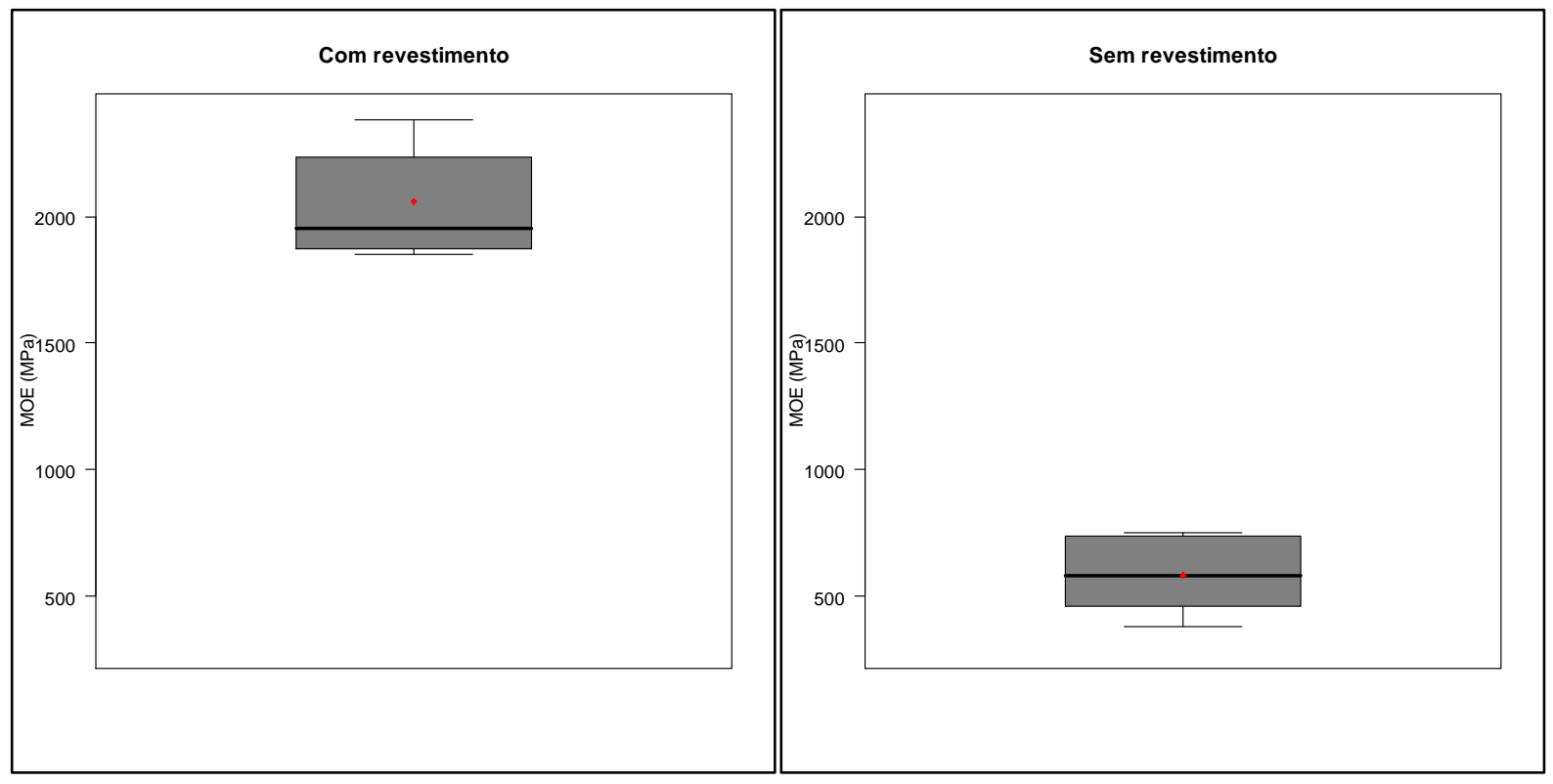

Figura 55 - Gráficos Boxplot do MOE de chapas de partículas com e sem revestimento de resina após envelhecimento natural.

A Figura 56 sumariza a comparação dos valores médios experimentais (MOE) entre os dois tratamentos. Onde se observa uma superioridade de $71,68 \%$ do valor médio das chapas com revestimento em relação ao valor médio das chapas sem revestimento. 


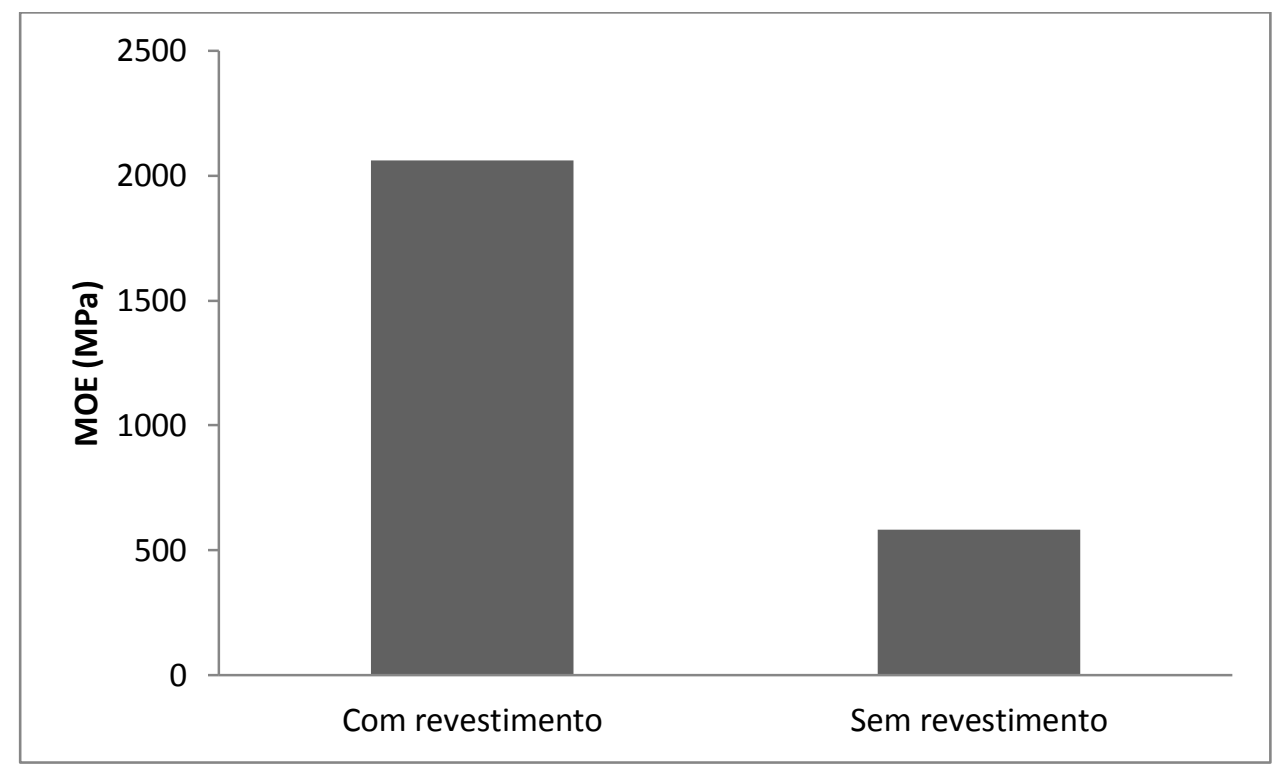

Figura 56 - Gráfico comparativo entre os valores médios experimentais.

\section{- Análise inferencial}

A Tabela 29 apresenta a análise de variância (ANOVA) para a variável MOE. Observa-se, que o P-valor foi menor que 0,05, podendo afirmar que existe diferença significativa entre os tratamentos do estudo (com revestimento e sem revestimento).

Tabela 29 - ANOVA do MOE de chapas de partículas com bagaço de cana com e sem revestimento após envelhecimento natural.

\begin{tabular}{cccccc}
\hline FV & GL & SQ & QM & Fc & P-valor \\
\hline Tratamento & 1 & 5449392,40 & 5449392,40 & 130,638 & $0,0000^{*}$ \\
erro & 8 & 333709,20 & 41713,65 & & \\
Total corrigido & 9 & 57831001,60 \\
\hline \multicolumn{5}{c}{ *valor significativo a $p<0,05}$.
\end{tabular}

\subsubsection{Envelhecimento acelerado}

Na Figura 57 pode ser observado a delaminação e deformações ocorridas nos CP após o término de todos os ciclos do ensaio de envelhecimento acelerado. Foi notável a interferência da aplicação do revestimento com a resina de mamona na superfície dos $C P$, 
sendo aqueles com revestimento os que apresentaram menores delaminação e deformação, além de propriedades mecânicas superiores aos sem revestimento superficial.
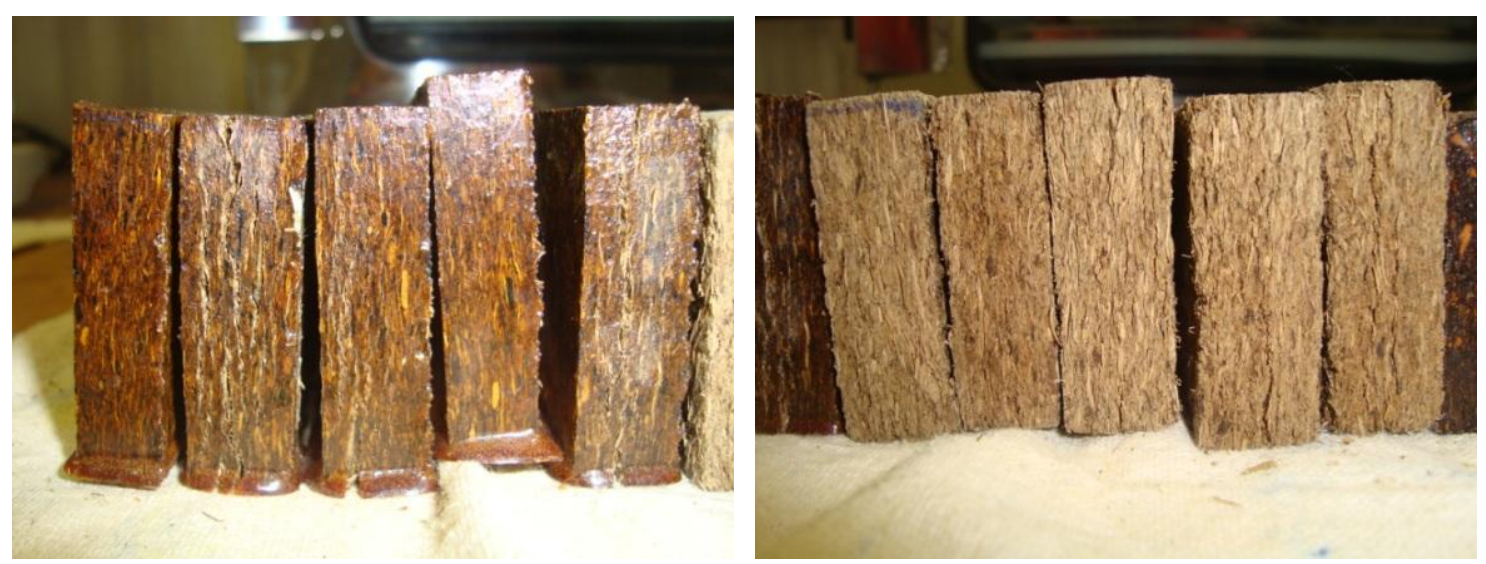

Figura 57 - CP com e sem resina após ciclo de envelhecimento.

\subsubsection{Módulo de ruptura (MOR)}

\section{- Análise descritiva}

A Tabela 30 apresenta a análise descritiva para a variável MOR. Como medida de tendência central foi utilizada a média aritmética e como medidas de dispersão foi o desvio padrão e coeficiente de variação (CV).

Tabela 30 - MOR médio de chapas de partículas com bagaço de cana com e sem revestimento após envelhecimento acelerado.

\begin{tabular}{ccc}
\hline MOR & Com revestimento & Sem revestimento \\
\hline Média (MPa) & 14,88 & 6,25 \\
Desv. Padrão (MPa) & 2,14 & 0,61 \\
CV (\%) & 14,38 & 9,69 \\
\hline
\end{tabular}

As chapas com revestimento na superfície externa apresentaram maiores valores médios experimentais para a variável MOR em relação às chapas sem revestimento com a resina. Em relação às medidas de dispersão, as chapas de partículas com revestimento superficial apresentaram CV (\%) maior do que as sem revestimento, demonstrando menor 
homogeneidade para a variável MOR. Os CV (\%) das chapas (com revestimento e sem revestimento) exibiram uma baixa heterogeneidade para esta característica mecânica. A Figura 58 representa a dispersão dos conjuntos de dados da variável MOR, onde se observa que as chapas com revestimento tendem a ter uma maior heterogeneidade para essa variável. Mesmo com a presença de dois pontos outliers, no conjunto de dados para as chapas sem revestimento, o CV (\%) ainda permaneceu baixo.

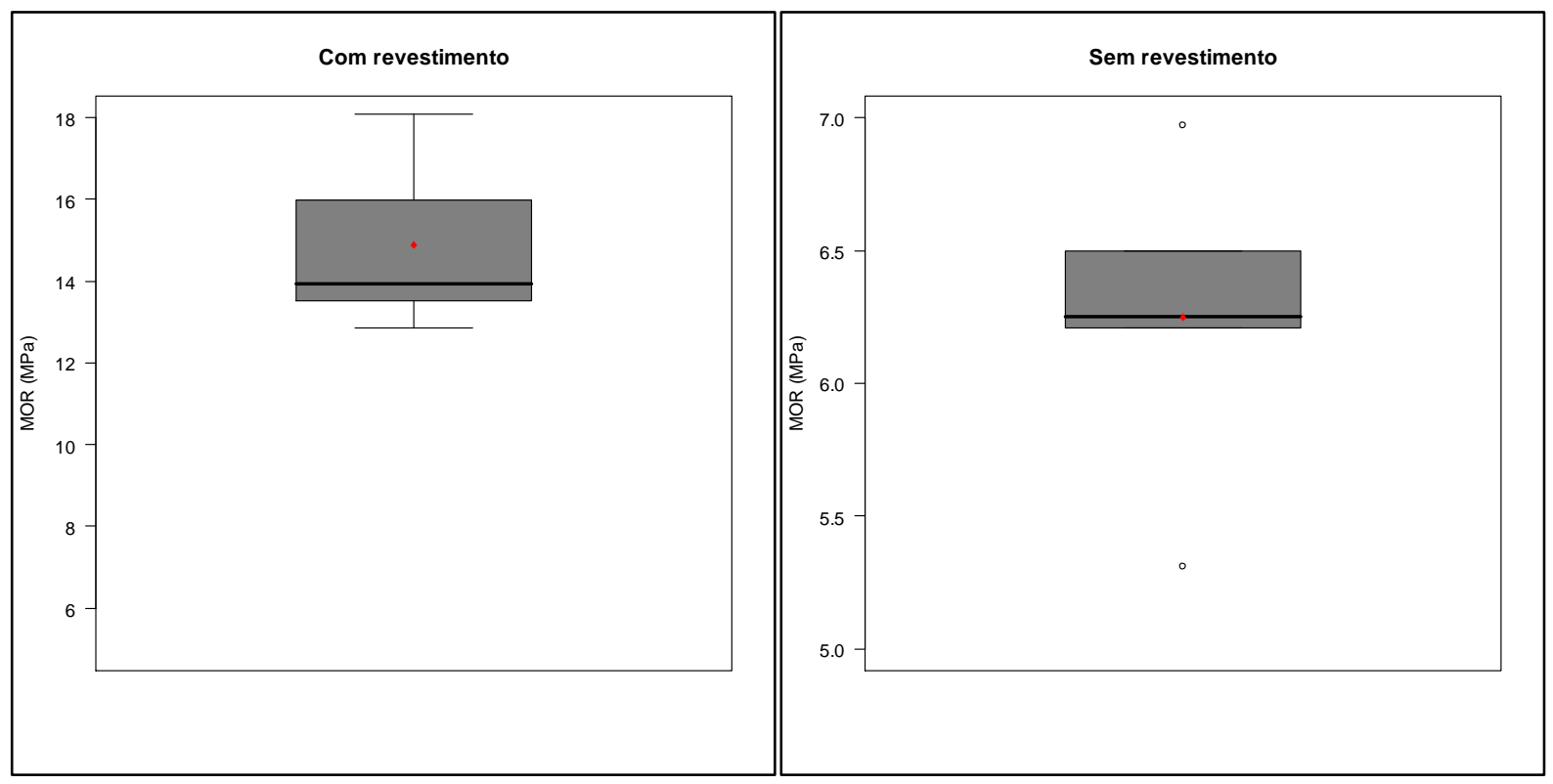

Figura 58 - Gráficos Boxplot do MOR de chapas de partículas com e sem revestimento de resina após envelhecimento acelerado.

A Figura 59 sumariza a comparação dos valores médios experimentais (MOR) entre os dois tratamentos. Onde se observa uma superioridade de $58 \%$ do valor médio das chapas com revestimento em relação ao valor médio das chapas sem revestimento. 


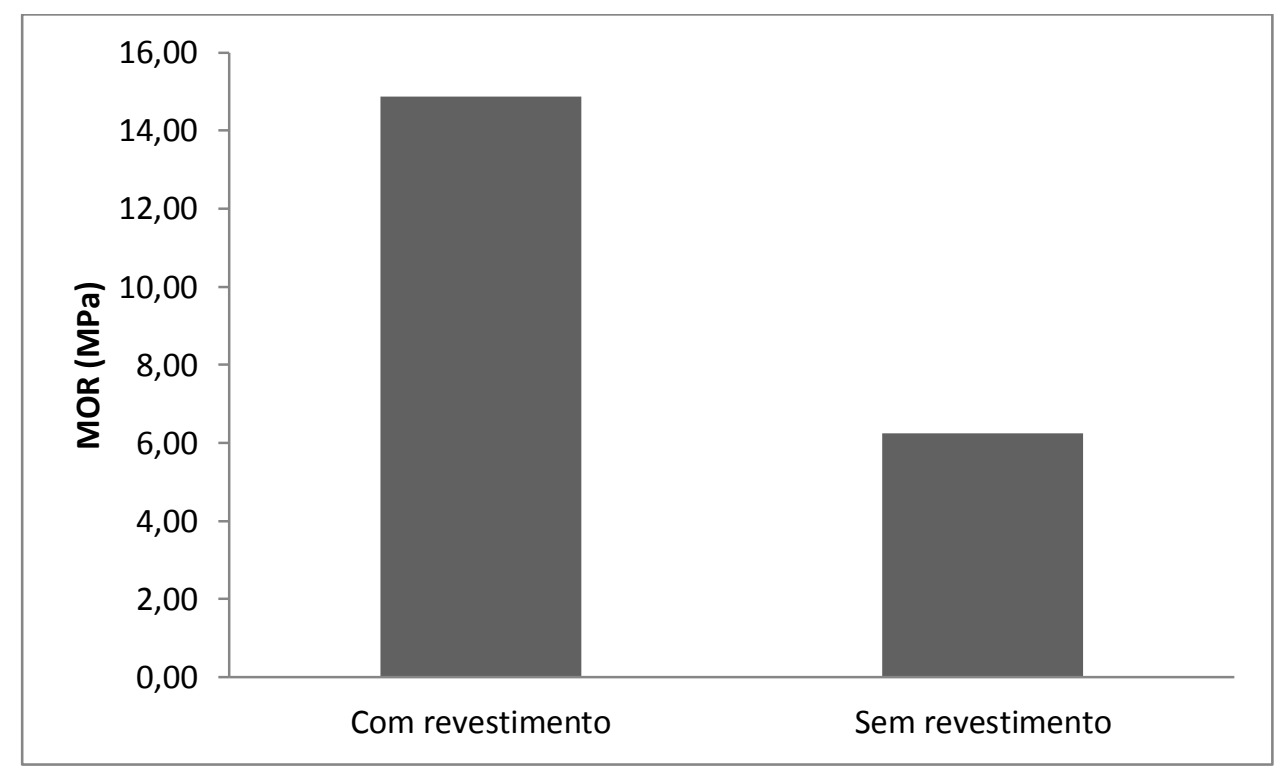

Figura 59 - Gráfico comparativo entre os valores médios experimentais.

\section{- Análise inferencial}

A Tabela 31 apresenta a análise de variância (ANOVA) para a variável MOR. Observa-se, que o P-valor foi menor que 0,05, podendo afirmar que existe diferença significativa entre os tratamentos do estudo (com revestimento e sem revestimento).

Tabela 31 - ANOVA do MOR de chapas de partículas com bagaço de cana com e sem revestimento após envelhecimento acelerado.

\begin{tabular}{cccccc}
\hline FV & GL & SQ & QM & Fc & P-valor \\
\hline Tratamento & 1 & 186,36 & 186,36 & 75,342 & $0,0000^{*}$ \\
erro & 8 & 19,78 & 2,47 & & \\
Total corrigido & 9 & 206,15 \\
\hline \multicolumn{5}{c}{ *valor significativo a $p<0,05}$.
\end{tabular}

\subsubsection{Módulo de elasticidade (MOE)}

\section{- Análise descritiva}

A Tabela 32 apresenta a análise descritiva para a variável MOE. Como medida de tendência central foi utilizada a média aritmética e como medidas de dispersão foi o desvio padrão e coeficiente de variação (CV). 
Tabela 32 - MOE médio de chapas de partículas com bagaço de cana com e sem revestimento após envelhecimento acelerado.

\begin{tabular}{ccc}
\hline MOE & Com revestimento & Sem revestimento \\
\hline Média (MPa) & 1534 & 523 \\
Desv. Padrão (MPa) & 370,52 & 87,57 \\
CV (\%) & 24,17 & 16,75 \\
\hline
\end{tabular}

As chapas com revestimento superficial externo apresentaram maiores valores médios experimentais para a variável $\mathrm{MOE}$ em relação às chapas sem revestimento de resina. Em relação às medidas de dispersão, as chapas de partículas com revestimento apresentaram CV (\%) maior do que as sem revestimento, demonstrando menor homogeneidade para a variável MOE. Os CV (\%) das chapas com revestimento exibiram uma alta heterogeneidade para esta característica mecânica. A Figura 60 representa a dispersão dos conjuntos de dados da variável $\mathrm{MOE}$, onde se observa que as chapas com revestimento tendem a ter uma maior heterogeneidade para essa variável, seguindo a mesma tendência para a propriedade MOR. Assim como também foi constatado a presença de pontos outliers para a propriedade MOR, sendo neste caso para o MOE apenas um, no conjunto de dados para as chapas sem revestimento, o CV (\%) ainda permaneceu menor que para as chapas com revestimento.

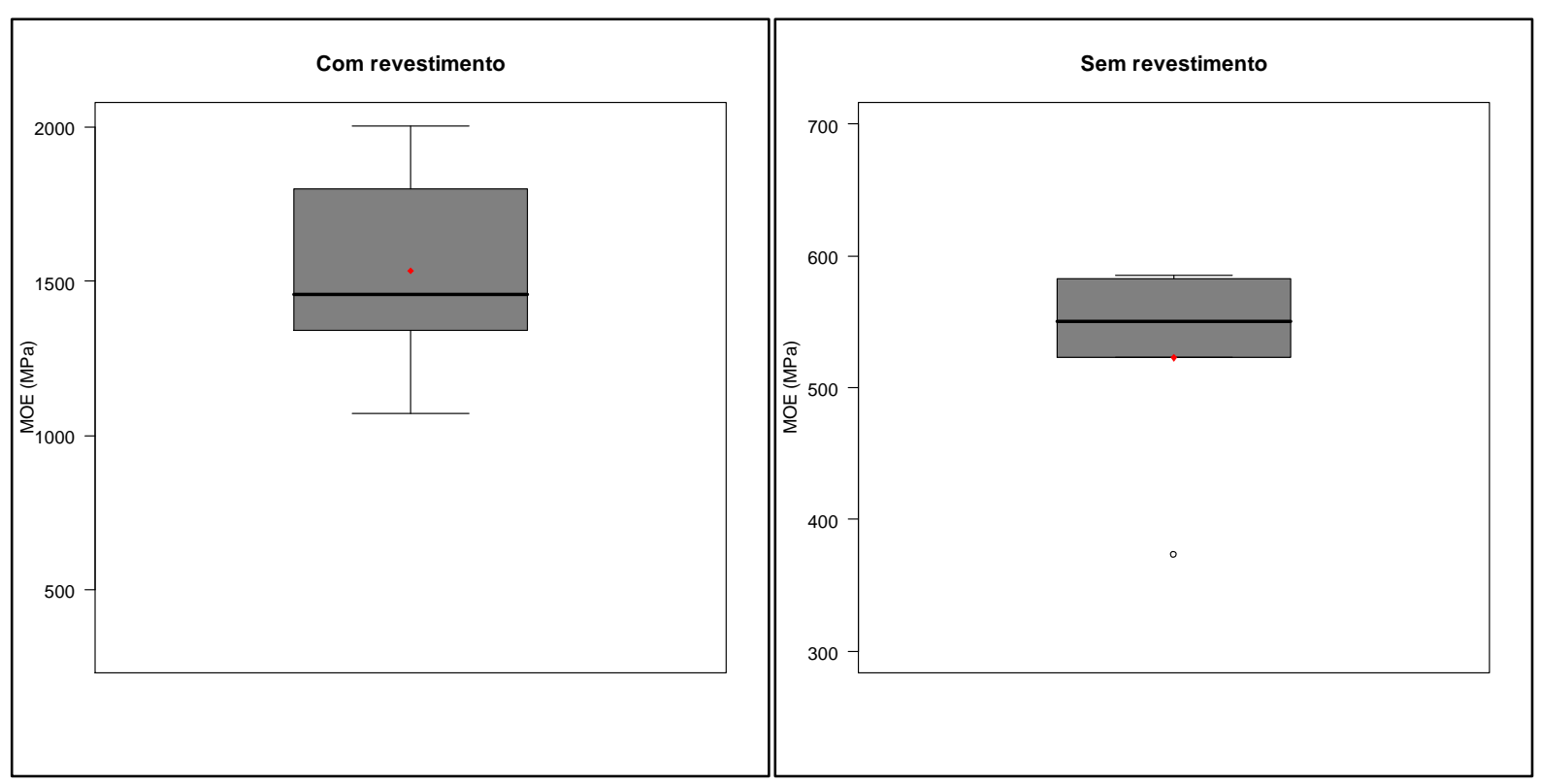

Figura 60 - Gráficos Boxplot do MOE de chapas de partículas com e sem revestimento de resina após envelhecimento acelerado. 
A Figura 61 sumariza a comparação dos valores médios experimentais (MOE) entre os dois tratamentos. Onde se observa uma superioridade de $65,90 \%$ do valor médio das chapas com revestimento em relação ao valor médio das chapas sem revestimento.

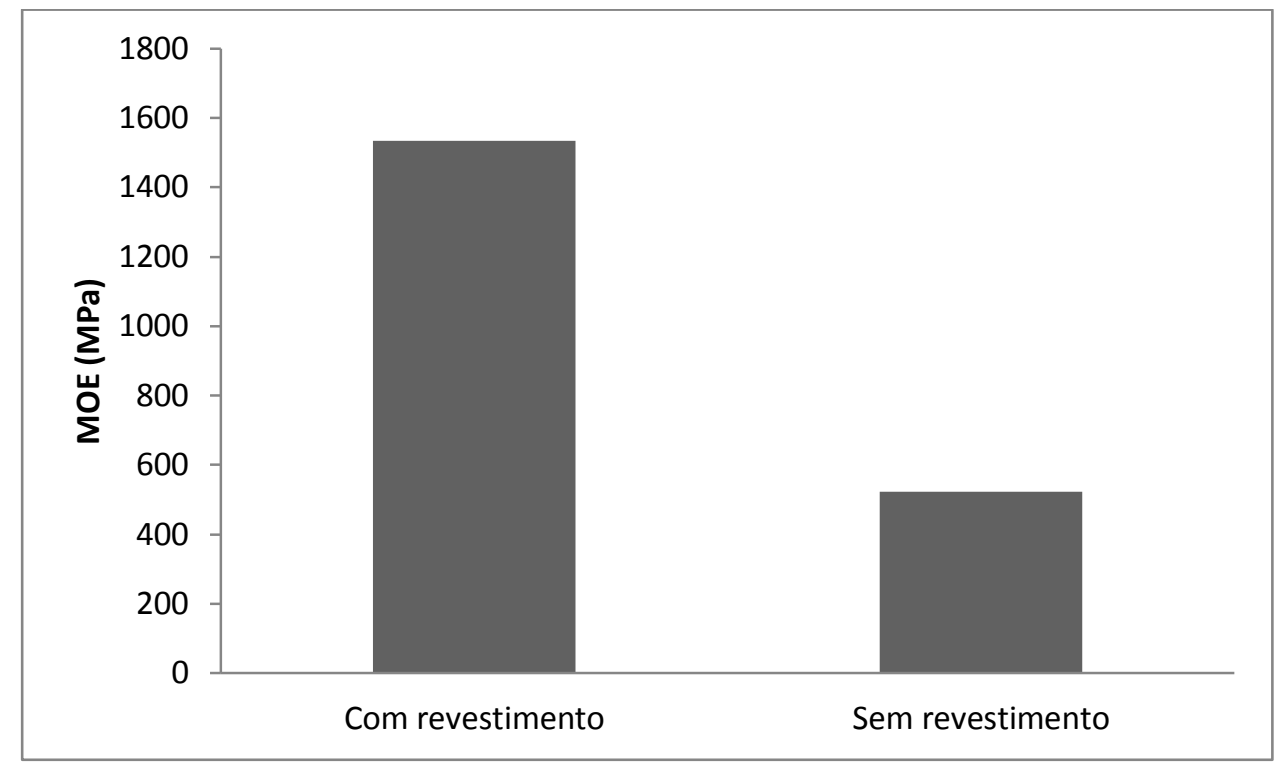

Figura 61 - Gráfico comparativo entre os valores médios experimentais.

\section{- Análise inferencial}

A Tabela 33 apresenta a análise de variância (ANOVA) para a variável MOE. Observa-se, que o P-valor foi menor que 0,05, podendo afirmar que existe diferença significativa entre os tratamentos do estudo (com revestimento e sem revestimento).

Tabela 33 - ANOVA do MOE de chapas de partículas com bagaço de cana com e sem revestimento após envelhecimento acelerado.

\begin{tabular}{cccccc}
\hline FV & GL & SQ & QM & Fc & P-valor \\
\hline Tratamento & 1 & 2554291,60 & 2554291,60 & 35,225 & $0,0003^{*}$ \\
erro & 8 & 580108,00 & 72513,50 \\
Total corrigido & 9 & 3134399,60 & & \\
\hline \multicolumn{5}{c}{ *valor significativo a $\mathrm{p}<0,05}$.
\end{tabular}




\subsection{Microscopia eletrônica de varredura (MEV)}

Neste item são apresentadas as figuras referentes à análise por microscopia eletrônica de varredura das chapas aglomeradas de partículas, produzidas com o bagaço da Usina A, com tamanhos de partículas diferentes (de até 8 e $5 \mathrm{~mm}$ ) e de envelhecimento (natural e acelerado).

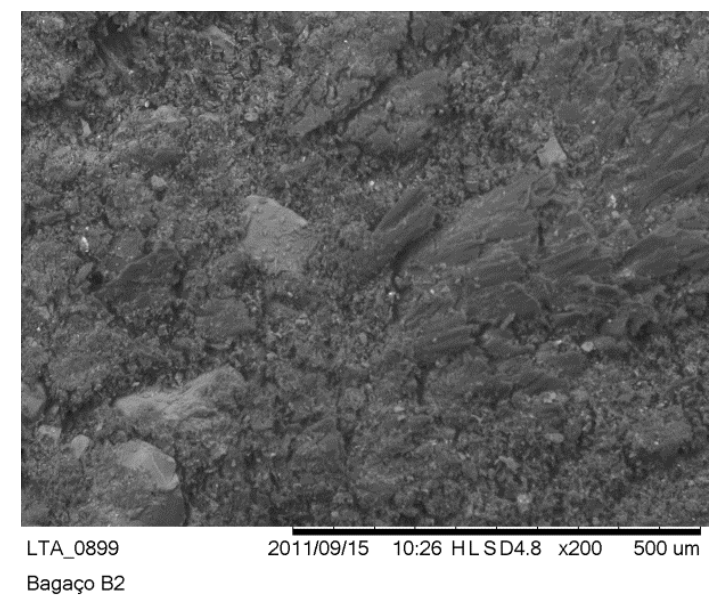

(a)

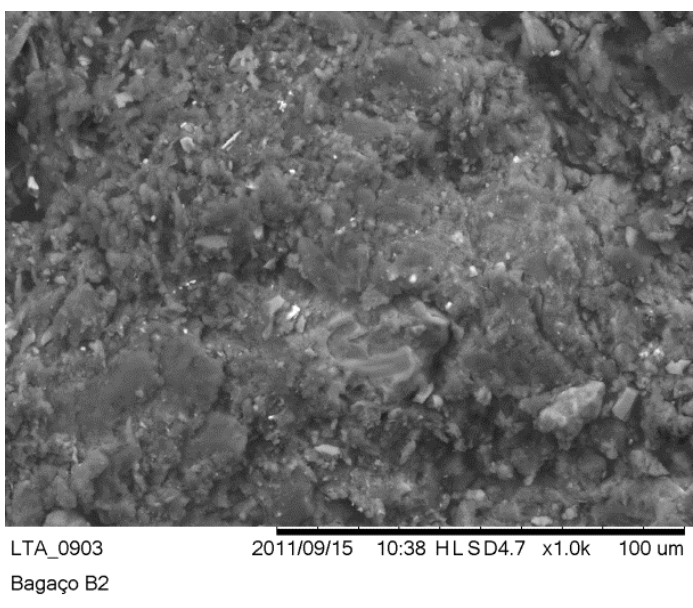

(b)

Figura 62 - Chapa de bagaço da Usina A em aumento de 200X (a) e 1000X (b).

Como apresentado na análise bromatológica (Item 4.1.1), os bagaços de cana-deaçúcar das duas diferentes Usinas (Usina A e B) foram submetidos a esta análise para comprovar a suspeita de que havia algum tipo de material misturado ao mesmo, que comprometeu as propriedades mecânicas das chapas produzidas. E como foi constatado, pelo alto índice de matéria mineral na amostra da Usina A, a suspeita de presença de terra ficou comprovada. Sendo possível notar essa presença nas Figuras $62 \mathrm{a}$ e $62 \mathrm{~b}$ pela presença de vários pontos nas imagens de MEV, conferindo o aspecto granulado ao material. 


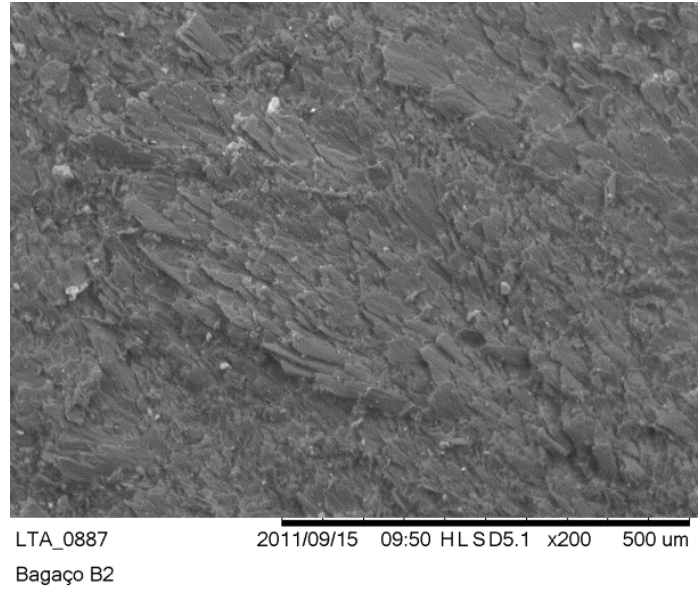

(a)

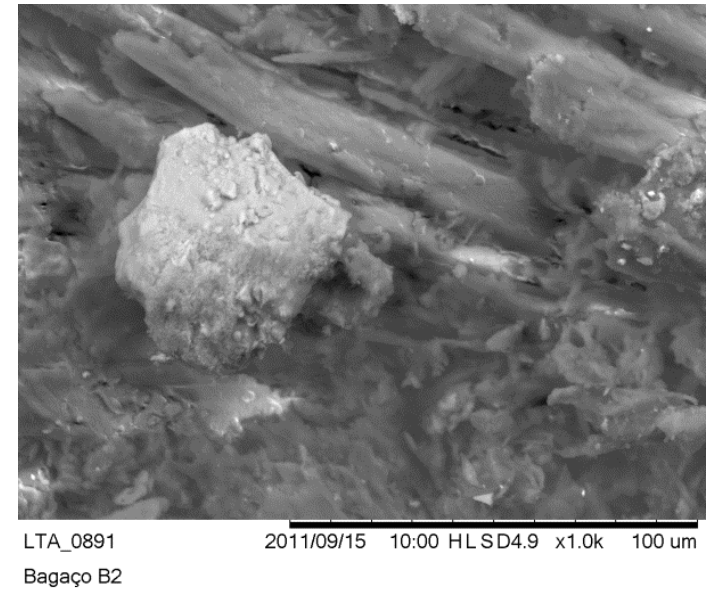

(b)

Figura 63 - Chapa de partículas com dimensões de até 8 mm em aumento de 200X (a) e 1000X (b).

As Figuras 63a e 63b apresentam imagens da amostra da chapa produzida com partículas de tamanho de até $8 \mathrm{~mm}$. Nota-se uma boa homogeneidade da chapa (Figura 63a), que não contem espaços vazios sem preenchimento com material e boa dispersão das fibras do bagaço de cana-de-açúcar e a resina poliuretana a base de óleo de mamona. $\mathrm{Na}$ Figura 63b tem-se o destaque para um ponto de cor mais clara, que demonstra um possível ponto de resina entre as fibras de bagaço.

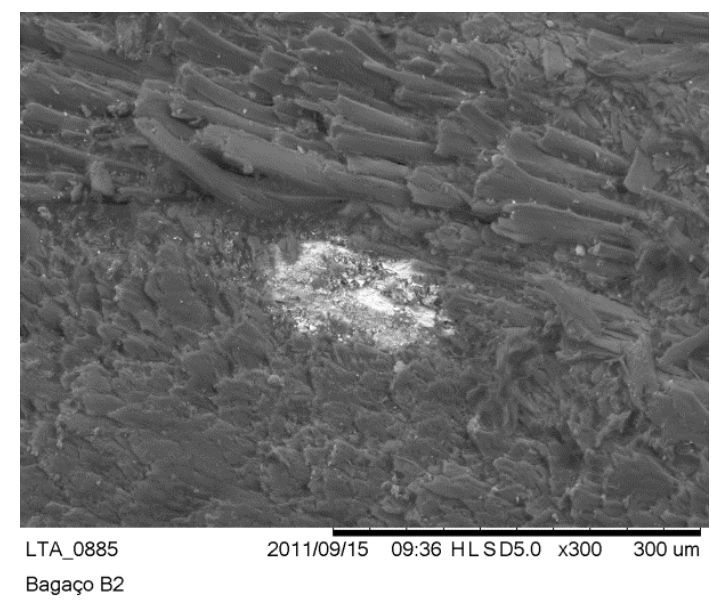

(a)

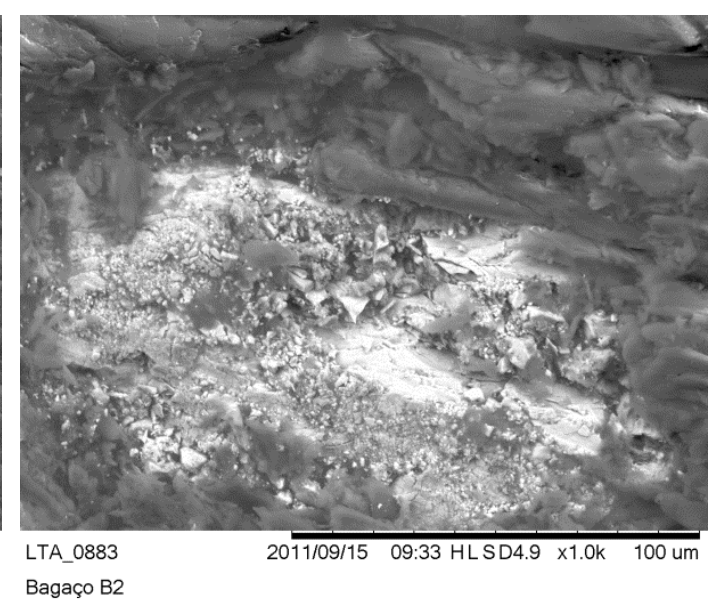

(b)

Figura 64 - Chapa de partículas com dimensões de até $5 \mathrm{~mm}$ em aumento de $300 \mathrm{X}$ (a) e 1000X (b).

Nas Figuras 64a e 64b é apresentada imagens da amostra das chapas produzidas com partículas de tamanho de até $5 \mathrm{~mm}$. Assim como nas imagens da amostra das chapas de partículas de até $8 \mathrm{~mm}$, não é possível notar a presença de espaços vazios no material e 
certa regularidade na dispersão das fibras e da resina. Na Figura 64b é destacada uma mancha de coloração mais clara, que possivelmente ocorreu um acúmulo de resina na amostra, sendo um fato isolado a região que a amostra foi retirada.

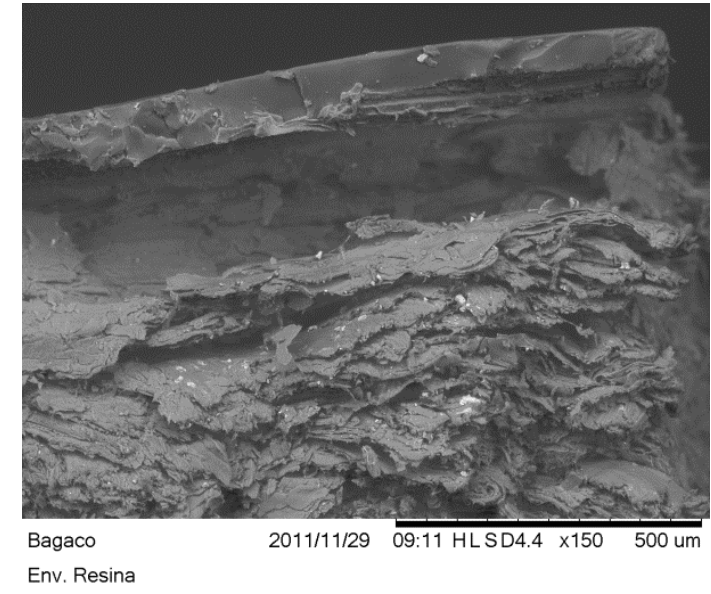

(a)

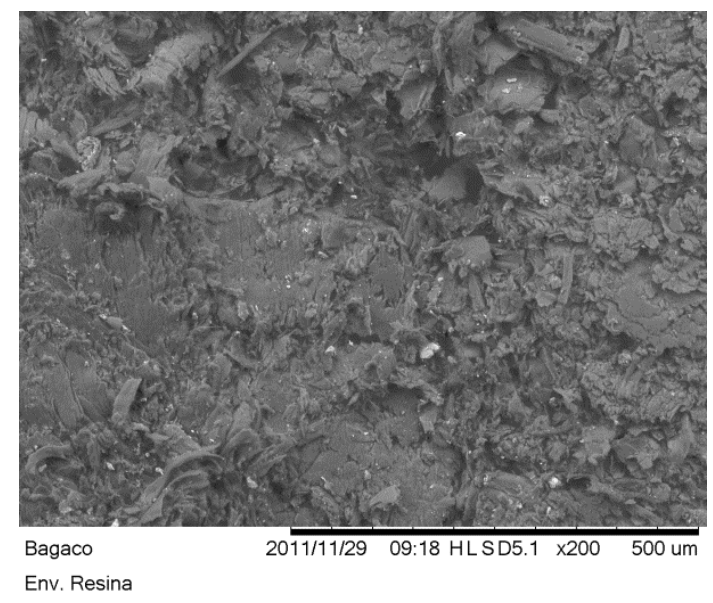

(c)

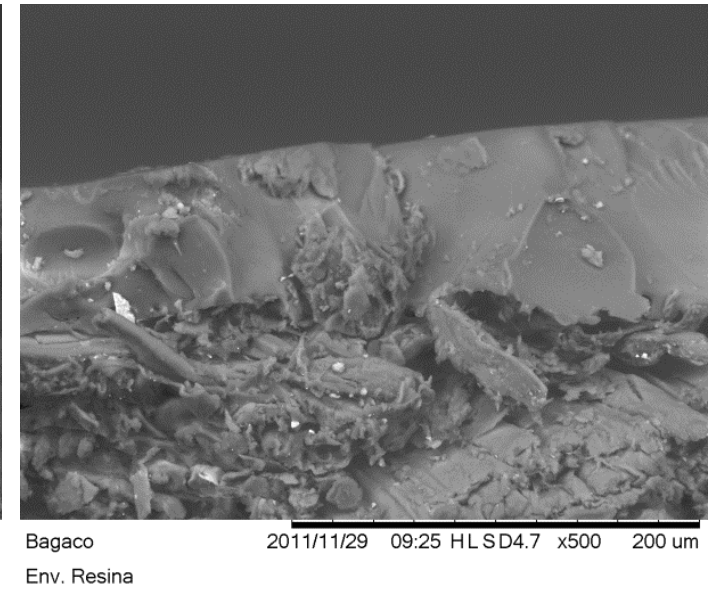

(b)

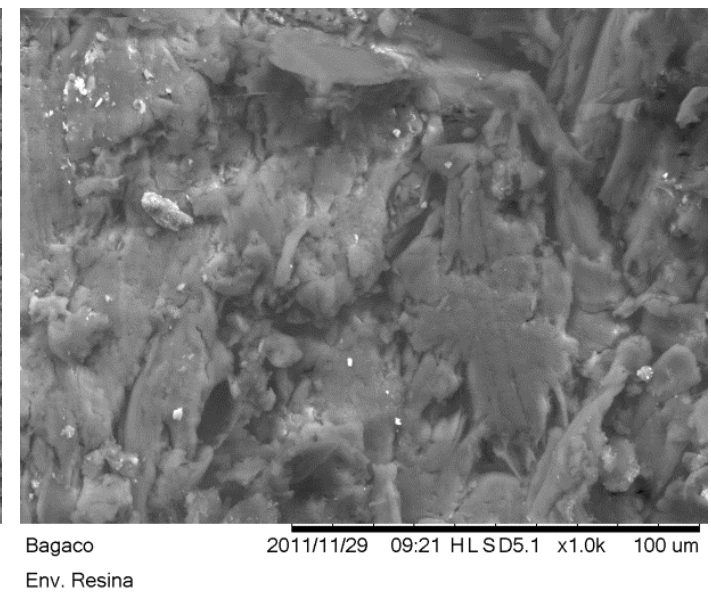

(d)

Figura 65 - Chapa de envelhecimento natural com aplicação externa de resina em aumento de 150X destacando a borda (a), 500X destacando a borda (b), 200X (c) e 1000X (d).

Nas imagens da Figura 65 é apresentada a análise da amostra retirada da chapa que passou pelo processo de envelhecimento natural com a aplicação externa de resina. As Figuras 65a e 65b demonstram a camada de resina formada na superfície da borda da chapa. Nas Figuras 65c e 65d pode ser notada uma leve alteração no aspecto e arranjo das fibras do material, em comparação com as do não envelhecido (Figuras 63 e 64), demonstrando uma certa degradação devido a exposição as intempéries do clima no período de 6 meses. 


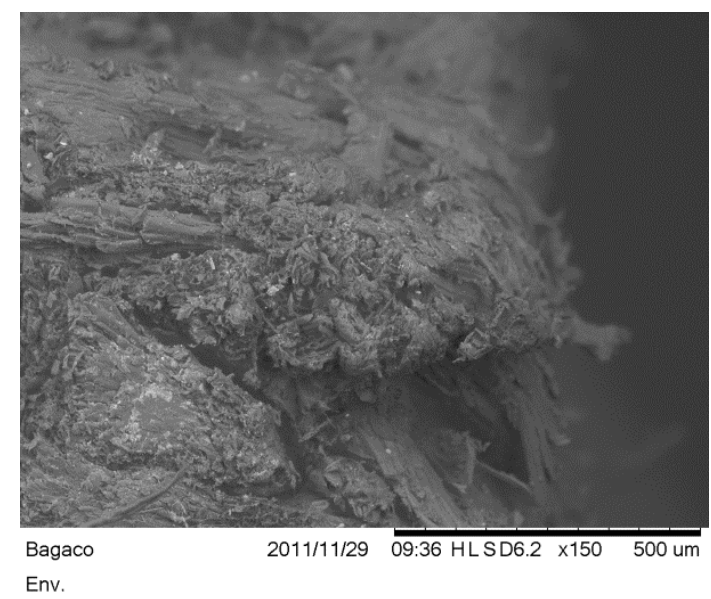

(a)

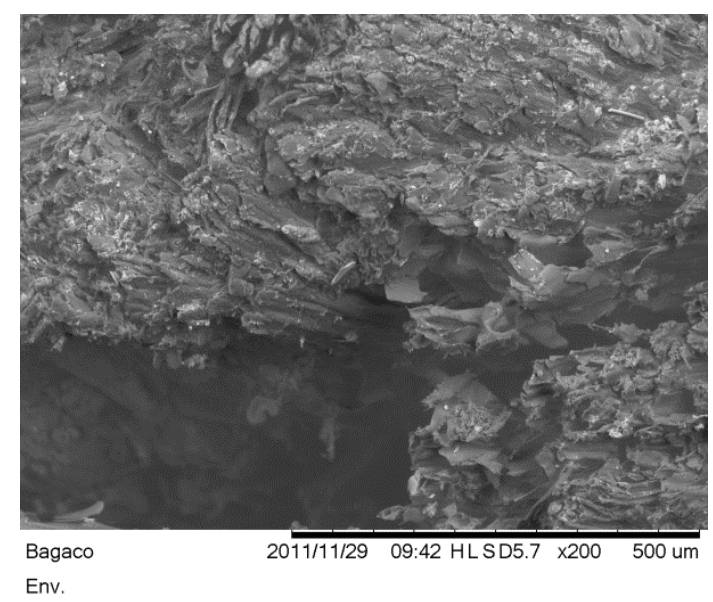

(c)

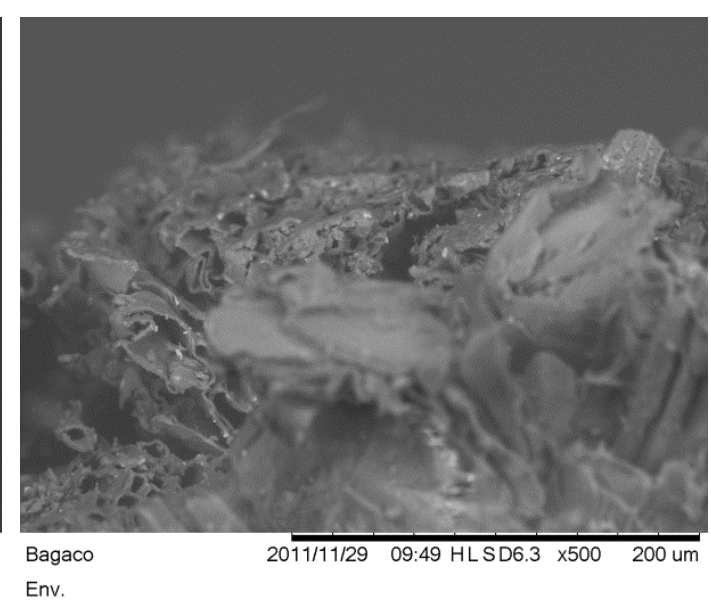

(b)

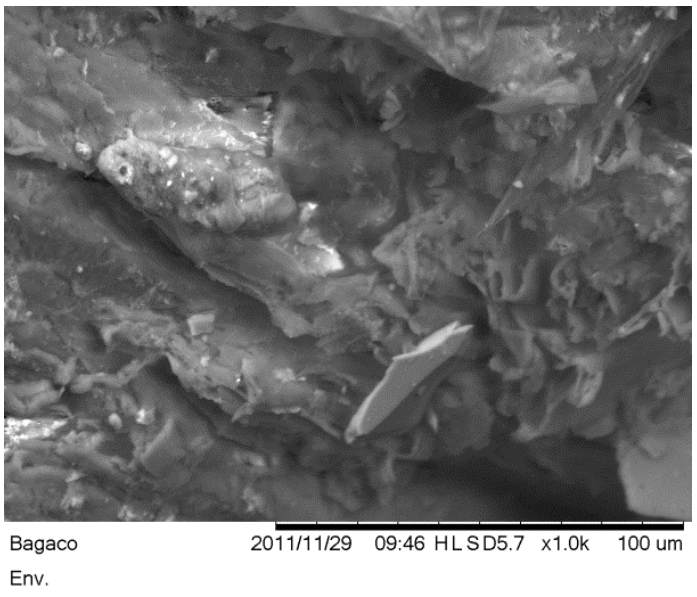

(d)

Figura 66 - Chapa de envelhecimento natural sem aplicação externa de resina em aumento de 150X destacando a borda (a), 500X destacando a borda (b), 200X (c) e 1000X (d).

Nas imagens da Figura 66 é apresentada a análise da amostra retirada da chapa que passou pelo processo de envelhecimento natural sem aplicação de resina em sua superfície. As Figuras 66a e 66b detalham a borda da amostra, que comparada com as imagens da chapa com revestimento (Figuras 65a e 65b), demonstram uma grande irregularidade devido a falta da camada protetora de resina, provocada pela exposição às intempéries climáticas. O mesmo pode ser notado na parte mais interna da amostra (Figuras 66c e 66d), onde observa-se um maior desarranjo das fibras e o aparecimento de espaços vazios sem o material. 


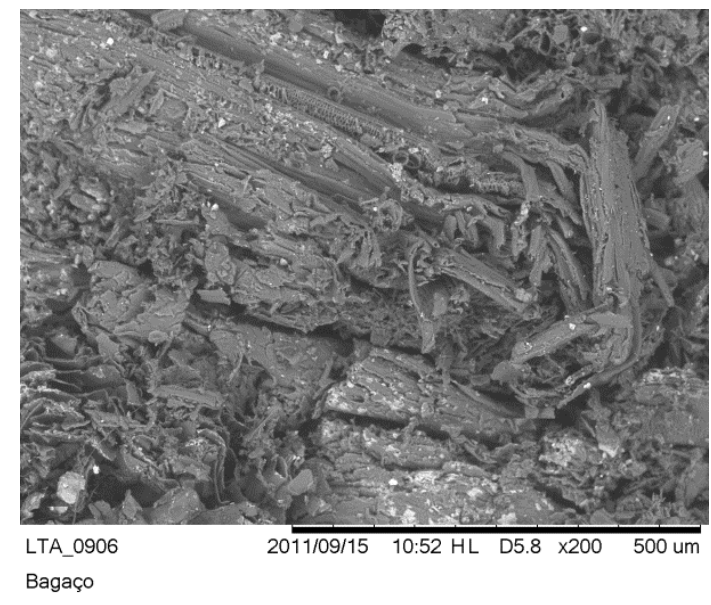

(a)

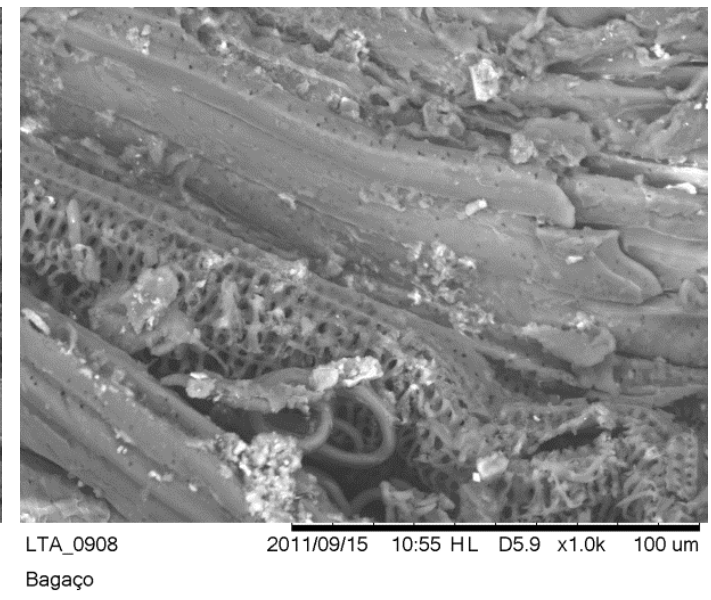

(b)

Figura 67 - Chapa de envelhecimento acelerado em aumento de 200X (a) e 1000X (b).

A Figura 67 representa a análise da amostra da chapa submetida ao envelhecimento acelerado. Nas Figuras 67 a e $67 \mathrm{~b}$ pode ser observada a alteração do aspecto morfológico das fibras do bagaço de cana-de-açúcar, sofridas após os ciclos de envelhecimento. Demonstrando a agressividade que o material é submetido neste ensaio, pela grande degradação sofrida pelo material e mais especificamente das fibras.

\subsection{Painel portante}

\subsubsection{Montagem do protótipo}

Para a montagem do painel portante (Figura 68) para fechamento lateral em centro de manejo para bovinos, foram utilizadas duas vigas e quatro travessas de madeira serrada do gênero eucalyptus sp., oriundas de reflorestamento, e quatro chapas $(\mathrm{e}=2 \mathrm{~cm})$ aglomeradas de bagaço de cana-de-açúcar e resina poliuretana bi componente à base de óleo de mamona. 

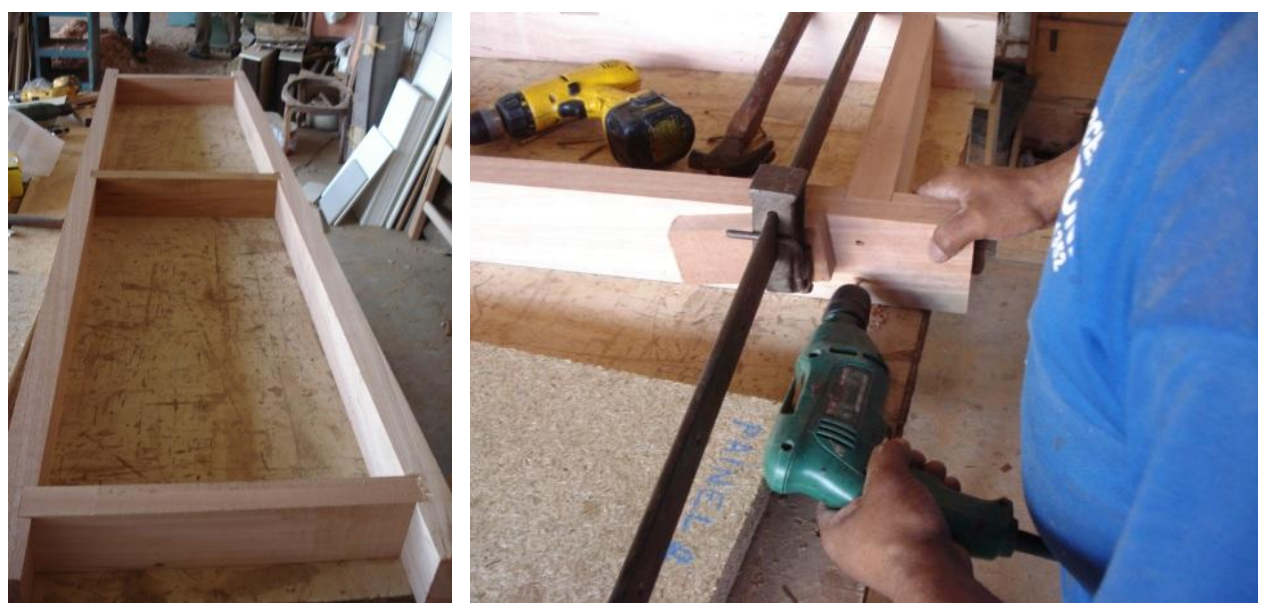

Figura 68 - Montagem da estrutura em madeira do protótipo.

As vigas de madeira possuíam dimensões de $220 \times 5 \times 11 \mathrm{~cm}$ e a cada $41,19 \mathrm{~cm}$ foram fixadas travessas de madeira, com dimensões de $6 \times 42 \times 11 \mathrm{~cm}$, com o objetivo de garantir estabilidade à estrutura.

Foram utilizadas quatro chapas aglomeradas, com dimensões de $52 \times 52 \times 2 \mathrm{~cm}$, que foram parafusadas em suas extremidades, diretamente nas vigas e travessas (Figura 69).
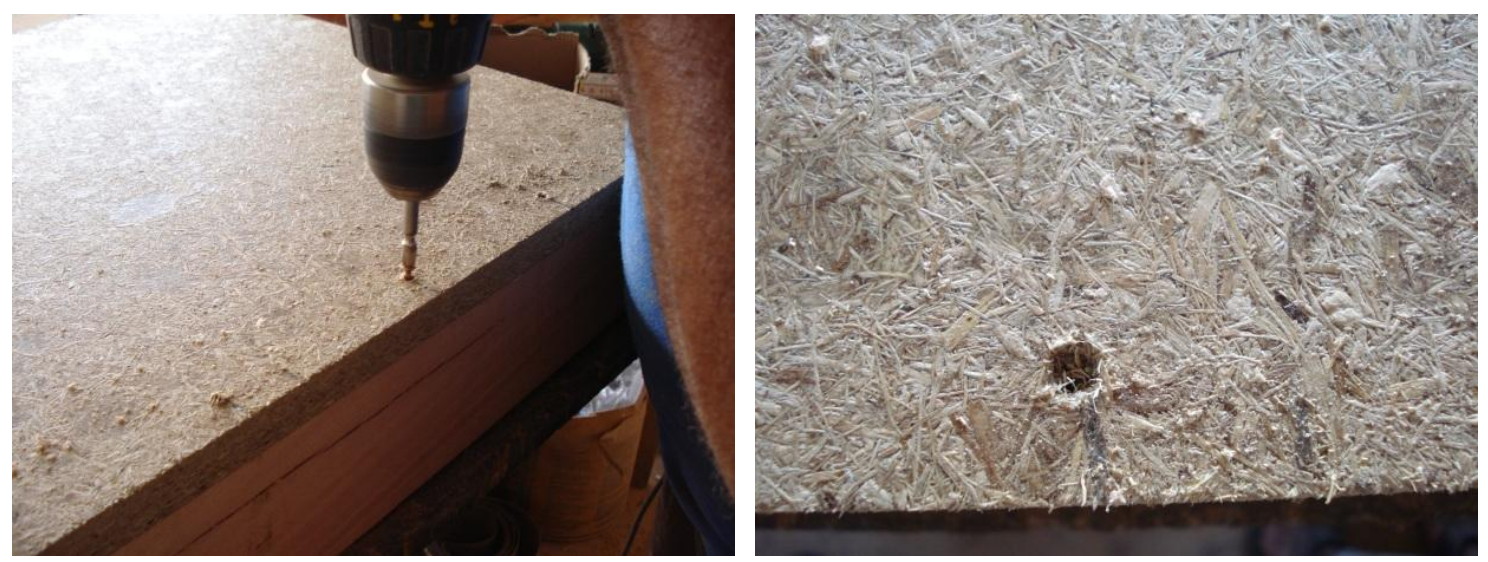

Figura 69 - Parafusamento das chapas aglomeradas na estrutura de madeira.

O painel portante para fechamento lateral após o término de sua montagem ficou com dimensões de $220 \times 52 \times 13 \mathrm{~cm}$ (Figura 70). Suas dimensões foram determinadas para que fossem as mais próximas possíveis das dimensões utilizadas em brete e seringas de centros de manejo para bovinos. A altura foi estipulada pela altura da parede de um brete real, sendo de até $200 \mathrm{~cm}$, assim considerando a altura somente das chapas, teve-se $208 \mathrm{~cm}$. 
Sobre sua largura, de $52 \mathrm{~cm}$, ficou reduzida pela limitação da capacidade da prensa hidráulica, sendo o limite para produção de painéis com essas dimensões de $52 \times 52 \mathrm{~cm}$.

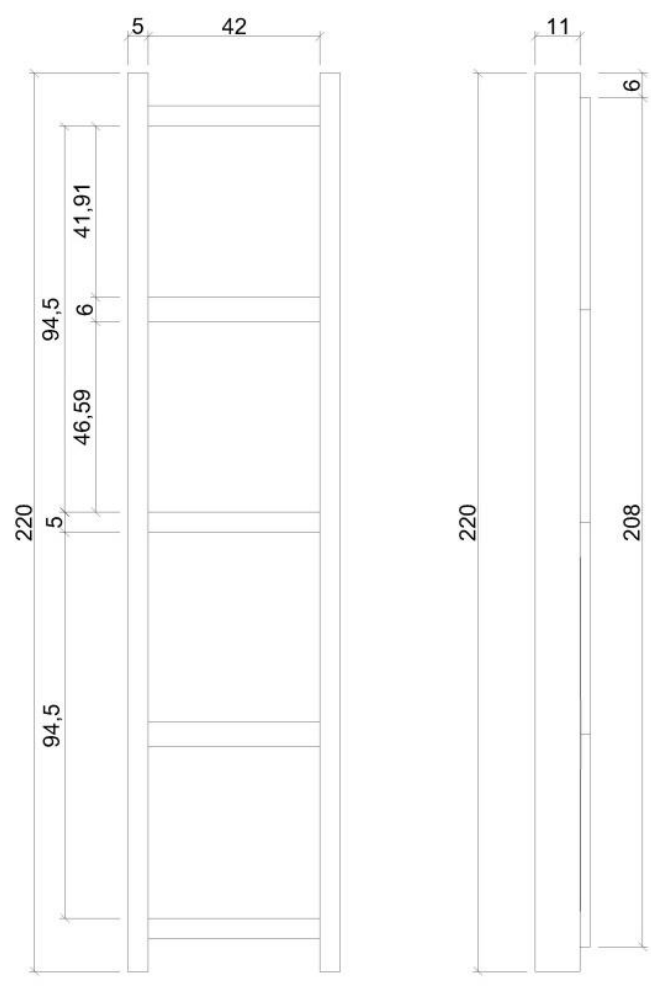

Figura 70 - Vista lateral e posterior do protótipo e suas dimensões em centímetros.

A Figura 71 apresenta o painel portante para fechamento lateral de brete e seringa.
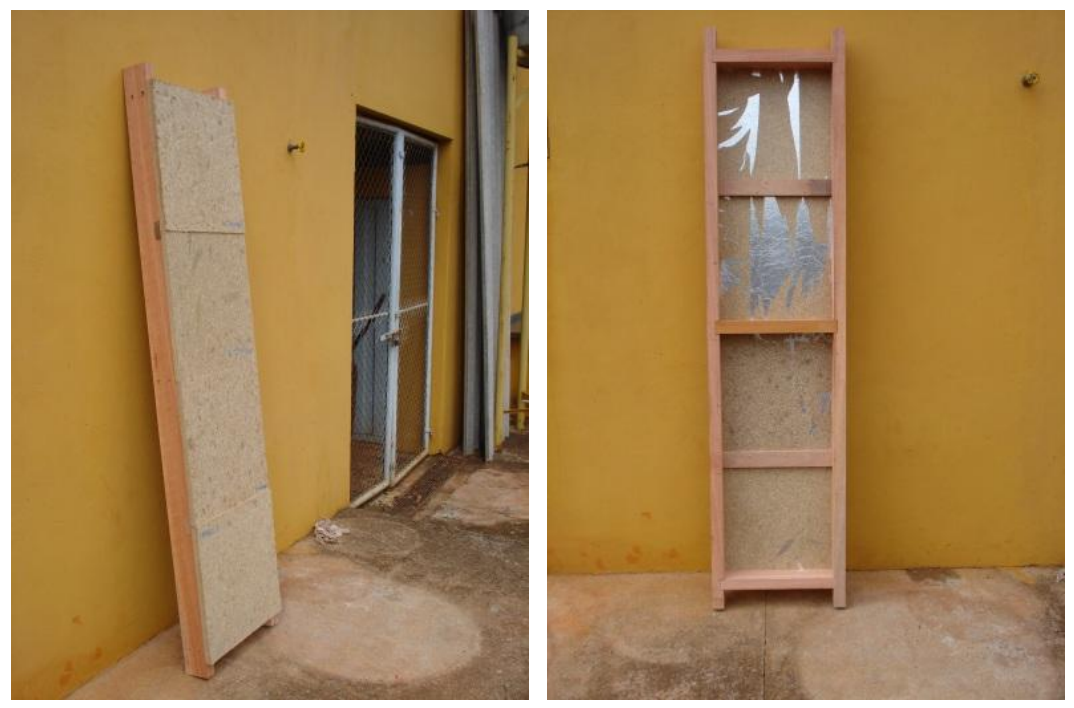

Figura 71 - Protótipo após finalização da montagem. 


\subsubsection{Modelo 3D do protótipo aplicado como painel de fechamento lateral}

Neste item serão apresentadas as imagens em 3D do painel portante e do modelo de centro de manejo para bovinos desenvolvido no Software Google SketchUp 8, de acordo com o modelo desenvolvido por Grandin (1997) como mencionado no Item 3.4.8.2.

A Figura 72 representa quatro diferentes vistas do painel portante, feito com as mesmas dimensões que o real, para que fosse usado como base para o desenvolvimento do centro de manejo.

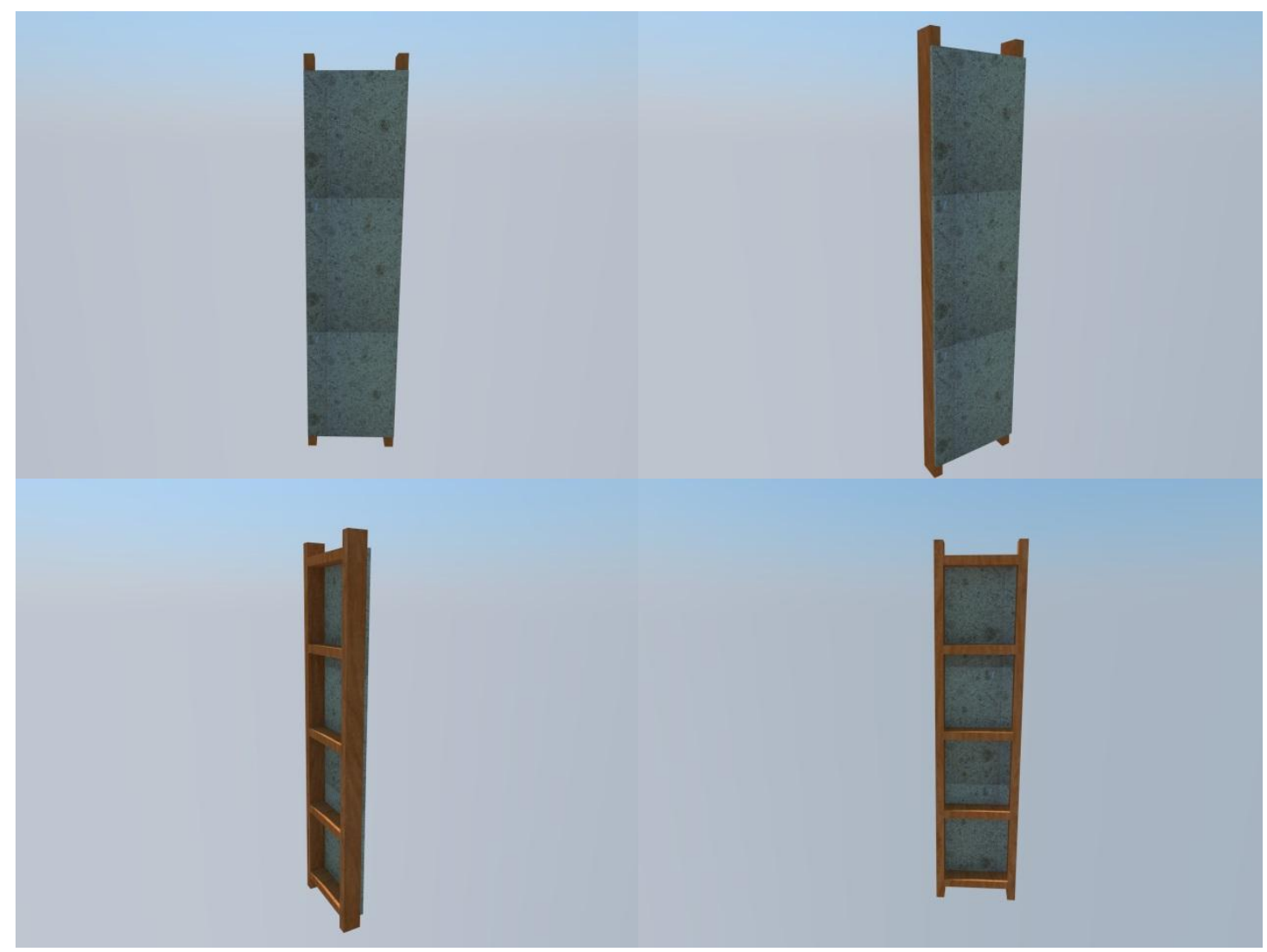

Figura 72 - Vistas do painel portante em 3D.

A Figura 73 destaca a seringa em formato de circulo, projetada com os painéis portantes. Pode-se visualizar a possibilidade da construção de seringas e bretes, como descrito por Grandin (1997); Bicudo et al. (2002); Huhnke e Harp (2009) que demonstram a preocupação de se construir laterais completamente fechadas e em curva, com objetivo de impedir que os animais vejam do lado externo das paredes, não permitindo que se distraiam 
com a movimentação externa e também aproveitar do comportamento bovino, de quererem voltar para a posição de onde vieram.

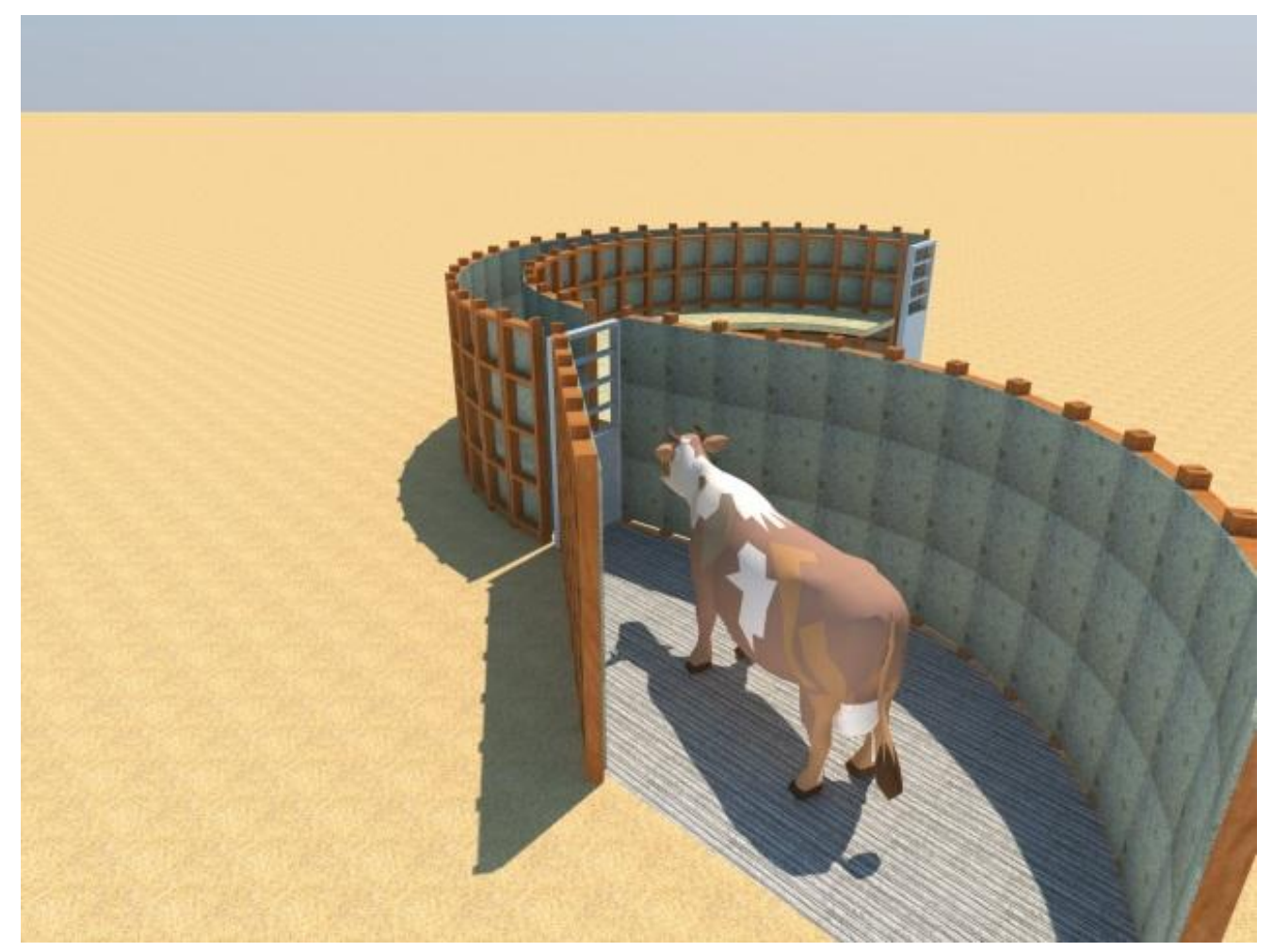

Figura 73 - Detalhe da seringa em formato circular.

Na Figura 74 é detalhado o brete em formato circular com passarela, na parte interna do circulo. A passarela instalada nessa posição se torna um item indispensável e de grande importância para o bom desempenho do manejo dos animais, pois força a pessoa que está realizando o manejo permanecer na zona de fuga do bovino, no ângulo correto, fazendo o mesmo sempre seguir em movimento para frente, como demonstra Grandin (1997). 


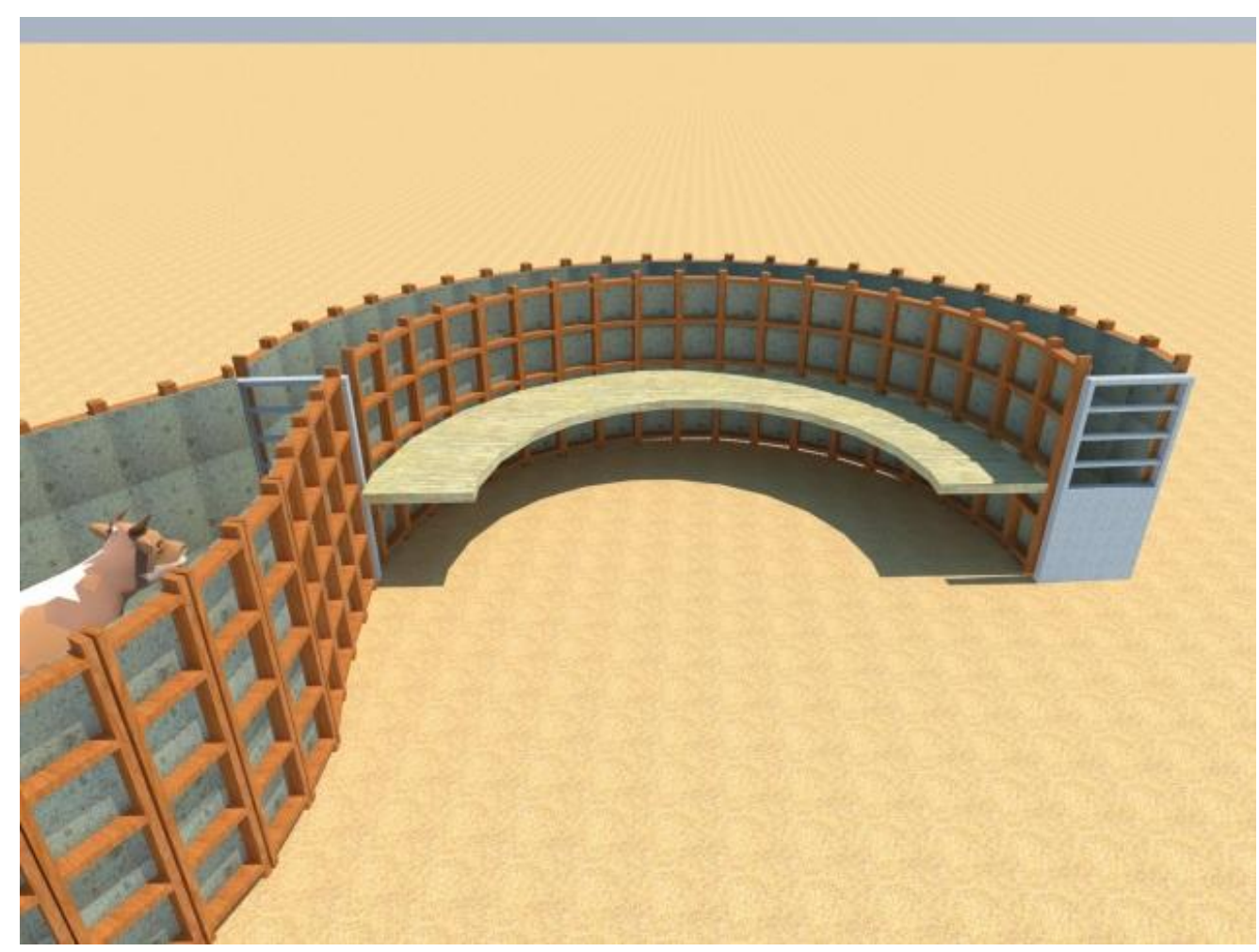

Figura 74 - Detalhe da parte interna do brete circular e sua passarela.

As Figuras 75 e 76 ilustram a vista da curvatura externa do brete e a vista superior de toda a instalação, respectivamente. 


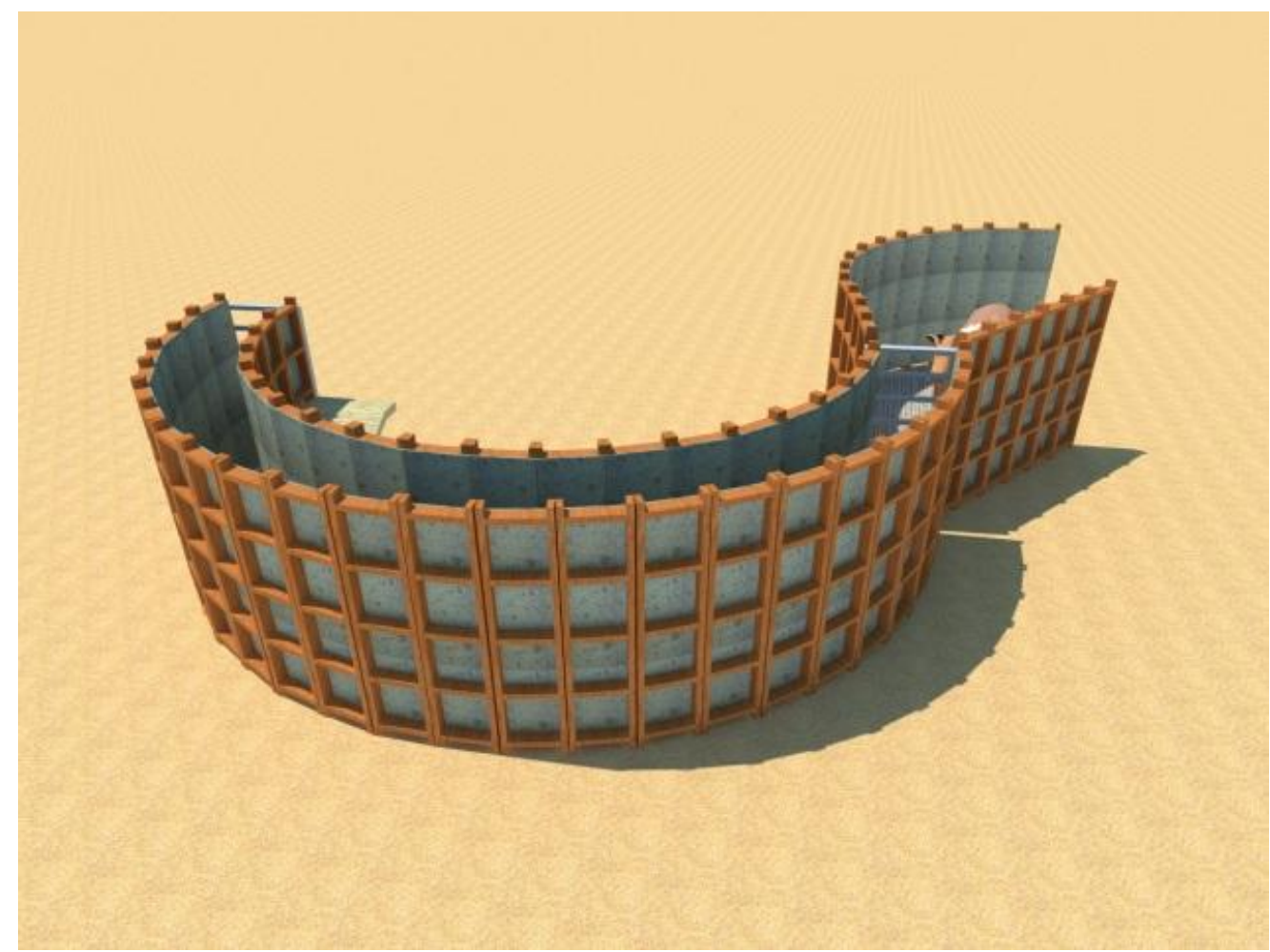

Figura 75 - Detalhe da parte externa do brete circular.

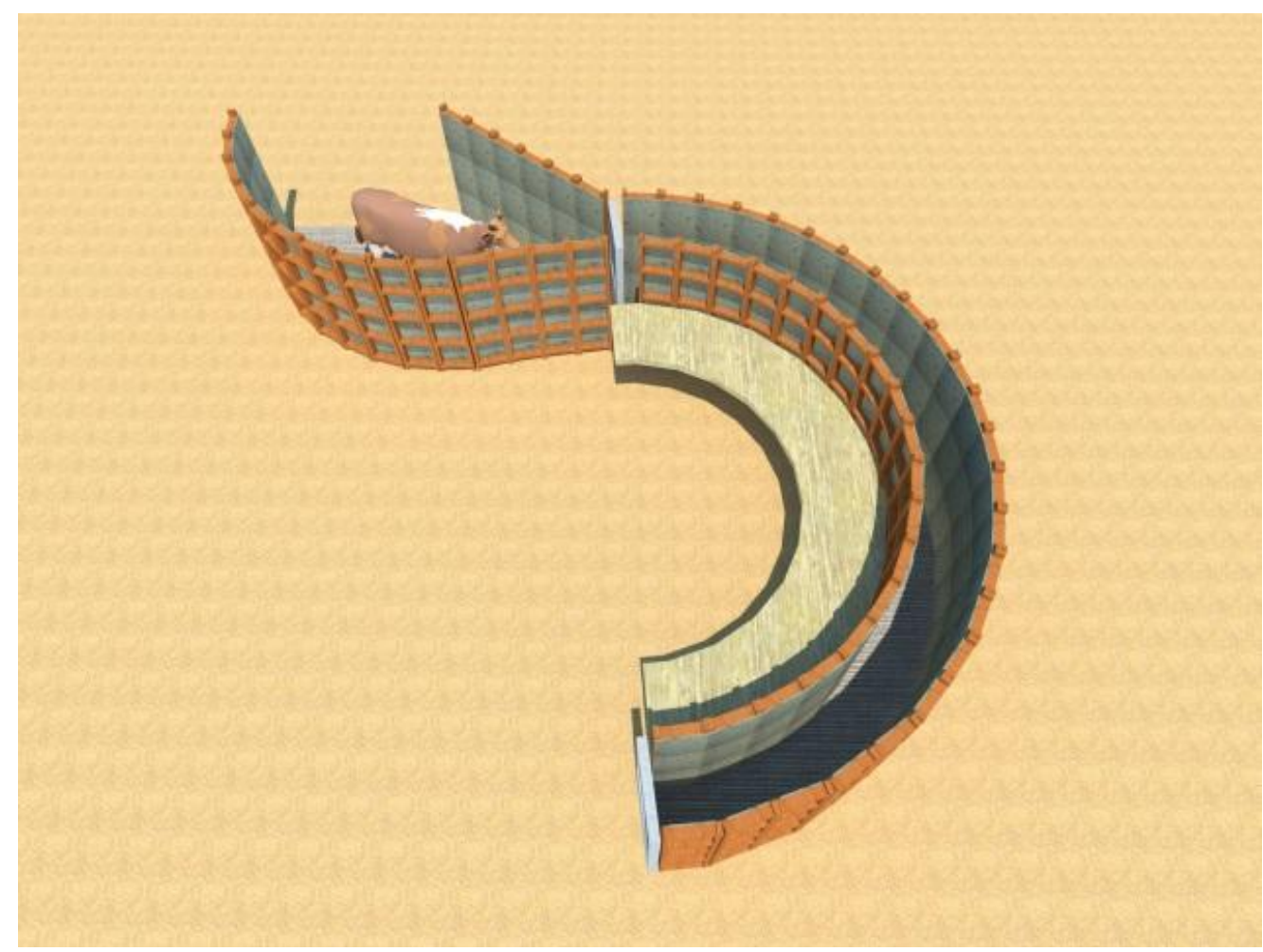

Figura 76 - Vista geral superior do brete e seringa. 


\subsubsection{Ensaio de impacto de corpo mole}

Após cada impacto (Figura 77) como descrito no Item 3.4.9, foi obtido um deslocamento horizontal registrado em papel milimetrado (Figura 78).

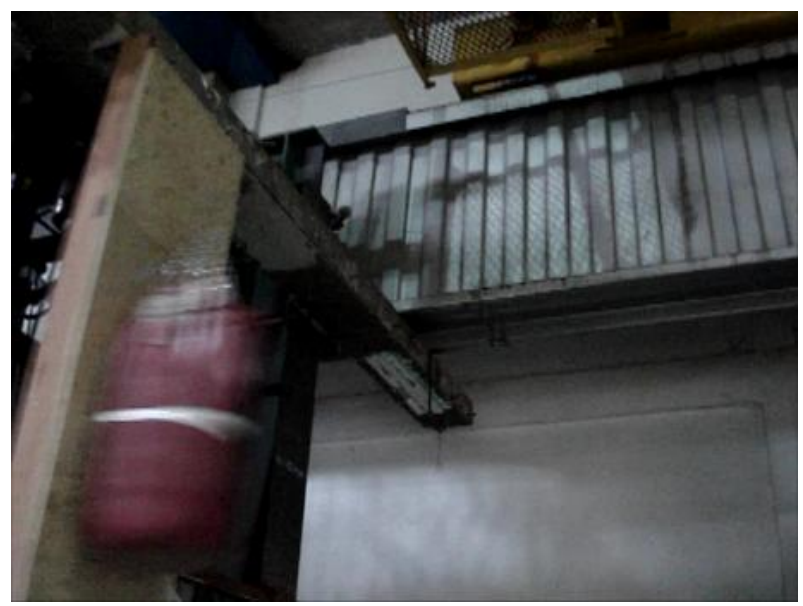

Figura 77 - Momento do impacto do corpo mole.

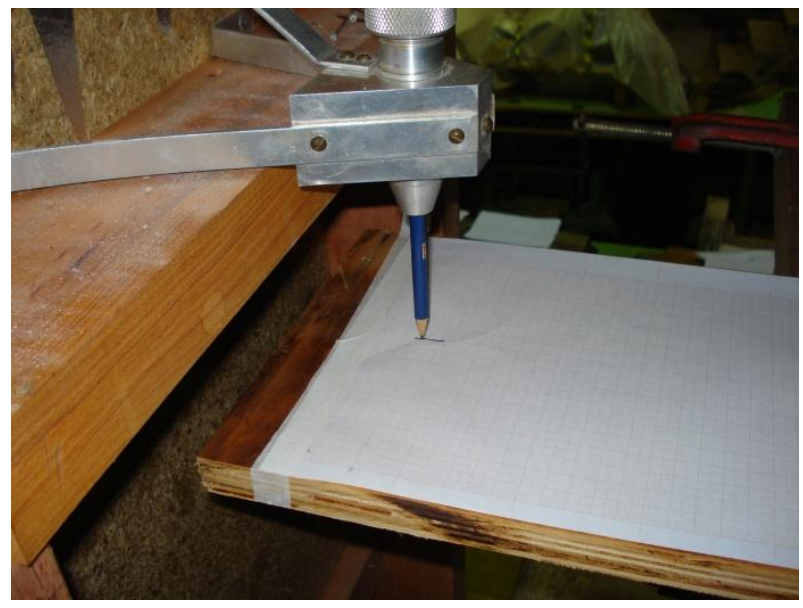

Figura 78 - Registro do deslocamento horizontal pelo dispositivo no papel milimetrado.

A tabela 34 apresenta valores referentes ao ensaio de corpo mole. A energia potência máxima utilizada no ensaio foi de $720 \mathrm{~J}$, devido a limitação em relação a altura que foi possível posicionar o corpo mole. Mas como citado no Item 3.4.9, o objetivo era alcançar um valor de energia de impacto de até $670,5 \mathrm{~J}$, que simula uma situação imaginada próxima o real da proposta, sendo uma vaca adulta de massa de $447 \mathrm{~kg}$ a uma altura de 0,15 cm. 
O painel demonstrou certa elasticidade, pois sofreu deslocamento horizontal de até $38 \mathrm{~mm}$ (ao impacto gerado a altura de $1,80 \mathrm{~m}$ ) e retornou a sua situação inicial sem sofrer danos.

Tabela 34 - Resultado do ensaio de impacto de corpo mole.

\begin{tabular}{cccccc}
\hline \multirow{2}{*}{ Altura (m) } & Peso (kg) & Energia (J) & \multicolumn{2}{c}{ Deslocamento horizontal (mm) } & \multirow{2}{*}{ Ocorrências } \\
\cline { 3 - 4 } & & & Instantâneo & Residual & \\
$\mathbf{0 , 1 5}$ & 40 & 60 & 7 & 2 & Não ocorrência de falhas \\
$\mathbf{0 , 3 0}$ & 40 & 120 & 12 & 4 & Não ocorrência de falhas \\
$\mathbf{0 , 4 5}$ & 40 & 180 & 18 & 7 & Não ocorrência de falhas \\
$\mathbf{0 , 6 0}$ & 40 & 240 & 23 & 8 & Não ocorrência de falhas \\
$\mathbf{0 , 9 0}$ & 40 & 360 & 25 & 11 & Não ocorrência de falhas \\
$\mathbf{1 , 2 0}$ & 40 & 480 & 34 & 13 & Não ocorrência de falhas \\
$\mathbf{1 , 8 0}$ & 40 & 720 & 38 & 15 & Não ocorrência de falhas \\
\hline
\end{tabular}

Foi realizada vistoria visual no painel após cada impacto gerado e como expresso na Tabela 34, não ocorreu nenhum tipo de falha, portanto não foi notado nenhum tipo de fissura, rompimento, fresta ou qualquer outro tipo de alteração, tanto nas chapas quanto na estrutura do painel portante. Na Figura 79 é apresentado o detalhe do local de aplicação da carga de impacto do corpo mole, mostrando que o painel portante e as chapas permaneceram inalterados.

Através do resultado obtido, pode-se dizer que o painel portante atendeu aos requisitos estabelecidos por sua proposta de uso e demonstrou aptidão para sua aplicação em fechamento lateral de brete e seringa em centro de manejo para bovinos, onde será exigido de tal forma como realizada no ensaio de corpo mole. 


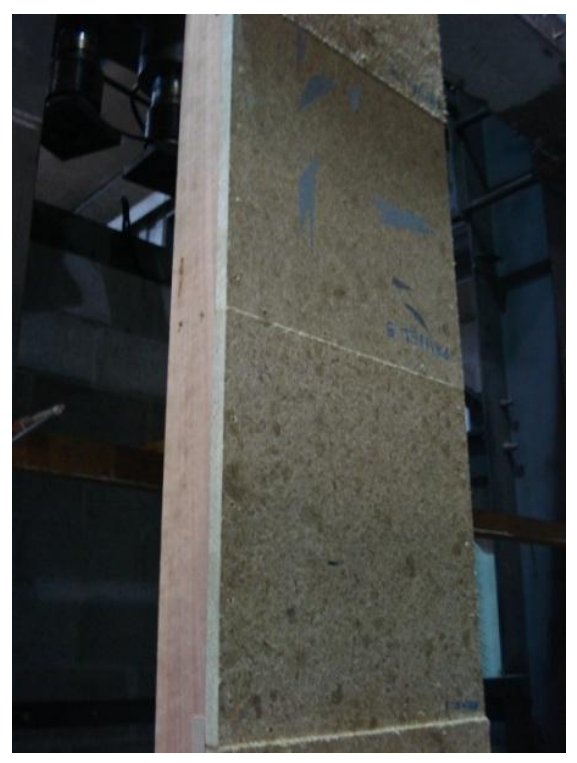

Figura 79 - Detalhe do local de recebimento dos impactos após o ensaio.

Portanto com os resultados do ensaio de impacto de corpo mole, pode-se concluir que o protótipo de painel portante sugerido como parede lateral para brete e seringa para tronco coletivo, obteve resultado satisfatório considerando que se chegou a uma energia de impacto maior que a prevista e não demonstrou nenhum tipo de falha. 


\section{Conclusão}

Com base nos resultados apresentados nesse trabalho, é possível identificar a viabilidade de produção de chapas de partículas com bagaço de cana-de-açúcar e resina poliuretana bi componente à base de óleo de mamona.

A qualidade da matéria-prima, dimensão das partículas, temperatura, teor de resina e pressão, são parâmetros de processo que devem ser controlados no momento da confecção das chapas de partículas à base de bagaço de cana-de-açúcar e resina poliuretana bi componente à base de óleo de mamona. O controle desses parâmetros garante qualidade às chapas produzidas.

Chapas produzidas com partículas de bagaço de cana-de-açúcar com dimensões de até $8 \mathrm{~mm}, 15 \%$ de teor de resina poliuretana bi componente à base de óleo de mamona e parâmetros de processo que empregou $5 \mathrm{MPa}$ de pressão e temperatura de $100^{\circ} \mathrm{C}$, apresentaram propriedades físico-mecânicas superiores as chapas produzidas com partículas de até $5 \mathrm{~mm}$. Essas chapas foram classificadas como de alta densidade, sendo possível indicar sua aplicação como componente estrutural, segundo recomendações de documentos normativos nacionais e internacionais.

A avaliação do desempenho físico-mecânico das chapas de partículas com dimensões de até $8 \mathrm{~mm}$ após serem submetidas ao ensaio de envelhecimento natural e acelerado, indicou que o uso de resina poliuretana bi componente à base de óleo de mamona como impermeabilizante foi eficiente, demonstrando assim a importância da proteção superficial das chapas antes de sua aplicação em uso.

As imagens de MEV nas chapas submetidas ao envelhecimento acelerado e natural ilustraram diferenças micro estruturais que justificam de forma qualitativa as propriedades físico-mecânicas do material.

O comportamento estrutural do painel portante em madeira de reflorestamento e chapas de partículas à base de bagaço de cana-de-açúcar, avaliado por meio de ensaio de corpo-mole, indicou a eficiência do conjunto em resistir às cargas de impacto existente nas condições de uso, sendo viável sua aplicação como fechamento lateral de centro de manejo para bovinos. 


\subsection{Sugestões de continuidade}

- Aplicação do painel portante como fechamento lateral de centro de manejo de gado de corte;

- Análise do desempenho estrutural do painel portante em condições de uso;

- Avaliação da durabilidade do painel quando expostos aos agentes do ambiente como sol, chuva, umidade e excretas animais;

- Estudo de novos produtos impermeabilizantes para proteção superficial das chapas;

- Análise de benefícios ao conforto e produtividade animal. 


\section{Referências}

AMERICAN NATIONAL STANDARDS INSTITUTE. ANSI A208.1: Particleboard. Gaithersburg, 1999.

AMERICAN SOCIETY OR TESTING AND MATERIALS. ASTM D 1037: Standard test methods for evaluating properties of wood-based fiber and particle panel materials. Philadelphia, 1996.

ANSELMI, R. Diversificação industrial inclui bioeletricidade, levedura, plástico biodegradável e gás carbônico. Jornalcana, Tecnologia Industrial, Ribeirão Preto, p.58, dez. 2007.

ANUALPEC 2010. Anuário da Agropecuária Brasileira. São Paulo: FNP Consultoria e comércio, 2010.

ARAÚJO, L. C. R. Caracterização química e mecânica de poliuretanas elastoméricas baseadas em materiais oleoquímicos. 1992. Dissertação (Mestrado) - Instituto de Física e Química de São Carlos, USP, São Carlos, 1992.

ASHORI, A.; NOURBAKHSH, A.; KAREGARFARD, A. Properties of médium density fiberboard based on bagasse fibers. Journal of Composite Materials, v.43, p.1927-1934, 2009.

ASSOCIAÇÃO BRASILEIRA DE NORMAS TÉCNICAS. MB-3256: Divisórias leves internas moduladas. Rio de Janeiro, 1990.

ASSOCIAÇÃO BRASILEIRA DE NORMAS TÉCNICAS. NBR 14810: Chapas de madeira aglomerada. Rio de Janeiro, 2006.

BARROS FILHO, R. M. Painéis aglomerados a base de cana-de-açúcar e resinas uréia formaldeído e melamina formaldeído. 2009. Dissertação (Mestrado em Engenharia de Materiais - Processos de Fabricação) - UFOP, Ouro Preto, 2009.

BATTISTELLE, R. A. G.; MARCILIO, C.; LAHR, F. A. R. Emprego do bagaço da cana-de-açúcar (saccharum officinarum) e das folhas caulinares do bambu da espécie dendrocalamus giganteus na produção de chapas de partículas. Revista Minerva, v 5, n.3, p. 297-305, 2009. 
BICUDO, J. R. et al. Cattle handling facilities: Planning, components and layouts. University of Kentucky Cooperative Extension Service AEN-82, Lexington, KY, 2002.

BLEDZKI, A.K.; GASSAN, J. Composites Reinforced with Cellulose-Based Fibres. Progress in Polymer Science. v. 24, p. 201-274, 1999.

BOTARO, V. R. Deslignificação organossolve de bagaço de cana-de-açúcar: fracionamento e benzilação das ligninas obtidas. 1996. Tese (Doutorado) - Instituto de Química de São Carlos, USP, São Carlos, 1996.

BRITO, E. O. et al. Propriedades de chapas produzidas com resíduos do fruto de coco e partículas de pinus. Revista Floresta e Ambiente, v. 11, n. 2, p. 01 - 06, 2004.

CAMPOS, C. I. Propriedades físico-mecânicas de MDF a partir de madeira de reflorestamento e adesivos alternativos em diferentes teores. 2005. Tese (Doutorado) Escola de Engenharia de São Carlos, USP, São Carlos. 2005.

CARASCHI, J. C.; LEÃO, A. L.; COIADO CHAMMA, P. V. Produção de painéis a partir de resíduos lignocelulósicos para uso na arquitetura. In: ENCONTRO BRASILEIRO EM MADEIRA E ESTRUTURAS DE MADEIRA, 11., 2008, Londrina, PR. Anais... Londrina, 2008.

CARVALHO, G. G. P. et al. Valor nutritivo do bagaço de cana-de-açúcar amonizado com quatro doses de uréia. Pesquisa Agropecuária Brasileira, v.41, n.1, p.125-132, 2006.

CASTRO, E. M. de. Processos de fabricação de chapas. In: GONÇALVES, M.T.T.

Processamento da madeira. Bauru : Document Center Xerox - USC, 2000. cap. 7, p.233-236.

CÉSAR, S. F. Chapas de madeira para vedação vertical de edificações produzidas industrialmente - projeto conceitual. 2002. 256 f. Tese (Doutorado em Engenharia de Produção) - Programa de Pós-graduação em Engenharia de Produção, UFSC, Florianópolis, 2002.

CINTRA, F. N.; ANDRADE, P. Avaliação dos impactos ambientais do setor canavieiro contemporâneo. In: Encontro nacional de gestão empresarial e meio ambiente, 7., 2003, São Paulo. Anais... São Paulo: ENGEMA, 2003. 
COMPANHIA NACIONAL DE ABASTECIMENTO. A geração termoelétrica com a queima do bagaço de cana-de-açúcar no brasil, análise do desempenho da safra 2009-2010, março/2011- Companhia Nacional de Abastecimento. - Brasília : Conab 2011.

COMPANHIA NACIONAL DE ABASTECIMENTO. Acompanhamento de safra brasileira: canade-açúcar, primeiro levantamento, abril/2012 - Companhia Nacional de Abastecimento. Brasília: Conab 2012.

CS - COMMERCIAL STANDARD. CS 236-66: mat formed wood particleboard. [S.I.], 1968. DIAS, F. M. (2008). Aplicação de resina poliuretana à base de mamona na fabricação de painéis de madeira aglomerada. Produtos Derivados da Madeira: síntese dos trabalhos desenvolvidos no Laboratório de Madeiras e de Estruturas de Madeira, SET-EESC-USP. Escola de Engenharia de São Carlos, Universidade de São Paulo. p. 73-92. São Carlos, SP, 2008.

FERREIRA, L. A. Diretrizes arquitetônicas nas instalações para bovinos. 1989. Dissertação (Mestrado em Arquitetura) - Escola de Engenharia de São Carlos, Universidade de São Paulo, São Carlos, 1989.

FIORELLI, J. et al. Painéis de partículas à base de bagaço de cana e resina de mamona produção e propriedades. Acta Scientiarum. Technology, v. 33, p. 401-406, 2011.

GATANI, M. P. Utilização de casca de Mani para fabricação de chapas de partículas. Pirassununga: USP, 2009. (Relatório de Pesquisa, Laboratório de Construções e Ambiência, FZEA/USP).

GRANDIN, T. Handling and processing feedlot cattle. In: Thompson, G.B., O'Mary, C.C. (Eds.), The Feedlot. Lea and Febiger, Philadelphia, p.213-235, 1983.

GRANDIN, T. Observation of cattle behavior applied to the design of cattle-handling facilities. Applied Animal Ethology. v.6, p.19-31, 1980.

GRANDIN, T. The design and construction of facilities for handling cattle. Livestock Production Science, v. 49, p.103-119, 1997.

HILLIG, E. Qualidade de chapas aglomeradas estruturais, fabricadas com madeiras de Pinus, Eucalipto e Acácia negra, puras ou misturadas, coladas com tanino-formaldeido. 2000. Dissertação (Mestrado) - Universidade Federal de Santa Maria Santa Maria, UFSM, 2000. 
HUHNKE, R. L.; HARP, S. Corral and Working Facilities for Beef Cattle. Stillwater, Oklahoma: Oklahoma State University, Cooperative Extension Service, 2009.

IWAKIRI, S. et al. Produção de painéis de madeira aglomerada de alta densificação com diferentes tipos de resinas. Revista Scientia Florestalis, v.1, n. 68, p. 39-43, 2005.

IWAKIRI, S. et al. Resíduos de serrarias na produção de painéis de madeira aglomerada de eucalipto. Revista Scientia Agrária, v.1, n. 2, p. 23-28, 2000.

IWAKIRI, S. et al. Produção de painéis de madeira aglomerada de Grevillea robusta A. Cunn. ex R. Br. Revista Árvore, v.28, p.883-887, 2004.

JOSÉ, F. J.; BERALDO, A. L. . Chapas prensadas de partículas de bambu e adesivo poliuretana à base de óleo de mamona. In: EBRAMEM- Encontro Brasileiro em Madeiras e em estruturas de Madeira, 10., 2006, São Pedro - SP. Anais... Botucatu: UNESP, 2006. v. 1. p. 1-11.

KELLY, M. W. Critical literature review of relationships between processing parameters and physical properties of particleboard. USDA Forest Service - Forest Products Laboratory GENERAL Technical Report FPL-10, 1977.

KHEDARI, J. et al. New insuleting particleboards from durian peel and coconut coir. Building Scientific Research Center. Boletin. Bangkok, Thailand, 2004.

LANA, R.P. Nutrição e alimentação animal: mitos e realidades. Viçosa: UFV, 2005. 344p.

MACIEL, A. S. et al. Painéis de partículas aglomeradas de madeira de Pinus elliottii Elgelm., poliestireno (PS) e poliestireno tereftalato (PET). Revista Árvore, Viçosa-MG, v.28, n.2, p.257-266, 2004.

MALONEY, T.M. Modern Particleboard \& Dry-process fiberboard manufacturing. San Francisco. 1977. 672p.

MALONEY, T.M. Modern particleboard and dry-process fiberboard manufacturing. 2.ed. São Francisco: M. Freeman, 1993. 689p. 
MALONEY, T.M. The development in the United States and Canada of Waferboard, oriented strand board, and medium density fibreboard. Holz Als Roh Und Werkstoff, Berlin, v. 42, n.10, p. 361-365. 1984.

MALONEY, T.M. The family of wood composite materials. Forest Products Journal. v.46, n.2, p. 19-26. 1996.

MENDES, L. M.; ALBUQUERQUE, C. E. C.; IWAKIRI, S. A indústria brasileira de painéis de madeira. Revista da Madeira, v. 1, n. 71, p. 12-12, 2003.

MENDES, R. F. et al. Painéis aglomerados produzidos com bagaço de cana em associação com madeira de eucalipto. Scientia Forestalis, Piracicaba, v. 38, n. 86, p. 285-295, jun. 2010.

MENDES, R.F. Utilização do bagaço de cana de alambique na produção de painéis aglomerados. 2008. 104p. Monografia (Graduação em Engenharia Florestal) - Universidade Federal de Lavras, Lavras, 2008.

MENDES, R.F. et al. The adhesive effect on the properties of particleboards made from sugar cane generated in the distiller. Revista de Ciências Agrárias, Lisboa, v.32, n.2, p.209-218, 2009.

MOSLEMI, A. A. Particleboard. Carbondale and Edwardsville. Southern Illinois University Press, 1974.

NASCIMENTO, M. F. CPH - Chapas de Partículas Homogêneas - Madeiras do Nordeste do Brasil. 2003. 143 f. Tese (Doutorado) - Escola de Engenharia de São Carlos, USP, São Carlos, 2003.

NASCIMENTO, M. F. CPH - Fabricação de chapas de Partículas de OSB - Oriented Strand Board, com matéria-prima proveniente de espécies de madeira da caatinga do Nordeste do Brasil. São Carlos: USP, 2006. (Relatório de Pesquisa - Programa de Desenvolvimento Regional/CNPq).

NORMA VENEZOLANA COVENIN. COVENIN № 847-91: Norma Venezolana para Tableros de Partículas. Caracas, Venezuela, 1991. 
OKINO, E. Y. A. et al. Physico-mechanical properties of chemically modified sugar cane bragasse partideboards. Scientia Forestalis, n.52, p. 35-42, 1997.

OLMOS, M.A.C. Equipamento e processo de fabricação de chapas de madeira aglomeradas a partir de resíduos de madeira. 1992. 110 f. Dissertação (Mestrado) - Escola de Engenharia de São Carlos, USP, São Carlos, 1992.

OTTAMAN, J. A. Marketing verde: desafios e oportunidades para a nova era do marketing. São Paulo. Makron Books, 1994.

PABLO, A. A.; PEREZ, E. B.; ELLA, A. B. Development of particleboard on a pilot-plant and semi-commercial scale using plantation and secondary wood species and agricultural fibrous waste materials. Forest Products Research and Industries Development Commission, University of the Philippines, Philippines, 1975.

PASSOS, P. R. A. Destinação sustentável de cascas de coco verde (Cocos nucifera): obtenção de telhas e chapas de partículas. 2005. $166 \mathrm{f}$. Tese (Doutorado) - COPPE, UFRJ, Rio de Janeiro, 2005.

PEDRAZZI, C. et al. Qualidade de chapas de partículas de madeira aglomerada fabricadas com resíduos de uma indústria de celulose. Ciência Florestal, Santa Maria, v. 16, n. 2, p. 201212, 2006.

PETROVIC, Z.S. et al. Thermosetting resins from vegetable oils. In: ANNUAL TECHNICAL CONFERENCE, 57., 1999, New York. Proceedings... New York, 1999. 1 CD-ROM.

PIZZI A. Advanced wood adhesives technology. Marcel Dekker, New York, 1994. 297p.

ROSA, A. N. et al. Peso adulto de matrizes em rebanhos de seleção da raça nelore no brasil. Revista Brasileira de Zootecnia, Viçosa, v.30, n.3, p.1027-1036, 2001.

ROWELL, R. M.; HAN, J. S.; ROWELL, J. S. Characterization and factors affecting fiber properties. In: NATURAL POLYMERS AND AGROFIBERS BASED COMPOSITES, 1., 2000, São Carlos. Anais... São Carlos: Embrapa Instrumentação Agropecuária, 2000. p. 115-134.

ROWELL, R.M.; KEANY, F.M. Fiberboards made from acetylated bagasse fiber. Wood and Fiber Science, v.23, n.1, p.15-22, 1991. 
SALDANHA, L. K. Alternativas tecnológicas para produção de chapas de partículas orientadas “OSB". 2004. 83 f. Dissertação (Mestrado em Engenharia Florestal) Universidade Federal do Paraná, Curitiba, 2004.

SALDANHA, L. K.; IWAKIRI, S. Influência da densidade e do tipo de resina nas propriedades tecnológicas de painéis OSB de Pinus taeda L. Floresta, v. 39, n. 3, p. 571-576, 2009. SANTANA, M.A.E.; TEIXEIRA, D.E. Uso de bagaço de cana-de-açúcar na confecção de chapas aglomeradas. In: CONGRESSO FLORESTAL BRASILEIRO, 7; CONGRESSO FLORESTAL PANAMERICANO, 1, Curitiba, 1993. Anais... Curitiba: SBS/SBEF, 1993. p. 667-672.

SILVA, A. J. P. Aplicação de partículas longas e orientadas de bagaço de cana-de-açúcar na produção de painel particulado similar ao OSB. 2006. Tese (Doutorado) - Escola de Engenharia de São Carlos, USP, São Carlos, 2006.

SILVA, A. J. P.; FRANÇA SANTOS, W. L.; ROCCO LAHR, F. A. Partículas longas e orientadas de bagaço de cana-de-açúcar na produção de painel similar ao OSB. In: ENCONTRO BRASILEIRO EM MADEIRA E ESTRUTURAS DE MADEIRA, 11., 2008. Londrina, PR. Anais... Londrina, 2008.

SILVA, V.L.M.M; GOMES, W.C.O.; ALSINA, L.S. Utilização do bagaço de cana de açúcar como biomassa adsorvente na adsorção de poluentes orgânicos. Revista Eletrônica de Materiais e Processos, Campina Grande, v.2, p.27-32, 2007.

SOUSA, M.F.B. et al. Separação e identificação dos constituintes do bagaço de cana-deaçúcar pelo processo "Organosolv". Ciência e Cultura, v.38, n.1, p.181-188, 1986.

SOUZA, C. F.; TINOCO, I. F. F.; SARTOR, V. Informações básicas para projetos de construções rurais. Viçosa - MG, 2003.

TEIXEIRA, D. E.; COSTA, F.; SANTANA, M. A. E. Aglomerados de bagaço de cana-de-açúcar: resistência natural ao ataque de fungos. Scientia Forestalis, Piracicaba, n. 5, p. 29-34, 1997.

VILAR, W.D. Química e tecnologia dos poliuretanos. [S.I.]: Grupo Pronor. 1993.

VOWLES, W.J., ELDRIDGE, G.A., HOLLIER, T.J. The behavior and movement of cattle through single file handling races. Proc. Sot. Anim. Prod. v.15, p.767, 1984. 
VOWLES, W.J., HOLLIER, T.J. The influence of cattle yard design on the movement of animals. Proc. Aust. Sot. Anim. Prod. v.14, p.597, 1982.

$X U, X ; Y A O, F . ; W U, Q . ; Z H O U, D$. The influence of wax-sizing on dimension stability and mechanical properties of bagasse particleboard. Industrial Crops and Products. v. 29, p. 8085, 2009.

WOODS, G. The ICI Polyurethanes book. New York: John Willey. 1990.

WU, Q. In-plane dimensional stability of oriented strand panel: effect of processing variables. Wood and Fiber Science. Madison, v. 31, n. 1, p. 28-40, 1999.

YOUNG, M.A. Madeira artificial feita com bagaço. Brasil açucareiro, v.70, n.3, p.23-25, 1967.

ZHANG, M. et al. Manufacture and properties of high-performance oriented strand board composite using thin strands. Japan Wood Science, Japan, n.44, p.191-197, 1998. 